\title{
EXPLORING THE TRANSFERABILITY OF CRASH MODIFICATION FACTORS: CASE STUDIES ON PASSING LANES AND DUAL RUMBLE STRIPS ON ONTARIO TWO-LANE HIGHWAYS
}

\author{
By \\ Shahram Almasizadeh \\ A Thesis \\ Presented to Ryerson University \\ in partial fulfillment of the \\ requirements of the degree of \\ Master of Applied Science \\ in the Program of \\ Civil Engineering
}

Bachelor of Engineering, Ryerson University, Toronto, Ontario, Canada, 2014

Toronto, Ontario, Canada, 2016

(O)(Shahram Almasizadeh) 2016 


\section{AUTHOR'S DECLARATION}

\section{AUTHOR'S DECLARATION FOR ELECTRONIC SUBMISSION OF A THESIS}

I hereby declare that I am the sole author of this thesis. This is a true copy of the thesis, including any required final revisions, as accepted by my examiners.

I authorize Ryerson University to lend this thesis to other institutions or individuals for the purpose of scholarly research

I further authorize Ryerson University to reproduce this thesis by photocopying or by other means, in total or in part, at the request of other institutions or individuals for the purpose of scholarly research.

I understand that my thesis may be made electronically available to the public. 
“EXPLORING THE TRANSFERABILITY OF CRASH MODIFICATION FACTORS: CASE

STUDIES ON PASSING LANES AND DUAL RUMBLE STRIPS ON ONTARIO TWO-

LANE HIGHWAYS"

By

Shahram Almasizadeh, 2016

Masters of Applied Science, Department of Civil Engineering, Ryerson University

\begin{abstract}
$\underline{\text { Abstract }}$
The safety effects of design and other highway improvement options are specified through Crash Modification Factors (CMFs). CMFs for two low cost safety treatment measures -- passing lanes and dual application of center line and shoulder rumble strips -- are explored separately in this paper. Using data provided from previous studies conducted in the United States, and generalized linear modeling, the transferability of the US-based knowledge on safety effects of passing lanes and rumble strips for application in Ontario was explored. It was found that the safety effects were consistent for passing lanes in Michigan and Ontario and a Crash Modification Function was developed relating the CMF to length of passing lane for the combined data. The dual rumble strip effects were also reasonably consistent with results from a limited analysis of Ontario data and are recommended for application in the province.
\end{abstract}




\section{Acknowledgements}

I would like to thank my Wife, Luecil, for her continued support and encouragement.

I would like to thank my brother Arash, my Father and my Uncle for their guidance and support throughout my university years.

A great thank you to my supervisor Dr. Bhagwant Persaud for everything he has done including academic and financial support.

I would like to thank Mr. Craig Lyon for his help throughout the research, including facilitating access to the US data for passing lanes and dual rumble strip applications.

I would also like to thank Taha Saleem for his kind help throughout my research.

Last but not least, I would like to thank the Ministry of Ontario, specifically Mr. Michael Pardo of the Traffic Office, for providing the data.

The research was supported by grants from the Natural Sciences and Engineering Research Council of Canada and the Ministry of Transportation, Ontario. 


\section{Table of Contents}

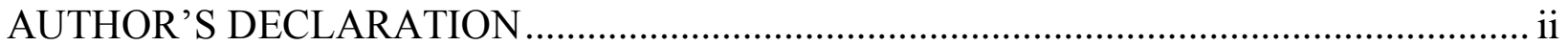

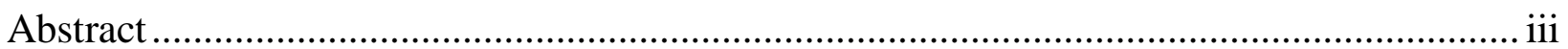

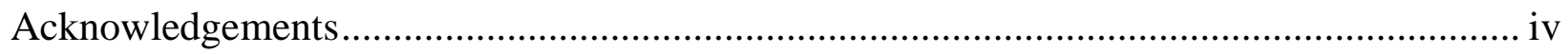

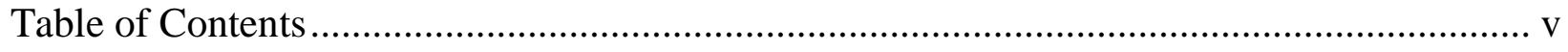

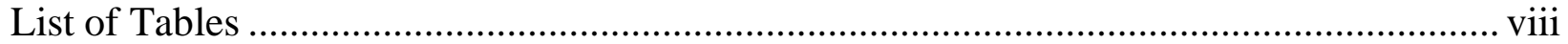

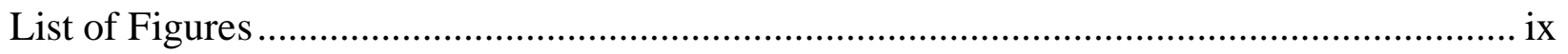

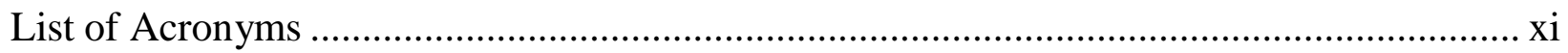

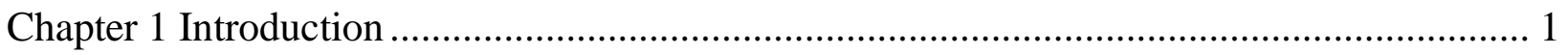

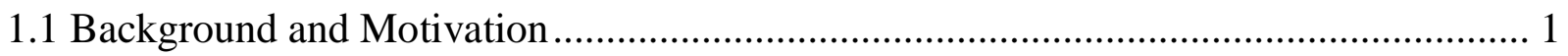

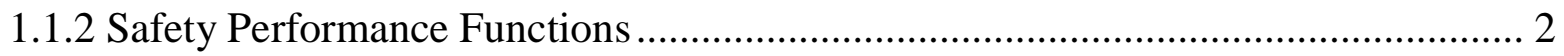

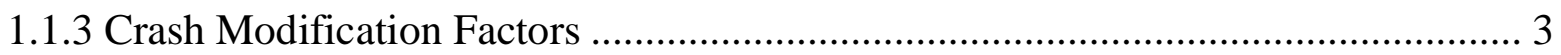

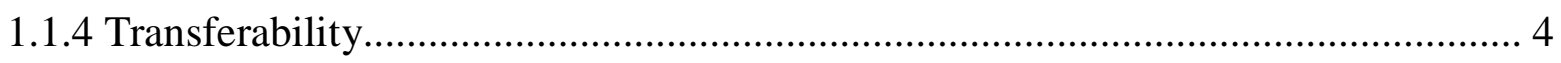

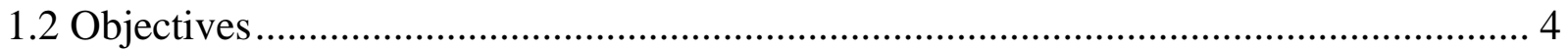

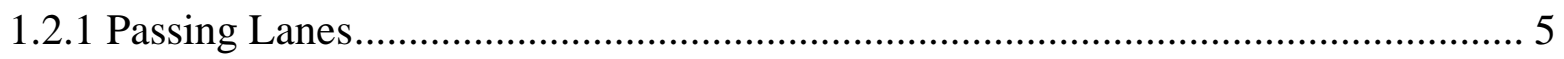

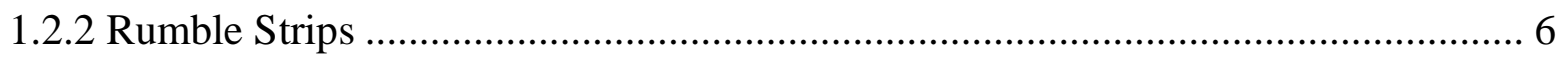

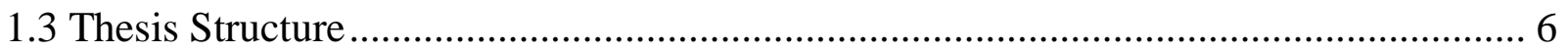

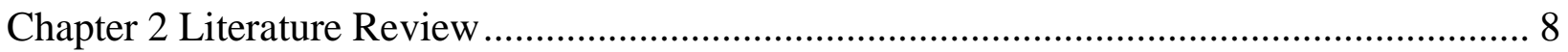

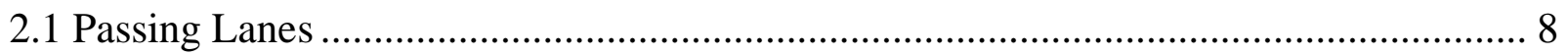

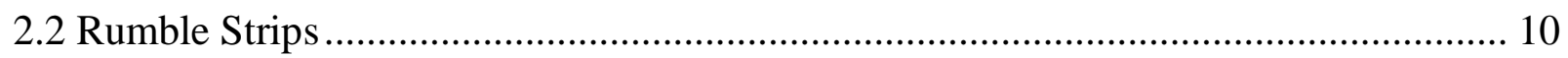

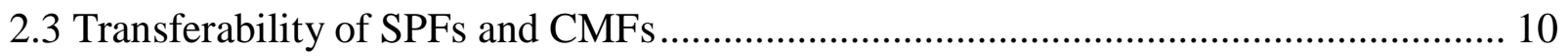

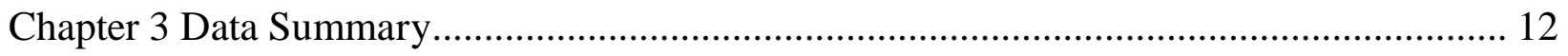

3.1 Ontario Crash Data and Average Annual Daily Traffic (AADT) .................................. 12

3.2 Ontario Highway Geometry Data ……………..................................................... 13 


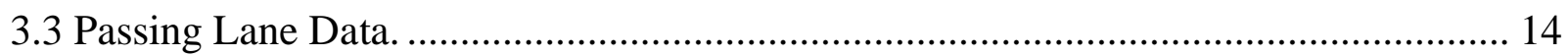

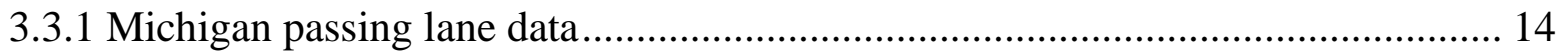

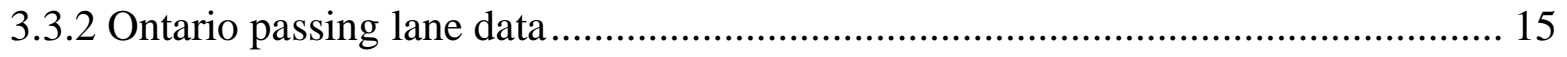

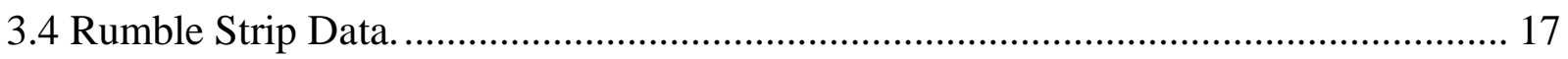

3.4.1 Ontario rumble strip data …............................................................................... 18

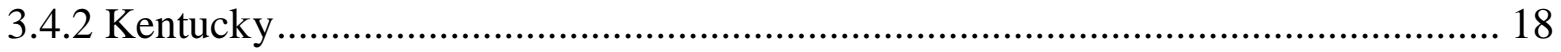

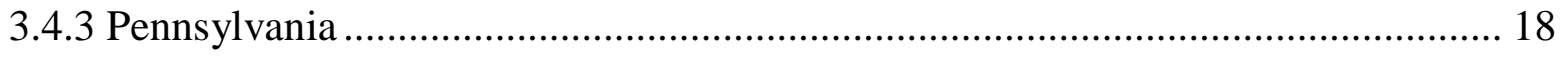

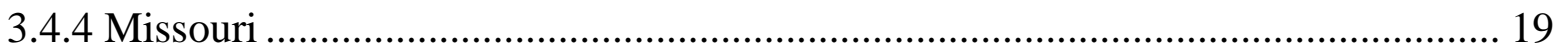

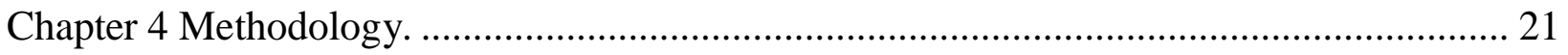

4.1 Crash Prediction Models .................................................................................... 21

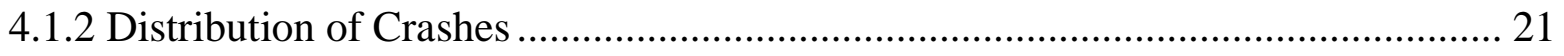

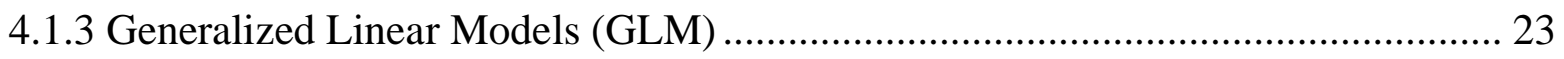

4.2 Empirical Bayes Before-After Study …………………........................................... 23

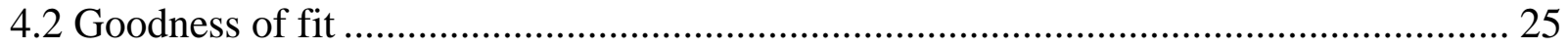

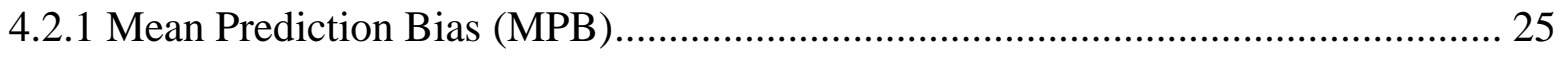

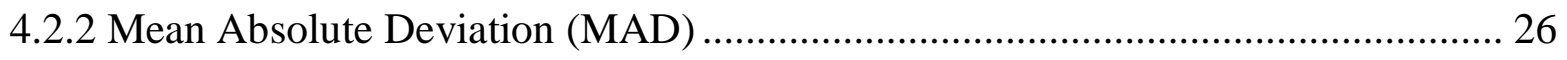

4.2.3 Mean Squared Prediction Error (MSPE) and Mean Squared Error (MSE) ............ 26

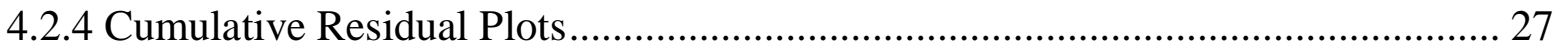

4.3 Calibrating an SPF to Another Jurisdiction ………................................................ 28

Chapter 5 Passing Lane Modeling Results. ......................................................................... 29

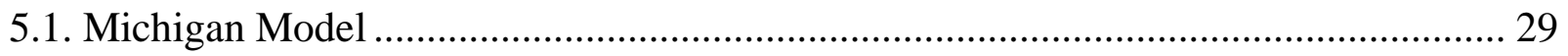

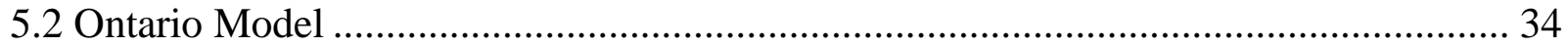

5.3 Calibration of Michigan Models to Ontario Data to Assess Transferability of Results 39

5.4 Combined Model Using Michigan and Ontario Data .................................................. 44 


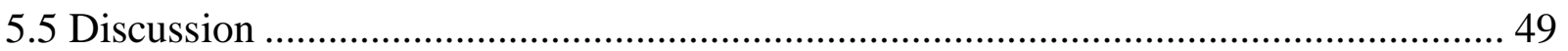

Chapter 6 Dual Rumble Strip Modeling Results. .................................................................. 51

6.1 Empirical Bayes Before-After Study ..................................................................... 51

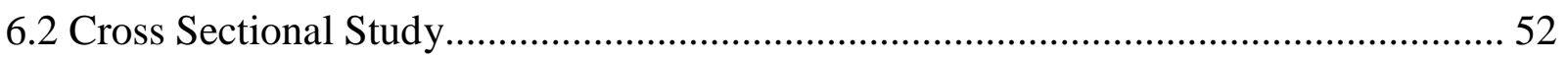

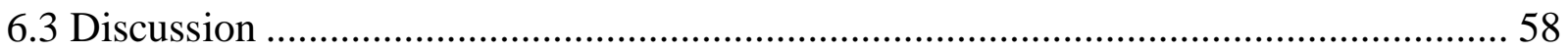

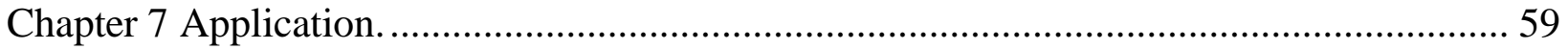

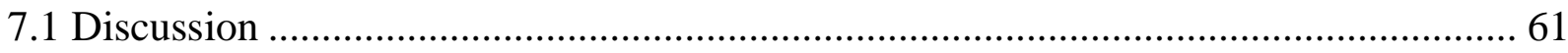

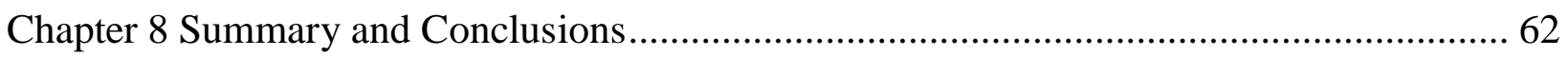

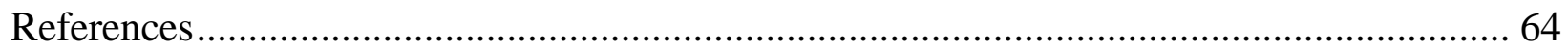




\section{List of Tables}

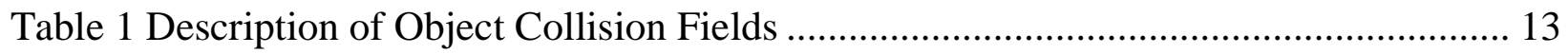

Table 2 Summary Statistics of Michigan Passing Lane Sites.................................................. 14

Table 3 Summary Statistics for Michigan Reference Sites ..................................................... 15

Table 4 Summary Statistics for Ontario Passing Lane Segments........................................... 16

Table 5 Summary Statistics for Ontario Passing Lane Reference Sites ................................... 16

Table 6 Location of Ontario Passing Lane Segments .......................................................... 17

Table 7 Location and Installation Year of the 6 Ontario Rumble Strip Segments .................. 18

Table 8 Summary Statistics of Rumble Strip Data (Persaud at al., 2016) .............................. 20

Table 9 Parameter Estimates for Michigan Passing Lane Model ............................................ 29

Table 10 Michigan Passing Lane Model GOF Measures .................................................... 31

Table 11 Parameter Estimates for Ontario Passing Lane Model ............................................. 35

Table 12 Ontario Passing Lane Model GOF Measures ........................................................ 35

Table 13 Parameter Estimates for Calibrated Michigan Model to Ontario Data .................... 40

Table 14 Calibrated Michigan Model Applied to Ontario Data GOF Measures..................... 41

Table 15 Parameter Estimates of Combined Model for Ontario and Michigan ...................... 45

Table 16 Combined Passing Lane Model GOF Measures........................................................ 46

Table 17 Parameter Estimates for SPF used in Empirical Bayes Methodology ...................... 51

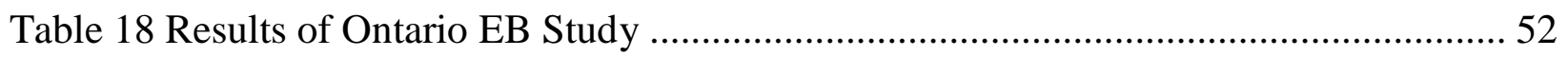

Table 19 Parameter Estimates for Kentucky Rumble Strip Models ......................................... 53

Table 20 Parameter Estimates for Pennsylvania Rumble Strip Models ................................. 54

Table 21 Parameter Estimates for Combined Rumble Strip Models........................................ 55

Table 22 Comparison of EB and Cross Sectional CMFs for Total Crashes ............................ 56

Table 23 Comparison of EB and Cross Sectional CMFs for Injury Crashes .......................... 56

Table 24 Comparison of EB and Cross Sectional CMFs for Run-off-road Crashes ............... 57

Table 25 Comparison of EB and Cross Sectional CMFs for Head-on Crashes ..................... 57

Table 26 Comparison of EB and Cross Sectional CMFs for Sideswipe Crashes.................... 57

Table 27 Economic Analysis Assumptions Table ……………………………...................... 59 


\section{List of Figures}

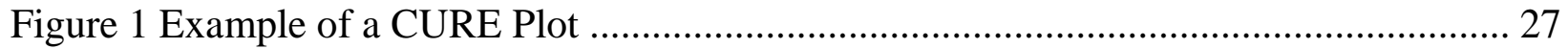

Figure 2 CMF for Passing Lanes in Michigan.................................................................. 30

Figure 3 Total Crash - AADT CURE Plot for Michigan Sites ............................................... 31

Figure 4 Total Crash - Length CURE Plot for Michigan Sites............................................. 32

Figure 5 Total Crash - Predicted Total CURE Plot for Michigan Sites .................................. 32

Figure 6 Injury Crash - AADT CURE Plot for Michigan Sites ............................................ 33

Figure 7 Injury Crash - Length CURE Plot for Michigan Sites ............................................. 33

Figure 8 Injury Crash - Predicted Injuries CURE Plot for Michigan Sites ............................. 34

Figure 9 Graph of CMF for Ontario Passing Lanes .............................................................. 36

Figure 10 Total Crash - AADT CURE Plot for Ontario Sites ................................................. 36

Figure 11 Total Crash - Length CURE Plot for Ontario Sites................................................ 37

Figure 12 Total Crash - Predicted Injury Crashes CURE Plot for Ontario Sites ................... 37

Figure 13 Injury Crash - AADT CURE Plot for Ontario Sites................................................ 38

Figure 14 Injury Crash - Length CURE Plot for Ontario Sites ............................................. 38

Figure 15 Injury Crash - Predicted Injury Crashes CURE Plot for Ontario Sites ................. 39

Figure 16 Total Crash - AADT CURE Plot for Calibrated Michigan Model to Ontario ........ 41

Figure 17 Total Crash - Length CURE Plot for Calibrated Michigan Model to Ontario ....... 42

Figure 18 Total Crash - Predicted Total Crashes CURE Plot for Calibrated Michigan Model

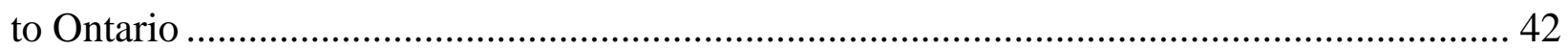

Figure 19 Injury Crash - AADT CURE Plot for Calibrated Michigan Model to Ontario ...... 43

Figure 20 Injury Crash - Length CURE Plot for Calibrated Michigan Model to Ontario...... 43

Figure 21 Injury Crash - Predicted Injury Crashes CURE Plot for Calibrated Michigan

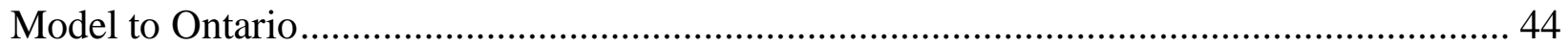

Figure 22 Combined Model for Ontario and Michigan ...................................................... 45

Figure 23 Total Crash - AADT CURE Plot for Combined Model .......................................... 46

Figure 24 Total Crash - Length CURE Plot for Combined Model ......................................... 47

Figure 25 Total Crash - Predicted Total Crashes CURE Plot for Model............................... 47

Figure 26 Injury Crash - AADT CURE Plot for Combined Model ......................................... 48

Figure 27 Injury Crash - Length CURE Plot for Combined Model....................................... 48 
Figure 28 Injury Crash - Predicted Injury Crashes CURE Plot for Combined Model 


\section{$\underline{\text { List of Acronyms }}$}

$\begin{array}{ll}\text { AADT } & \text { Average Annual Daily Traffic } \\ \text { CLRS } & \text { Centerline Rumble Strips } \\ \text { CMF } & \text { Crash Modification Factor } \\ \text { CMFunction } & \text { Crash Modification Function } \\ \text { CRF } & \text { Capital Recovery Factor } \\ \text { CURE } & \text { Cumulative residual } \\ \text { DOT } & \text { Department of Transportation } \\ \text { EB } & \text { Empirical Bayes } \\ \text { ELRS } & \text { Edge line Rumble Strips } \\ \text { GOF } & \text { Goodness of fit } \\ \text { HSM } & \text { Highway Safety Manual } \\ \text { LHRS } & \text { Linear Highway Referencing System } \\ \text { MAD } & \text { Mean Absolute Deviation } \\ \text { MDOT } & \text { Michigan Department of Transportation } \\ \text { MPB } & \text { Mean Prediction Bias } \\ \text { MSE } & \text { Mean Squared Error } \\ \text { MSPE } & \text { Mean Squared Prediction Error } \\ \text { MTO } & \text { Ministry Transportation Ontario } \\ \text { NB } & \text { Negative Binomial } \\ \text { PL } & \text { Passing Lane } \\ \text { RS } & \text { Rumble Strip } \\ \text { RTM } & \text { Regression to the Mean } \\ \text { SPF } & \text { Safety Performance Function } \\ & \end{array}$




\section{Chapter $1 \underline{\text { Introduction }}$}

Traffic accidents are a significant cause of injury and death in all developed countries. The World Health Organization estimates that 1.2 million people die every year on the roads and between 20 and 50 million people suffer injuries (World Health Organization, 2009). In 2009, 30,800 people were killed in the USA and 1.6 million people were injured in traffic related accidents (U.S. Census Bureau). This calculates to approximately one death every 20 minutes. In 2012 Transport Canada (Transport Canada, 2013) reported 2,700 deaths and 10,315 people were seriously injured. These yearly death tolls continue to accumulate year over year and thus provides convincing justification for the pursuit of road safety research in an attempt to reduce preventable deaths and injuries.

\subsection{Background and Motivation}

There has been a shift in the way transportation engineers make design decisions for roadway design in the recent decades. It was often assumed that roads built to standards were safe and that drivers, not roads, were the reason there are accidents (Hauer, 1999). No consideration was given to determine whether a road could be designed safer and to what extent. It is important to define what describes the "safety" of a road unit, such as a highway segment or intersection, and how safety is measured. In the realm of road safety management the safety of a road unit is defined as "the number of accidents by type and severity expected to occur on the entity during a specified time period" (Hauer, 1997). Meeting a standard does not suggest the relative safety that may be achieved by exceeding them. Sound measures of effectiveness for exceeding minimum standards in design can justify to policy makers that the additional expenditure required during construction may be offset from the costs of saved accidents.

Understanding the marginal benefits of design choices is of great concern for engineers who wish to design roads to a premeditated safety level. Although safety standards had existed and had laid out minimum standards, the marginal safety benefits of designing above standards was never considered. A prime example of this occurred in Ontario, Canada 
during the construction of the Highway 407 Express Toll Route. This freeway facility was an early Private-Public-Partnership and was built within the standards set by the Ministry Transportation Ontario. Nevertheless, prior to its opening the police deemed the highway unsafe and questioned the safety of some of the design elements such as acceleration lanes being too short, ramp curvatures being too large, the presence of high-mast lighting in the medians, among others (Professional Engineers of Ontario, 1997). The highway remained closed while an independent safety review was conducted by the request of the Minister of Transport. The results of the safety review had an influence on how safety was viewed in the design process. For instance, a standard may call for $2.5 \mathrm{~m}$ shoulders along a highway. A prudent engineer should ask how the safety of the road would benefit by the additional $0.5 \mathrm{~m}$ of shoulder. Then by performing a Cost/Benefit analysis, can determine whether the additional cost for the additional $0.5 \mathrm{~m}$ shoulder is justified. The following section explains how research into answering these sorts of questions is performed.

\subsubsection{Safety Performance Functions}

Being able to predict the number of expected crashes for a road unit, such as a road segment or intersection, is fundamental to understanding its safety. Since safety was defined as the expected number of crashes by type and severity in a specific time period, engineers require a means to estimate this number. This estimate is obtained from Crash Prediction Models or Safety Performance Functions (SPFs). A SPF creates a relationship between a crash type or severity, such as injury, rear-ends, or run-off-road crashes and roadway characteristics such as traffic volume, roadway geometry, speed limit, length, among others. This implies that a multitude of SPFs are required for different combinations of crash type and roadway characteristics. The uses for SPFs in road safety management are plentiful. These include network screening, where sites with unusually high crashes can be identified for potential treatment. Another use of SPFs is to determine the effect of a treatment by comparing the expected crashes of one population with a treatment to another population without the treatment. This difference can indicate what may be the average effect of the treatment (Hauer, 2015). Furthermore, SPFs are useful when a site has no prior accident history or when the expected number of crashes is estimated by the Empirical Bayes (EB) 
methodology. The EB method for determining the expected crashes of a site uses a mixture of the crash history of the site along with the expected number of crashes expected from similar sites and this is taken from the SPF. EB is discussed further in section 4.2 Empirical Bayes Before-After Study.

\subsubsection{Crash Modification Factors}

The safety effect of treatments in road safety management are estimated by Crash Modification Factors (CMFs) or Crash Modification Functions (CMFunctions). A CMF is a decimal percent change in the expected number of accidents if a treatment of interest is implemented. For example, if the presence of passing lanes had a CMF of 0.67 , this would imply a 33\% reduction in crashes would be expected if a passing lane were installed. A CMFunction is an equation that provides a CMF as a function of the characteristics of a specific site. A countermeasure or treatment can have varying degrees of effectiveness and a CMFunction allows the CMF to vary according to the characteristics of an individual site. Although CMFunctions are preferred over a single CMF value in practice it is often more difficult to create CMFunctions since more data is required to detect the differences in the degree of safety (Gross, Persaud, \& Lyon, 2010). CMFs are currently commonly obtained by either of two approaches:

- Cross sectional studies

- Empirical Bayes Before - After Studies

Cross sectional studies are comparison studies of two populations whose characteristic are otherwise similar except for the treatment effect variable of interest. The difference in the number of crashes is assumed to be the safety impact of the treatment. Empirical Bayes before-after studies provide estimates of the long term expected number of accidents of a site had treatment not been implemented by combining two sources of information. It takes into account the historical crash records of a site along with the number of crashes that would be expected for a similar site, taken from a SPF. This is done through comparing the crash data

for a period before a treatment is implemented with crash data for a period after a treatment is implemented on the same sites. The EB methodology is discussed in section 4.2 Empirical Bayes Before-After Study. 


\subsubsection{Transferability}

The notion of transferability in road safety management refers to how well models or CMFs developed in one jurisdiction fit the data of another jurisdiction. Is it reasonable to assume that a SPF/CMF developed in California can be used in Michigan? Will widening shoulder widths have the same safety impact in Europe as in North America with respect to crashes? It is reasonable to assume that the same treatment applied to similar sites will produce similar results. However, for example, sites in Europe will be inevitably different that those in North America in terms of their geometric design standards, weather, demographics, and reporting practices among others. The extent of which these differences occur will affect "transferability" (OECD, 2012). The empirical assessment of the transferability of CMFs and SPFs could enable researchers to pool research results across jurisdictions.

The importance of assessing the transferability of treatment effects arises from the costs and time it takes to perform studies to produce quality results. Estimates for developing a reliable CMF in the USA is about \$US 200,000 and a study can take years to complete (OECD, 2012). Thus, developing countries may not have the resources to undertake such research. By understanding the factors that affect the transferability of safety effects between jurisdictions, it may be possible to reduce the costs of performing these studies by taking advantage of results from previous research.

\subsection{Objectives}

The Ministry Transportation Ontario (MTO) is in the process of implementing a roadsafety management tool called Safety Analyst, developed by the American Association of State Highway and Transportation Officials (AASHTO, 2010). This set of software includes automated procedures for six main categories of road safety management, including network screening, diagnosis, countermeasure selection, economic appraisal, priority ranking, and countermeasure evaluation (AASHTO, 2010). Safety Analyst required several CMFs that were not configured in the software in order to get its full functionality. The objective of this study is to contribute to the understanding of the safety effects pertaining to two treatment types and to provide the results to MTO for the following: 
- Installation of Passing Lanes

- Installation of Rumble Strips

Furthermore, data were made available from previous studies in the US, which allowed for the assessment of the transferability of the effect of these treatments from other jurisdictions for use in Ontario, Canada. In order to meet this objective this study was divided into 2 parts corresponding to the passing lane research and the rumble strip research. Each of these objectives is described in more detail below.

\subsubsection{Passing Lanes}

Passing lanes allow drivers an opportunity for safer overtaking of vehicles and their presence is expected to have a safety effect. Previous studies have shown crash reductions as a result of installing passing lanes (Harwood et al., 2000; Persaud, et al., 2013) but there has not been any research to show if the safety effect varies with their length. Studies have also shown that there are operational benefits of longer passing lanes (Wooldridge et al., 2001) and that operational benefits may translate to reduced crashes (Harwood, 1995). Combining these notions implies that the effect of passing lanes on safety may be related to the length of the passing lane. With this motivation, data were provided for passing lane sites and reference sites from a previous study in Michigan by Persaud et al. (2013). The ultimate objective was for the development of CMFs for passing lanes that vary with length and the steps described below:

1. Use Google Maps to identify and record the location of passing lanes and reference sites in Ontario along with their crash history.

2. Develop cross sectional models to produce SPFs for Ontario and Michigan sites in order to infer CMFs that vary according to the length of passing lanes separately for total collisions and fatal plus injury collisions.

3. Assess the transferability of the passing lane SPF developed for Michigan for use in Ontario. 


\subsubsection{Rumble Strips}

Rumble strips are milled grooves along the length of the centerline and/or shoulder of a road way. The noise and vibration produced by driving over them behave as a warning to the driver that they are departing their lane. As a result rumble strips have been a known countermeasure for reducing crashers related to vehicles departing from the laneway, such as head-on collisions or run-off-road crashes. Part of the objectives of this study is to determine CMFs from an EB Before-After study with data provided by the MTO for dual application of center line and shoulder rumble strip locations within Ontario. Data were also made available from a previous study by Persaud, Lyon, Eccles, and Soika (2016) for the states of Kentucky, Missouri, and Pennsylvania. Using these data sets, the following are the objectives for the rumble strip investigation:

1. Perform an Empirical Bayes before-after study for the dual application of center line and shoulder rumble strips for Ontario sites

2. Using the after-period crashes along with the reference sites to develop cross sectional models and explore how it agrees with the EB study in objective 1.

3. Assess the transferability of the rumble strip safety effects in each jurisdiction for application in Ontario.

\subsection{Thesis Structure}

The remainder of this thesis has been organized into seven chapters.

Chapter 2 presents a literature review of crash based modelling and of previous studies undertaken to detect the safety effects of passing lanes or rumble strips and to assess the transferability.

Chapter 3 presents the data that were used in this research, along with some summary statistics.

Chapter 4 describes the methodology used in the study.

Chapter 5 presents the proposed models for passing lanes and rumble strips as well as the goodness of fit measures. A discussion is held about the results. 
Chapter 6 presents an application of how the findings can be applied in practice. A cost benefit analysis was presented using the models obtained in this study.

Lastly, Chapter 7 summarizes the findings and contributions for safety analysis and provides recommendations about how to improve the knowledge about the safety effects of passing lanes and rumble strips. 


\section{Chapter 2 Literature Review}

The safety of a road unit, such as a road segment or intersection, is measured by frequency and severity of accidents in a given time period (Hauer, 1997). It is no surprise that there have been numerous studies devoted to developing models that can predict these numbers. The following summarizes research from the literature about the safety of passing lanes and rumble strips.

\subsection{Passing Lanes}

Passing lanes are short 3 or 4 lane segments along two-lane highways that allow vehicles to overtake other vehicles without travelling on the advancing traffics lane of travel. A twolane highways' performance can be measured by calculating the percent of time a vehicle spends following another vehicle without having the ability to overtake it (TRB, 2010). The inability to overtake another vehicle can lead to driver frustration and depends on the following factors (MTO, 1985):

- rolling terrain

- sparse development

- a high percentage of long-distance, high-speed trips

- a significant percentage of slow-moving

- vehicles generating platoons

- traffic volumes high enough to restrict passing but too low to warrant widening to four lanes

These conditions are prevalent in northern Ontario and so passing lanes can be an economical treatment for improving safety or operations. Passing lanes are a low cost alternative for improving the level of service of a 2-lane rural highway where the costs of upgrading to a 4-lane highway are prohibitive (Wooldridge et al., 2001). The recommended lengths of passing lanes are similar for Ontario and Michigan, roughly between $1.5 \mathrm{~km}$ to 2.4 km (MDOT, 2012; MTO, 1985). In Ontario however, consideration is given to northern 
regions where it may be common to have convoys of logging trucks travelling together. As a result, longer passing lanes may be encountered in these regions in Ontario (MTO, 1985).

A review of drivers' attitudes through a survey conducted by Mutabazi, Russell, and Stokes (1998) showed that drivers support the construction of passing lanes and they believed it was more beneficial for "improving safety than for saving time". The degree to which the length of passing lanes affect safety is void in the literature however; several studies have shown safety improvements for its presence. The Highway Safety Manual (HSM) provides a CMF value for total crashes of 0.75 for the installation of passing lanes (AASHTO, 2010) taken from a study done by Harwood and St John (1985). This translate to a 25\% reduction in crashes. More recently, Persaud et al. (2013) evaluated the safety performance of passing lanes in Michigan. Using data from 231 passing lane sites and 100 reference sites CMFs were developed from cross sectional models and an extensive EB before-after study. The cross sectional models were used to corroborate the EB study due to the small sample size. Using Generalized Linear Modelling and assuming a negative binomial error distribution, which is consistent with the state-of-the-art of current research, the CMFs showed a $33 \%$ reduction in total crashes and a $29 \%$ reduction in injury crashes. It was also found that similar safety effects occur on section $1.6 \mathrm{~km}$ downstream and upstream of the passing lane sites.

Potts and Harwood (2004) examined the operational and safety performance of passing lane sites. The study found the safety effects of introducing passing lanes ranges from $12 \%$ to $24 \%$ lower accident frequency per mile per year than for conventional two-lane highway sections. They found the higher end of accident reductions occurred on the segments with the highest AADT. This was justified, since passing opportunities are reduced due to high opposing traffic volumes. Another study conducted by Neuman et al. (2003) suggested that more analysis is required in order to sufficiently evaluate the safety effects of passing lanes. Although no significant findings of negative implications existed, caution was advised, since differences in effects have been shown between studies. 


\subsection{Rumble Strips}

Rumble strips are milled grooves placed along the centerline (CLRS) and/or shoulder (ELRS) of a roadway. They are a low cost treatment for reducing crashes related to veering off the lane way such as run-off-road crashes and head-on collisions. Although numerous studies have been performed for use of either center line or shoulder rumble strips, notably by Torbic et al. (2009), the combined effect has not been established. As a result, the Highway Safety Manual (AASHTO, 2010) does not provide a CMF for the combined effect.

A study done by Sayed, deLeur, and Pump (2010) looked at rural highways in British Columbia, Canada. By performing an EB Before-After study including 47 treated sites and 225 comparison sites to correct for confounding factors they showed that the installation of the combined centerline and shoulder rumble strips can reduce total crashes by $18 \%$. A higher reduction of $21.4 \%$ were seen in run-off-road and head-on collisions. In another study

of relevance, Kay et al. (2015) assessed the safety impacts of the statewide CLRS treatment being conducted by the Michigan Department of Transportation (MDOT) between the years of 2008-2010. The program was meant to blanket cover more than $8,000 \mathrm{~km}$ of rural nonfreeway highways maintained by Michigan DOT. ELRS were also installed in combination with CLRS in areas where paved shoulders were at least $1.83 \mathrm{~m}(6 \mathrm{ft})$. Using the EB methodology a $27.3 \%$ reduction in CLRS sites and a $32.8 \%$ reduction was estimated for the combined treatment effect for target crashes. Target crashes were set to be any crash involving crossing the centerline.

The last study of relevance was performed by Torbic, Bauer, Hutton, and Campbell (2013) who used the EB before-after methodology for evaluating the combined effect of CLRS and ELRS treatments in the state of Mississippi. They looked at two-lane rural highways and defined their target collisions as head-on, sideswipe-opposite-direct, and runoff-road. The results showed a $35 \%$ reduction in total crashes and a $39.6 \%$ reduction in fatal/injury collisions.

\subsection{Transferability of SPFs and CMFs}

The transferability of SPFs and CMFs from one jurisdiction to another has been a subject of discussion and research among road safety researchers. The importance of 
transferability was discussed in the paper Sharing Road Safety: Developing an International Framework for CMFs (OECD, 2012). In it, the authors detail that the costs associated with developing CMFs are too great for developing countries to afford. CMFs are generally specific to the location for which it was developed and using it directly in a different location may produce inaccurate results. Differences in weather, reporting patterns, geometric design codes among others need to be accounted for between where the CMF was produced to where it will be applied. The Highway Safety Manual (AASHTO, 2010) has outlined a procedure for which an SPF can be transferred to another location by applying a calibration factor. The calibration factor is the ratio between observed and predicted crashes and is multiplied by the model in order to proportion the predicted crashes to the location of interest. Several research efforts have tried to verify or improve the transferability procedures laid out in the Highway Safety Manual (HSM). Persaud, Lord, and Palmisano (2002) tested the calibration and transferability of SPFs for urban intersections from Toronto to Vancouver and California. The procedure from the HSM was applied and the results were mixed, suggesting that a single calibration factor may not be appropriate.

Elvik (2013) tried to study the transferability of the safety effects of flattening horizontal curves by analyzing research from 10 countries: Australia, Canada, Denmark, Germany, Great Britain, New Zealand, Norway, Portugal, Sweden, and the United States. The main research goal was to determine if the SPFs developed in these countries were similar and to what extent. A sensitivity analysis produced mixed results. The models were different in their forms but were consistent with respect to estimating lower crashes on roads with a larger radius. Other factors, such as proximity to other curves and length of curve, were inconsistent between models. 


\section{Chapter 3 Data Summary}

This section provides information about the data used in this research for both passing lanes and rumble strips

\subsection{Ontario Crash Data and Average Annual Daily Traffic (AADT)}

The crash and AADT data for Ontario were made available through the Ministry Transportation Ontario, with the same database used for both passing lanes, and rumble strips. The raw crash data for the years between 2000-2013 was provided in a spreadsheet and included a separate tab to document to decipher the coded fields (MTO, 2009). The crash data was very detailed and included the type and severity of accidents as well as the location and the number of vehicles involved among many other variables. The location was provided under MTOs' Linear Highway Referencing System, which identifies a location on the highway, by a unique milepost plus an offset from that milepost in the cardinal direction. Furthermore, a sequence of events that described what a vehicle collided with during the course of the crash was available through the Object Collision fields. These fields identify collisions under three different categories and their descriptions are provided Table 1:

- Movable Objects

- Other Objects

- Fixed Objects

In order to remain consistent with the Persaud et al. (2013) study, all animal related crashes were removed from the data and were not included in any of the analysis. In the period of 2009-2013, there were 162,516 crash records for Ontario highways and of these 64,093 were animal related. This calculated to 12,819 animal crashes per year or to a significant $39 \%$ of the entire data. Moreover, intersection and non-intersection related crashes could be identified separately within the data and this allowed for separate analysis if desired. The MTO defined any intersection related collision as "regardless of the distance from the intersection, if it involves vehicles waiting at or processing towards the intersection, except when the cause is related to a non-intersection activity (MTO, 2009)." 
Table 1 Description of Object Collision Fields

\begin{tabular}{lll}
\hline $\begin{array}{c}\text { Object } \\
\text { Type }\end{array}$ & \multicolumn{1}{c}{ Description } & \multicolumn{1}{c}{ Objects } \\
\hline Movable & $\begin{array}{l}\text { Moveable Objects are self-propelled or } \\
\text { have the capacity for motion }\end{array}$ & $\begin{array}{l}\text { Other Vehicles; unattended vehicle; } \\
\text { pedestrian; cyclist; railway train; street } \\
\text { car; farm tractor; animal; }\end{array}$ \\
& $\begin{array}{l}\text { Fixed Objects are natural topographical } \\
\text { features, highway appurtenances, snow } \\
\text { accumulations, and other immovable } \\
\text { objects on the roadside. }\end{array}$ & $\begin{array}{l}\text { Rnifing; load spill; fire/explosion; } \\
\text { submersion; rollover; debris on road; } \\
\text { debris off vehicle; }\end{array}$ \\
Other & $\begin{array}{l}\text { Other Objects represent events that } \\
\text { occur either before or after the initial } \\
\text { impact and do not involve fixed or } \\
\text { moveable objects. }\end{array}$ & $\begin{array}{l}\text { Cable guide rail; concrete guide rail; } \\
\text { fteel guide rail; pole-utility; pole-sign; } \\
\text { face; snow pile; ditch; curb; crash } \\
\text { cushion; building; tree; }\end{array}$
\end{tabular}

\subsection{Ontario Highway Geometry Data}

The MTO also provided a spreadsheet of highway characteristics for all of Ontario highways. The locations were provided using MTO's Linear Highway Referencing System (LHRS) and characteristics included:

- Lane width

- Shoulder width

- Terrain

- Divided/undivided

- Presence of passing lanes 
The LHRS plus offset and length were used to extract all of the necessary characteristics at the location of the treatment.

\subsection{Passing Lane Data.}

The data for the passing lanes study were acquired from two sources: Data for the state of Michigan from a previous study by Persaud et al. (2013) for which the effect of the presence of passing lanes was determined to have a CMF of 0.67.; and data for the province of Ontario, provided by the MTO for a list of highway segments that have a passing lane somewhere along its length. The passing lanes had to be identified through manual extractions from Google Maps. Each data set is discussed in detail below.

\subsubsection{Michigan passing lane data}

There were a total of 129 passing lane sites and 100 reference sites that were provided for use in this study from previous research in Michigan (Persaud, Lyon, Bagdade et al., 2013). The passing lane sites ranged in length from $0.6 \mathrm{~km}$ to $4.0 \mathrm{~km}$ and they had an average length of $2.5 \mathrm{~km}$; the total sum of lengths of passing lanes was $321 \mathrm{~km}$. The reference sites that were provided did not include passing lanes but were otherwise similar to the passing lane sites. All of the reference sites for Michigan were the same length of $1.6 \mathrm{~km}$. Table 2 and Table 3 show the summary statistics for the passing lane sites and reference sites respectively below.

Table 2 Summary Statistics of Michigan Passing Lane Sites

\begin{tabular}{ccccc}
\hline \multicolumn{5}{c}{ Passing Lane Segments $(\mathrm{n}=124)$} \\
\hline Data Item & Minimum & Maximum & Mean & Sum \\
AADT & 1016 & 16688 & 4965 & - \\
Passing Lane Length $(\mathrm{km})$ & 0.6 & 4.0 & 2.5 & 321.7 \\
Total Crashes & 0 & 66 & 12 & 1555 \\
Fatal/Injury Crashes & 0 & 26 & 3 & 446
\end{tabular}


Table 3 Summary Statistics for Michigan Reference Sites

\begin{tabular}{|c|c|c|c|c|}
\hline \multicolumn{5}{|c|}{ Reference Segments $(n=100)$} \\
\hline Data Item & Minimum & Махітит & Mean & Sum \\
\hline AADT & 1020 & 29334 & 5181 & - \\
\hline Segment Length (km) & 1.6 & 1.6 & 1.6 & 160.9 \\
\hline Total Crashes & 0 & 108 & 12.0 & 1168 \\
\hline Fatal/Injury Crashes & 0 & 28 & 3.4 & 335 \\
\hline
\end{tabular}

\subsubsection{Ontario passing lane data}

MTO had provided a list of the location of highway segments, which contain passing lanes somewhere along its length. The locations were provided using MTOs' Linear Highway Referencing System (LHRS). The LHRS identifies a location along the highway using a unique milepost plus an offset in the cardinal direction. For example, a passing lane may exist somewhere along a 20km stretch of the highway between LHRS $20340+0 \mathrm{~km}$ and $20340+20 \mathrm{~km}$. The LHRS and offset locations are available on Google Maps through the MTO maintained website iCorridor.org (MTO, 2015). Using the satellite view on Google Maps, passing lanes were identified through visual inspection and their starting milepost, offset, and length were recorded. Overlapping passing lanes were avoided in order to avoid short 4-lane highway segments. A total of 44 passing lanes and 122 reference sites were identified. The reference sites were gathered similarly, through iCorridor, and were chosen to be otherwise similar to the passing lane sites. To avoid any influence from other passing lanes or reduced speed limits the reference sites were at least $5 \mathrm{~km}$ away from any other passing lanes, $1.5 \mathrm{~km}$ away from signalized intersections, and small towns.

Once the locations of the passing lanes were identified, they were matched with 5 years of crash data that were provided by MTO as well as the highway characteristics of interest. The summary statistics for the passing lane and reference sites are shown below in Table 4 and Table 5 respectively. 
Table 4 Summary Statistics for Ontario Passing Lane Segments

\begin{tabular}{ccccc}
\hline \multicolumn{5}{c}{ Passing Lane Segments $(\mathrm{n}=44)$} \\
\hline Data Item & Minimum & Maximum & Mean & Sum \\
AADT & 2000 & 11300 & 5514 & - \\
Passing Lane Length $(\mathrm{km})$ & 1.2 & 3.2 & 2 & 87.7 \\
Total Crashes & 1 & 15 & 5.7 & 251 \\
Fatal/Injury Crashes & 0 & 4 & 1.3 & 56
\end{tabular}

Table 5 Summary Statistics for Ontario Passing Lane Reference Sites

\begin{tabular}{|c|c|c|c|c|}
\hline \multicolumn{5}{|c|}{ Reference Segments $(n=122)$} \\
\hline Data Item & Minimum & Maximum & Mean & Sum \\
\hline AADT & 2060 & 12400 & 4965 & - \\
\hline Segment Length $(\mathrm{km})$ & 1.2 & 3.8 & 1.9 & 227.9 \\
\hline Total Crashes & 0 & 22 & 5.7 & 696 \\
\hline Fatal and Injury & 0 & 8 & 1.5 & 182 \\
\hline
\end{tabular}


Table 6 Location of Ontario Passing Lane Segments

\begin{tabular}{|c|c|c|c|c|c|c|c|}
\hline LHRS & From & To & Length (km) & LHRS & From & To & Length (km) \\
\hline 14150 & 17.4 & 19.8 & 2.4 & 20870 & 8.6 & 10.6 & 2.0 \\
\hline 14210 & 1.6 & 3.4 & 1.8 & 20900 & 1.4 & 3.7 & 2.3 \\
\hline 14210 & 8.4 & 10.4 & 2.0 & 20900 & 3.9 & 5.9 & 2.0 \\
\hline 17280 & 2.0 & 4.1 & 2.1 & 20990 & 0.3 & 2.0 & 1.7 \\
\hline 17293 & 2.0 & 4.2 & 2.2 & 21000 & 7.6 & 9.1 & 1.5 \\
\hline 17293 & 4.6 & 6.0 & 1.4 & 21010 & 7.1 & 9.3 & 2.2 \\
\hline 17300 & 3.6 & 6.0 & 2.4 & 21010 & 19.0 & 20.3 & 1.3 \\
\hline 17310 & 4.6 & 6.7 & 2.1 & 21020 & 1.0 & 2.4 & 1.4 \\
\hline 17320 & 7.8 & 9.8 & 2.0 & 21150 & 1.5 & 3.5 & 2.0 \\
\hline 17330 & 1.0 & 3.2 & 2.2 & 21175 & 2.9 & 4.8 & 1.9 \\
\hline 17350 & 5.6 & 6.9 & 1.3 & 21210 & 8.1 & 10.3 & 2.2 \\
\hline 17360 & 0.3 & 1.9 & 1.6 & 21220 & 1.4 & 3.1 & 1.7 \\
\hline 17615 & 36.3 & 38.9 & 2.6 & 21280 & 5.2 & 7.2 & 2.0 \\
\hline 17660 & 4.1 & 6.8 & 2.7 & 21380 & 5.1 & 6.7 & 1.6 \\
\hline 17660 & 8.5 & 11.1 & 2.6 & 21400 & 0.3 & 2.0 & 1.7 \\
\hline 17680 & 11.4 & 13.4 & 2.0 & 21400 & 10.3 & 12.2 & 1.9 \\
\hline 20060 & 10.4 & 12.6 & 2.2 & 22030 & 7.7 & 9.7 & 2.0 \\
\hline 20722 & 0.2 & 2.0 & 1.8 & 22100 & 2.6 & 4.2 & 1.6 \\
\hline 20730 & 5.4 & 6.9 & 1.5 & 35460 & 0.9 & 3.2 & 2.3 \\
\hline 20746 & 2.0 & 4.1 & 2.1 & 35465 & 0.1 & 2.3 & 2.2 \\
\hline 20761 & 3.1 & 4.3 & 1.2 & 35510 & 7.9 & 10.5 & 2.6 \\
\hline 20820 & 11.7 & 14.9 & 3.2 & 35523 & 0.9 & 3.1 & 2.2 \\
\hline
\end{tabular}

\subsection{Rumble Strip Data.}

The crash data and locations for the dual application of centerline and shoulder rumble strips was acquired for the states of Kentucky, Pennsylvania, and Missouri from a previous study by Persaud et al. (2016) for which the safety effects for the presence of dual rumble strips was evaluated. For the province of Ontario, rumble strip locations and crash data were provided by the Ministry Transportation Ontario. The dataset for each state/province is discussed separately in the following sections. 


\subsubsection{Ontario rumble strip data}

The data that were provided by the MTO was very limited in terms of the number of sites and since most of the dual application sites were installed recently, there were no crash data available for them. A total of 24 sites were provided from which only 6 could be utilized for the study and measured a total sum length of $69.5 \mathrm{~km}$. Furthermore, the Ontario rumble strip sites only had shoulder rumble strips installed and centerline rumble strips may or may not have been installed earlier. Information on location and installation dates of the six rumble strip segments is presented in Table 7 and summary statistics are provided in Table 8 .

Table 7 Location and Installation Year of the 6 Ontario Rumble Strip Segments

\begin{tabular}{lll|lll}
\hline Highway & \multicolumn{2}{c|}{ From } & \multicolumn{2}{c}{ To } & Installation \\
\cline { 2 - 5 } No. & LHRS & Offset & LHRS & Offset & Year \\
\hline 17 & $\mathbf{2 0 7 6 1}$ & 1.4 & $\mathbf{2 0 7 7 1}$ & 0.0 & 2012 \\
17 & $\mathbf{2 0 7 3 0}$ & 1.3 & $\mathbf{2 0 7 5 1}$ & 0.0 & 2012 \\
17 & $\mathbf{2 0 7 0 8}$ & 0.0 & $\mathbf{2 0 7 2 2}$ & 8.9 & 2011 \\
17 & $\mathbf{2 0 6 8 8}$ & 0.0 & $\mathbf{2 0 7 0 1}$ & 1.1 & 2009 \\
17 & $\mathbf{2 0 6 8 2}$ & 0.0 & $\mathbf{2 0 6 8 8}$ & 0.0 & 2008 \\
15 & $\mathbf{2 0 0 3 0}$ & 4.9 & $\mathbf{2 0 0 3 0}$ & 6.4 & 2006
\end{tabular}

\subsubsection{Kentucky}

The data for Kentucky included 27 rumble strip sites as well as 1,005 untreated reference sites. All of the treated sites previously had shoulder rumble strips. Therefore, the effects would only be an incremental one, from shoulder to combined effect of shoulder and centerline. Lastly, it was noted that the rumble strips may have exceeded their service life; however, this could not be verified (Persaud et al., 2016). The summary statistics are provided below in Table 8 .

\subsubsection{Pennsylvania}

The Pennsylvania data consist of a large number of sites that had both CLRS and ELRS recently installed did not exist previously. There were $351 \mathrm{~km}$ of rumble strip sites and 17,931 km of reference sites provided. The state of Pennsylvania has been pursuing a goal to blanket cover their entire highway network with rumble strips. As a results, high priority 
sites have been treated prior to obtaining the data which resulted in the data under representing the safety effect (Persaud et al., 2016). The summary statistics are provided below in Table 8.

\subsubsection{Missouri}

The data from the state of Missouri consisted of $740 \mathrm{~km}$ where both centerline and edge line rumble strips had been installed. This state was installing rumble strips whenever a resurfacing project was undertaken and thus no reference sites were available as a result. The summary statistics are provided below in Table 8. 
Table 8 Summary Statistics of Rumble Strip Data (Persaud at al., 2016)

\begin{tabular}{|c|c|c|c|c|c|c|c|}
\hline \multirow[b]{2}{*}{ Variable } & \multicolumn{4}{|c|}{ Treatment Sites } & \multicolumn{3}{|c|}{ Reference Sites } \\
\hline & ON & KY & MO & $\mathbf{P A}$ & $\mathbf{O N}$ & KY & PA \\
\hline Number of km (mi) & $\begin{array}{c}69.5 \\
(43.1)\end{array}$ & $\begin{array}{l}264 \\
(164)\end{array}$ & $\begin{array}{c}740 \\
(460)\end{array}$ & $\begin{array}{c}351 \\
(218)\end{array}$ & $\begin{array}{c}196 \\
(313.6)\end{array}$ & 1,532 & 17,931 \\
\hline $\begin{array}{l}\text { Number of years of } \\
\text { data }\end{array}$ & 10 & 11 & 13 & 10 & 5 & 11 & 10 \\
\hline $\mathrm{Km}$ (mi)-years before & $\begin{array}{c}658 \\
(409)\end{array}$ & $\begin{array}{c}972 \\
(604)\end{array}$ & $\begin{array}{c}6,820 \\
(4,238)\end{array}$ & $\begin{array}{c}2,274 \\
(1,407)\end{array}$ & \multirow{2}{*}{$\begin{array}{c}981.7 \\
(1,571)\end{array}$} & \multirow{2}{*}{$\begin{array}{c}27,121 \\
(16,852)\end{array}$} & \multirow{2}{*}{$\begin{array}{c}259,711 \\
(161,377)\end{array}$} \\
\hline $\mathrm{Km}$ (mi)-years after & $\begin{array}{c}246 \\
(154)\end{array}$ & $\begin{array}{l}1,230 \\
(764)\end{array}$ & $\begin{array}{c}2,070 \\
(1,286)\end{array}$ & $\begin{array}{c}824 \\
(512)\end{array}$ & & & \\
\hline $\begin{array}{l}\text { Crashes/km (mi)/year } \\
\text { before }\end{array}$ & $\begin{array}{c}0.76 \\
(1.21)\end{array}$ & $\begin{array}{l}1.00 \\
(1.61)\end{array}$ & $\begin{array}{c}0.46 \\
(0.74)\end{array}$ & $\begin{array}{c}0.70 \\
(1.13)\end{array}$ & \multirow{2}{*}{$\begin{array}{l}0.513 \\
(1.23)\end{array}$} & \multirow{2}{*}{$\begin{array}{c}0.66 \\
(1.07)\end{array}$} & \multirow{2}{*}{$\begin{array}{c}0.76 \\
(1.23)\end{array}$} \\
\hline $\begin{array}{l}\text { Crashes/km (mi)/year } \\
\text { After }\end{array}$ & $\begin{array}{c}0.70 \\
(1.11)\end{array}$ & $\begin{array}{c}0.58 \\
(0.94)\end{array}$ & $\begin{array}{c}0.30 \\
(0.49)\end{array}$ & $\begin{array}{c}0.70 \\
(1.13)\end{array}$ & & & \\
\hline $\begin{array}{l}\text { Injury crashes/km } \\
\text { (mile)/year before }\end{array}$ & $\begin{array}{c}0.23 \\
(0.37)\end{array}$ & $\begin{array}{c}0.31 \\
(0.50)\end{array}$ & $\begin{array}{c}0.20 \\
(0.32)\end{array}$ & $\begin{array}{c}0.39 \\
(0.62)\end{array}$ & \multirow{2}{*}{$\begin{array}{c}0.14 \\
(0.23)\end{array}$} & \multirow{2}{*}{$\begin{array}{c}0.21 \\
(0.34)\end{array}$} & \multirow{2}{*}{$\begin{array}{c}0.40 \\
(0.64)\end{array}$} \\
\hline $\begin{array}{l}\text { Injury crashes/km } \\
\text { (mi)/year after }\end{array}$ & $\begin{array}{c}0.16 \\
(0.26)\end{array}$ & $\begin{array}{c}0.17 \\
(0.27)\end{array}$ & $\begin{array}{c}0.11 \\
(0.18)\end{array}$ & $\begin{array}{c}0.39 \\
(0.62)\end{array}$ & & & \\
\hline $\begin{array}{l}\text { Run-off-road } \\
\text { crashes/km (mi)/year } \\
\text { before }\end{array}$ & $\begin{array}{c}0.20 \\
(0.33)\end{array}$ & $\begin{array}{c}0.39 \\
(0.62)\end{array}$ & $\begin{array}{c}0.19 \\
(0.30)\end{array}$ & $\begin{array}{c}0.10 \\
(0.16)\end{array}$ & \multirow{2}{*}{$\begin{array}{c}0.11 \\
(0.17)\end{array}$} & \multirow{2}{*}{$\begin{array}{c}0.24 \\
(0.38)\end{array}$} & \multirow{2}{*}{$\begin{array}{c}0.14 \\
(0.22)\end{array}$} \\
\hline $\begin{array}{l}\text { Run-off-road } \\
\text { crashes/km (mi)/year } \\
\text { after }\end{array}$ & $\begin{array}{c}0.17 \\
(0.28)\end{array}$ & $\begin{array}{c}0.12 \\
(0.20)\end{array}$ & $\begin{array}{c}0.13 \\
(0.21)\end{array}$ & $\begin{array}{c}(0.11) \\
0.18\end{array}$ & & & \\
\hline $\begin{array}{l}\text { Head-on crashes/km } \\
\text { (mi)/year before }\end{array}$ & $\begin{array}{l}0.06 \\
(0.1)\end{array}$ & $\begin{array}{c}0.04 \\
(0.06)\end{array}$ & $\begin{array}{c}0.02 \\
(0.04)\end{array}$ & $\begin{array}{c}0.03 \\
(0.05)\end{array}$ & \multirow{2}{*}{$\begin{array}{c}0.02 \\
(0.03)\end{array}$} & \multirow{2}{*}{$\begin{array}{c}0.02 \\
(0.03)\end{array}$} & \multirow{2}{*}{$\begin{array}{c}0.03 \\
(0.05)\end{array}$} \\
\hline $\begin{array}{l}\text { Head-on crashes/km } \\
\text { (mi)/year after }\end{array}$ & $\begin{array}{c}0.07 \\
(0.12)\end{array}$ & $\begin{array}{c}0.01 \\
(0.02)\end{array}$ & $\begin{array}{c}0.01 \\
(0.02)\end{array}$ & $\begin{array}{c}0.03 \\
(0.05)\end{array}$ & & & \\
\hline $\begin{array}{l}\text { Sideswipe } \\
\text { crashes/km (mi)/year } \\
\text { before }\end{array}$ & $\begin{array}{c}0.07 \\
(0.12)\end{array}$ & $\begin{array}{c}0.06 \\
(0.10)\end{array}$ & $\begin{array}{c}0.03 \\
(0.05)\end{array}$ & $\begin{array}{c}0.02 \\
(0.03)\end{array}$ & \multirow{2}{*}{$\begin{array}{c}0.03 \\
(0.05)\end{array}$} & \multirow{2}{*}{$\begin{array}{c}0.03 \\
(0.05)\end{array}$} & \multirow{2}{*}{$\begin{array}{c}0.02 \\
(0.03)\end{array}$} \\
\hline $\begin{array}{l}\text { Sideswipe } \\
\text { crashes/km (mi)/yr } \\
\text { after }\end{array}$ & $\begin{array}{c}0.07 \\
(0.12)\end{array}$ & $\begin{array}{c}0.02 \\
(0.04)\end{array}$ & $\begin{array}{c}0.01 \\
(0.02)\end{array}$ & $\begin{array}{c}0.02 \\
(0.03)\end{array}$ & & & \\
\hline Avg. AADT before & 9,017 & 6,101 & 5,290 & 4,990 & 6,343 & 2,702 & 4,350 \\
\hline Min. AADT before & 5,400 & 1,282 & 154 & 782 & 2,750 & 10 & 473 \\
\hline Max. AADT before & 12,900 & 20,433 & 15,848 & 25,796 & 14,200 & 17,701 & 25,067 \\
\hline Avg. AADT after & 9,312 & 6,101 & 5,106 & 4,657 & 6,343 & 2,702 & 4,350 \\
\hline Min. AADT after & 5,523 & 1,282 & 155 & 562 & 2,750 & 10 & 473 \\
\hline Max. AADT after & 12,921 & 20,433 & 13,522 & 26,118 & 14,200 & 17,701 & 25,067 \\
\hline
\end{tabular}




\section{Chapter 4 Methodology.}

This chapter describes the methodology used throughout this research.

\subsection{Crash Prediction Models}

The crash prediction models used in this study are consistent with the state-of-the-art methods used in current research. The main features of crash-based modelling are discussed here, along with their underlying assumptions.

\subsubsection{Distribution of Crashes}

Since crashes are rare discrete independent events it is generally accepted that crash occurrences on a single site, (road segment or intersection) follows a Poisson process such that:

$$
P\left(X=y_{i} \mid \mu\right)=\frac{\mu_{i}^{y_{i}} e^{-\mu_{i}}}{y_{i}}
$$

In this equation $P\left(X=y_{i}\right)$ is the probability that the observed number of crashes equals $y$ during period $i$ and $\mu_{i}$ is the expected number of crashes that occurs during the $i$ interval (Shahdah, Saccomanno, \& Persaud, 2012). The Poisson distribution has two noteworthy properties:

1. If $X \sim$ Poisson then $\operatorname{Var}(X)=\mu$

2. If $X_{1}, X_{2, \ldots,} X_{n}$ are accident counts with mean $\mu_{i}$, then $\sum_{i=1}^{n} X_{i}=\mu_{1}+\mu_{2}+\cdots+\mu_{n}$

In a population of similar road segments, each segment will have a number of traits in common but will inevitably differ in others. Lane widths, speed limits, shoulder widths, reporting practices, weather, demographics among other unmeasured uncertainties and unobserved differences can vary from site to site (Hauer, 2015). These differences cause the variance to be greater than the mean in empirical data and contradicts the Poisson property that $\operatorname{Var}(x)=\mu$ among sites in a population. When this occurs the data are said to be "over dispersed." The problem of over dispersion can be resolved by assuming a Negative 
Binomial (NB) distribution since it can capture the dispersion of the data. The underlying assumptions for assuming a NB distribution for crash counts in a population of road units are the following (Hauer, 2015):

i. The accident count on every unit in a population is Poisson distributed

ii. The mean of the each unit within the population is different

iii. The frequency of the means can be approximated by a Gamma distribution.

The first and second assumptions have been addressed above. The third assumption that the frequency of means can be approximated by a Gamma distribution are motivated by convenience and flexibility (Hauer, 2015). The NB distribution can be expressed as (Hauer, 2015):

$$
P\left(K_{i}=k_{i}\right)=\frac{\Gamma\left(k_{i}+b_{i}\right)}{\Gamma\left(b_{i}\right) k_{i} !} \frac{a_{i}^{b_{i}}}{\left(a_{i}+1\right)^{k_{i}+b_{i}}}
$$

Where

$$
\begin{aligned}
& k_{i} \text { is the observed number of crashes } \\
& \Gamma(.)=\text { Gamma function } \\
& a_{i}, b_{i}=\text { the parameters from the Gamma distribution describing } \mu
\end{aligned}
$$

The parameters $a, b$ are part of the Gamma probability density function:

$$
f(\mu)=\frac{a^{b} \mu^{b-1} e^{-a \mu}}{\Gamma(b)}
$$

And the mean and variance are:

$$
E\{u\}=\frac{b}{a} \quad \text { and } \quad V\{\mu\}=\frac{E\{\mu\}^{2}}{b}
$$


For a given value of $E\{\mu\}$, the variance $V\{\mu\}$ is proportional to value of $\frac{1}{b}$. For this reason $b$ is known as the dispersion parameter; a larger value would signify a small variance and vice-versa. Due to the properties of the NB distribution explained above it is used widely in state-of-the-art research in crash prediction modelling (Hauer, 2015). This is discussed further in the next section.

\subsubsection{Generalized Linear Models (GLM)}

Generalized Linear Models can utilize the Negative Binomial distribution in order to estimate the parameters in Safety Performance Functions (SPFs). Software packages such as SAS ${ }^{\circledR}$ are capable of performing this type of modeling (SAS $\left.{ }^{\circledR}, 2014\right)$. The parameters in a SPF are commonly estimated by a maximum likelihood technique whereby the NB likelihood function is maximized. A likelihood function uses its underlying distribution to determine the probability of producing the observed accident counts for a given value of $\mu$. The $\mu$ that best supports the observed data occurs at the peak or maximum of the likelihood function (Hauer, 2015), for example, by entering the $\mu$ as:

$$
\mu=\beta_{1} A A D T^{\beta_{2}}
$$

SAS ${ }^{\circledR}$ uses an iterative procedure whereby it finds the values of the parameters $\beta_{1}, \beta_{2}$ by maximizing the Negative Binomial likelihood function. Conveniently, the dispersion parameter is calculated alongside the parameter estimation. The dispersion parameter is used in the Empirical Bayes methodology and can also serve as a goodness of fit measure. These are explained further in the following sections.

\subsection{Empirical Bayes Before-After Study}

The Empirical Bayes (EB) Methodology for observational before-after studies is considered a rigorous approach in road safety since it can account for regression-to-the-mean (RTM) phenomenon. RTM is the notion that short term accident counts are not indicative of long term expected crashes on a given site and since sites with high short term crash counts are usually prioritized for treatment RTM will bias the results. Hauer (1997) explained that the estimate of the expected number of crashes is best determined by combining the crash history of a site and the expected crashes for similar sites obtained from a SPF. This 
combination helps smooth fluctuations in crash data and help specify the expected long-term crash average. The expected number of crashes for a specific site using the EB methodology is estimated as:

$$
\lambda_{i}=w_{i} \mu_{i}+\left(1-w_{i}\right) y_{i}
$$

Where

$\lambda_{i}=$ the expected number of crashes for site $i$ over a given time period.

$\mu_{i}=$ the estimated number of expected crashes at site $i$ over the given period taken from safety performance functions (SPFs)

$y_{i}=$ the observed number of crashes at site I over the given time period

$w_{i}=$ a weight used to combine the observed crashes, $y_{i}$, and the predicted crashes, $\mu_{i}$ taken from the SPF

The weight $w$ is estimated from the mean and variance of the SPF as:

$$
w=\frac{1}{1+k \mu_{i}}
$$

Where

$k=$ the over dispersion parameter is a constant obtained from the negative binomial maximum likelihood function during parameter estimation

A factor $C_{i}$, is applied to $\lambda_{i}$ in order to account for differences in traffic volumes and the length of the before and after periods:

$$
C_{i}=\frac{(\text { sum of } S P F \text { predictions in after period })}{(\text { sum of SPF predictions in before period })}
$$

The value of $\lambda=C_{i} \lambda_{i}$ and its variance is then summed across all of the sites to calculate the expected number of crashes that would have occurred in the after period without the treatment. The was compared to $\pi_{\text {sum }}$, the sum of the number of reported crashes in the after period, in order to obtain he index of effectiveness (Persaud et al., 2016): 


$$
\begin{gathered}
\theta=\frac{\frac{\pi_{\text {sum }}}{\lambda_{\text {sum }}}}{1+\left(\frac{\operatorname{Var}\left(\lambda_{\text {sum }}\right)}{\lambda_{\text {sum }}^{2}}\right)} \\
\operatorname{StDev}(\theta)=\sqrt{\frac{\theta^{2}\left(\frac{\operatorname{Var}\left(\pi_{\text {sum }}\right)}{\pi_{\text {sum }}^{2}}+\frac{\operatorname{Var}\left(\lambda_{\text {sum }}\right)}{\lambda_{\text {sum }}^{2}}\right)}{\left(1+\frac{\operatorname{Var}\left(\lambda_{\text {sum }}\right)}{\lambda_{\text {sum }}^{2}}\right)^{2}}}
\end{gathered}
$$

The $\theta$ is equivalent to a CMF with a $\theta=0.8$ and a standard deviation of 0.1 would imply a $20 \%$ reduction in crashes and a standard deviation of $10 \%$.

\subsection{Goodness of fit}

Several goodness of measures were used to evaluate the SPFs estimated in this study. Each are discussed separately below.

\subsubsection{Mean Prediction Bias (MPB)}

The mean prediction bias provides an insight into the average model bias as compared to the observed data. A value of 0 would indicate that the model, on average, does not over predict or under predict observations. A MPB greater than 1 implies an average over prediction value and a number less than one is an average under prediction value. The MPB is determined by:

$$
M P B=\frac{\sum_{i=1}^{n}\left(\hat{Y}_{i}-Y_{i}\right)}{n}
$$

Where

$$
\begin{aligned}
& n=\text { sample size } \\
& \hat{Y}_{i}=\text { the predicted crashes for site } i \\
& Y_{i}=\text { the observed observed for site } i
\end{aligned}
$$


A satisfactory MPB measure would be close to 0 in order to show no bias in under predicting or over predicting.

\subsubsection{Mean Absolute Deviation (MAD)}

The Mean Absolute Deviation (MAD) is the absolute value of the difference between observed and predicted crashes divided by the sample size. It provides an indication of the average magnitude of variability in the model. The MAD can only be a positive number and smaller numbers are preferred to larger ones (Begum, S.M. Morjina Ara, 2008). The MAD is given by:

$$
M P B=\frac{\sum_{i=1}^{n}\left|\hat{Y}_{i}-Y_{i}\right|}{n}
$$

Where

$$
\begin{aligned}
& n=\text { sample size } \\
& \hat{Y}_{i}=\text { predicted crashes for site } i \\
& Y_{i}=\text { observed crashes for site } i
\end{aligned}
$$

\subsubsection{Mean Squared Prediction Error (MSPE) and Mean Squared Error (MSE)}

MSPE and MSE can be used to reveal potential over fitting or under fitting of the model. Values close in comparison to each other is desired since it indicates that deterministic and stochastic components are stable across the comparison being made (Begum, S.M. Morjina Ara, 2008). MSE and MPSE are determined by:

$$
M S E=\frac{\sum_{i=1}^{n}\left(Y_{i}-\hat{Y}_{i}\right)^{2}}{n-p}
$$




$$
M P S E=\frac{\sum_{i=1}^{n}\left(Y_{i}-\hat{Y}_{i}\right)^{2}}{n}
$$

Where

$$
\begin{aligned}
& n=\text { sample size } \\
& p=\text { number of parameters }
\end{aligned}
$$

\subsubsection{Cumulative Residual Plots}

It is important to test the models against the range of the dependent variables in order to identify any long stretches of bias or poor predictions. A Cumulative Residual (CURE) Plot is a graph of the cumulative difference between the observed and predicted crashes and any covariate in the model. The steps to creating a CURE plot are to simply sort the data according to the covariate of interest and then plot the cumulative residuals. An example of a CURE plot is shown in Figure 1. A consistent drift upward or downward indicates bias in the model of consistently over or under predicting respectively. A satisfactory CURE plot would do a "random walk" around the horizontal axis and stay within the $95 \%$ confidence as represented by the dotted lines in Figure 1.

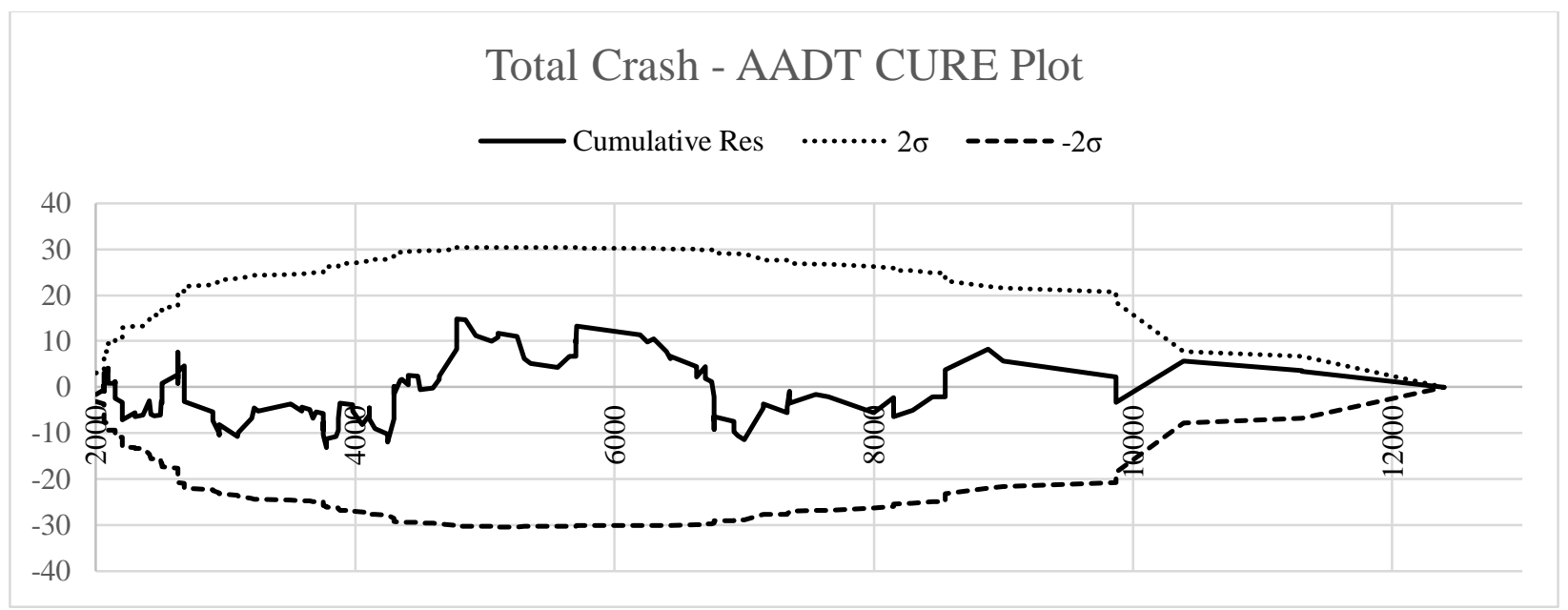

Figure 1 Example of a CURE Plot 


\subsection{Calibrating an SPF to Another Jurisdiction}

The calibration of the models to another jurisdiction was performed according to the recommended methodology presented in the Highway Safety Manual (AASHTO, 2010). In order to account for differences between the jurisdictions, such as different design standards, reporting practices, demographics, and other influences a calibration factor was determined based on the observed and predicted crash counts. This was done by applying the model developed in another jurisdiction to local data. Then taking the ratio of observed and predicted crashes as the calibration factor, which is multiplied into the SPF. The new SPF is then considered calibrated to the local settings. 


\section{Chapter 5 Passing Lane Modeling Results.}

This section will present the results of the modeling for passing lanes in Ontario and Michigan. The development of the models as well as their goodness of fit measures will be presented for each state separately below.

\subsection{Michigan Model}

The cross-sectional model that was developed for Michigan is shown below (Eq. 5-1) and the parameter estimates are presented in Table 9.

$$
\begin{aligned}
& \frac{\text { Crashes }}{\text { Year } * k m}=e^{\alpha} A A D T^{\beta_{1}} e^{\beta_{2}(\text { Length*PL })} \\
& \mathrm{PL}=\text { if a passing lane is present }
\end{aligned}
$$

Table 9 Parameter Estimates for Michigan Passing Lane Model

\begin{tabular}{ccccc}
\hline Crash Type & \multicolumn{2}{c}{ Total } & \multicolumn{2}{c}{ Injury } \\
\hline Coefficient & Estimate & $\operatorname{Pr}>$ ChiSq & Estimate & Pr $>$ ChiSq \\
\hline$\alpha$ & -6.691 & $<.0001$ & -7.3546 & $<.0001$ \\
$\beta_{1}$ & 0.7493 & $<.0001$ & 0.6796 & $<.0001$ \\
$\beta_{2}$ & -0.1955 & 0.0653 & -0.183 & 0.0038 \\
$\mathrm{k}$ & & 1.4538 & & \multicolumn{2}{c}{1.1318}
\end{tabular}

The SPF in Equation (5-1) was used to infer a CMFunction for passing lanes with respect to length. The CMFunction was derived as the following (Eq. 5-2) and is graphed in Figure 2.

$$
\text { CMFunction }=e^{\beta_{2}(\text { Length } * P L)}
$$

Figure 2 also shows the CMF that is provided in the HSM as well as the CMF developed by Persaud et al. (2013). It can be seen from the graph that the CMF provided by Persaud et al. (2013) is an average value over the range of the passing lane lengths. The CMF value provided by the HSM was 0.75 and according to the HSM the standard error was 
unknown. It is likely that it falls within the realm of uncertainty with the Persaud et al. (2013) value. Although data for passing lanes were provided in Michigan for up to $4 \mathrm{~km}$ long the recommended length for a passing lane given from Michigan Department of Transportation (MDOT) was between $1.6 \mathrm{~km}$ to $2.4 \mathrm{~km}$ (MDOT, 2012). The data reveal that passing lanes shorter than $1.6 \mathrm{~km}$ have CMFs higher what is given in the HSM and that the safety benefits may extend beyond the recommended upper limit of $2.4 \mathrm{~km}$.

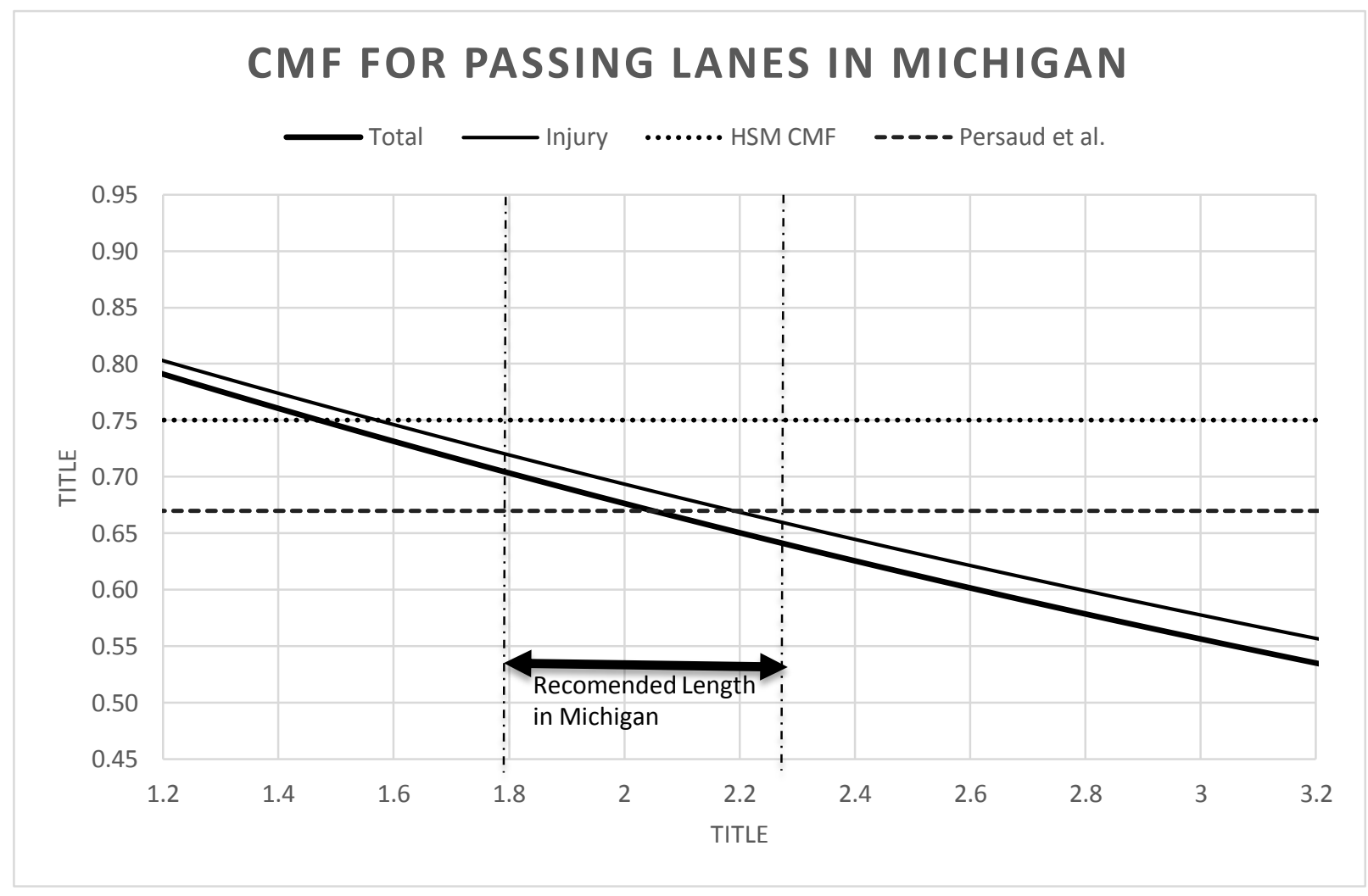

Figure 2 CMF for Passing Lanes in Michigan

The goodness of fit measures show satisfactory results, as the MPB and MAD are small. Furthermore, the MSE and MPSE are close to each other, which is desirable. The pvalues in the parameter estimations in Table 13 are below the 5\% level, which is satisfactory. The CURE plots are presented below in Figure 3 to Figure 8. For total crashes, the CURE plots are reasonable as they stay below the $5 \%$ level through the range of the covariates. The CURE plot for the predicted total crashes is also shown in order to reveal any existing bias 
across the range of values, and was determined satisfactory. Moreover, the injury CURE plots are reasonable as well although they do cross the 2 standard deviation boundaries at a few points; overall, the majority of points are within these bounds.

Table 10 Michigan Passing Lane Model GOF Measures

\begin{tabular}{ccc}
\hline Performance Measure & Total & Injury \\
\hline$M P B=\frac{\sum_{i=1}^{n}\left(\hat{Y}_{i}-Y_{i}\right)}{n}$ & -0.265 & -0.092 \\
$M A D=\frac{\sum_{i=1}^{n}\left|\hat{Y}_{i}-Y_{i}\right|}{n}$ & 8.737 & 2.671 \\
$M S E=\frac{\sum_{i=1}^{n}\left(\hat{Y}_{i}-Y_{i}\right)^{2}}{n-p}$ & 159.500 & 15.567 \\
$M P S E=\frac{\sum_{i=1}^{n}\left(\hat{Y}_{i}-Y_{i}\right)^{2}}{n}$ & 157.364 & 15.359
\end{tabular}

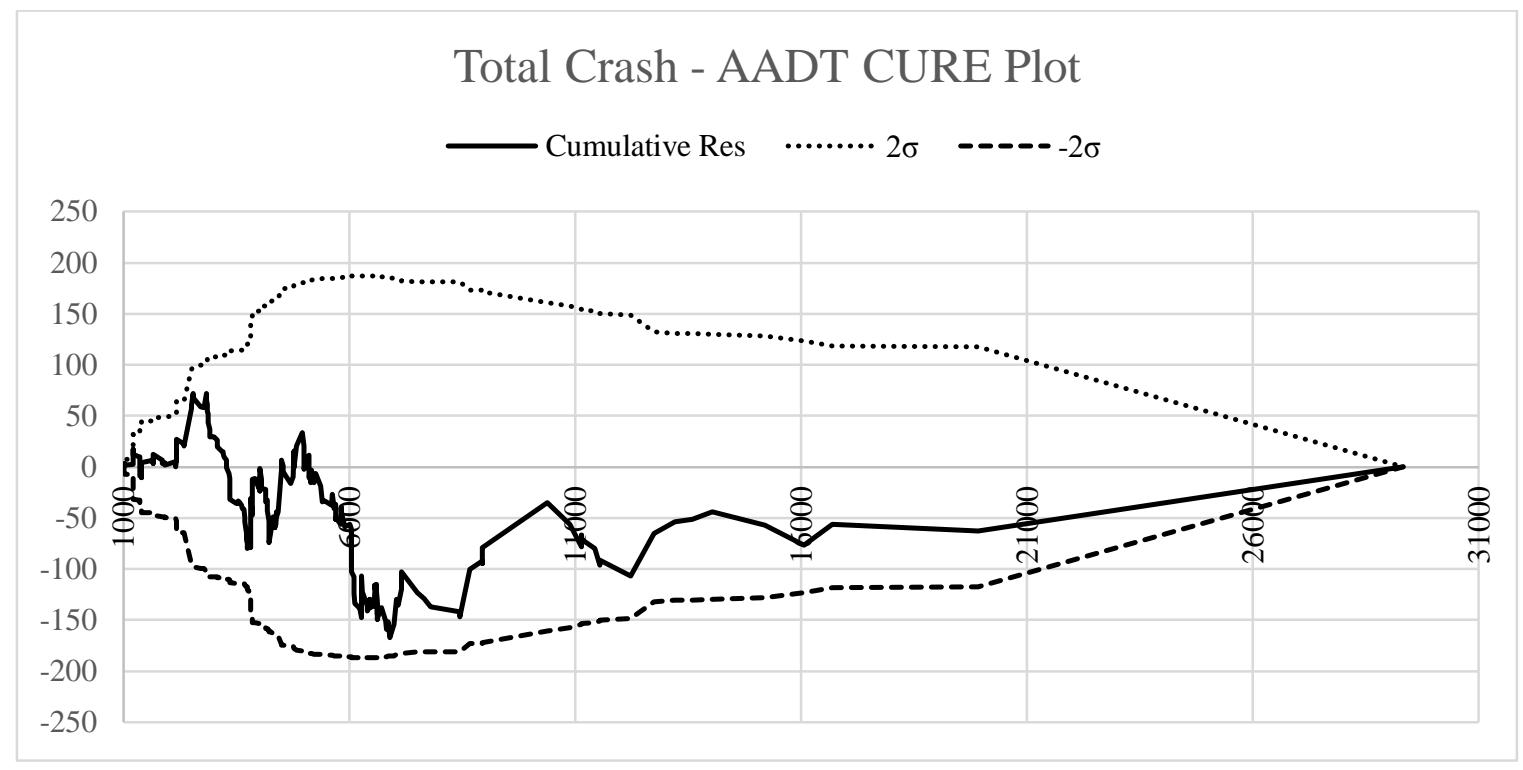

Figure 3 Total Crash - AADT CURE Plot for Michigan Sites 


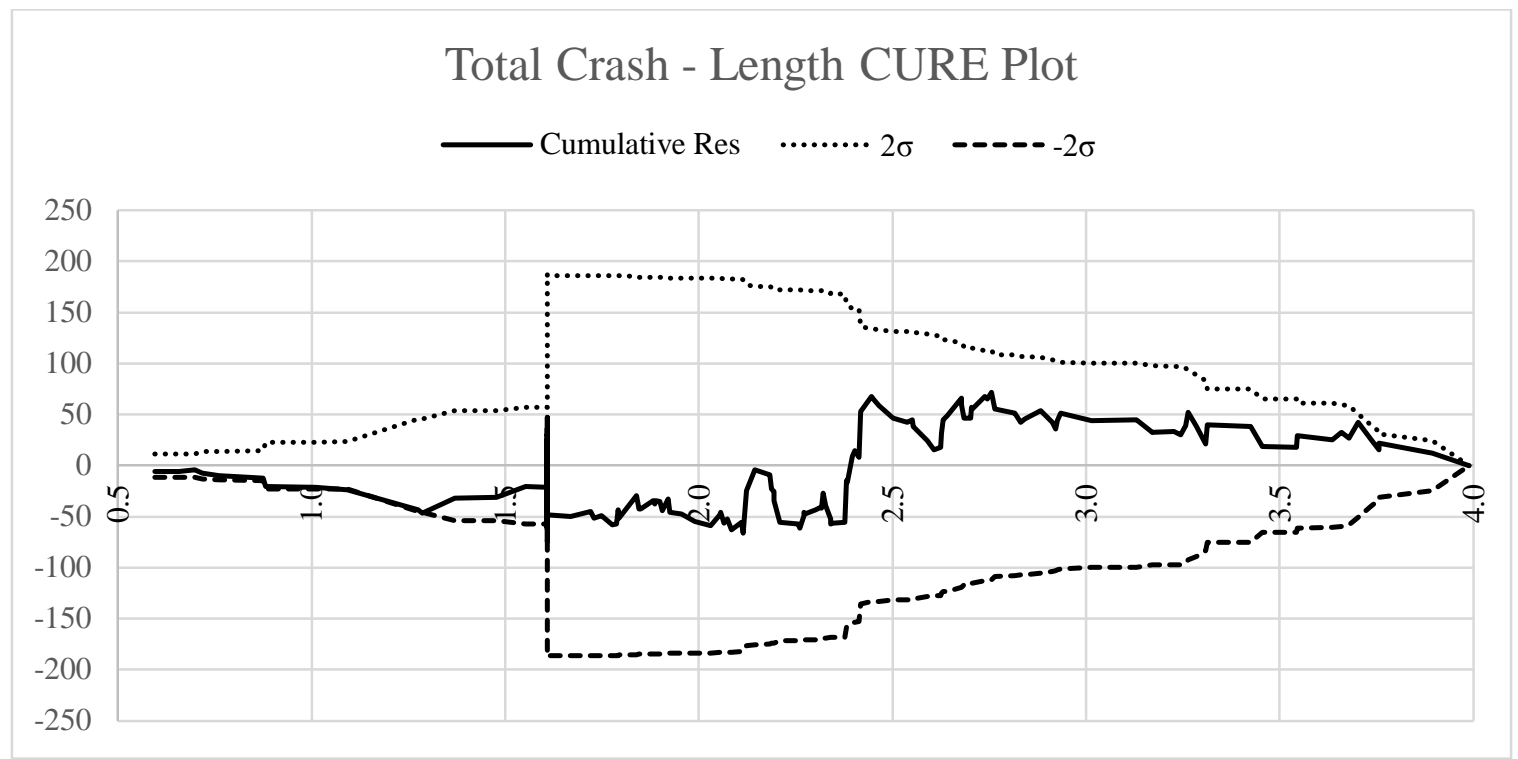

Figure 4 Total Crash - Length CURE Plot for Michigan Sites

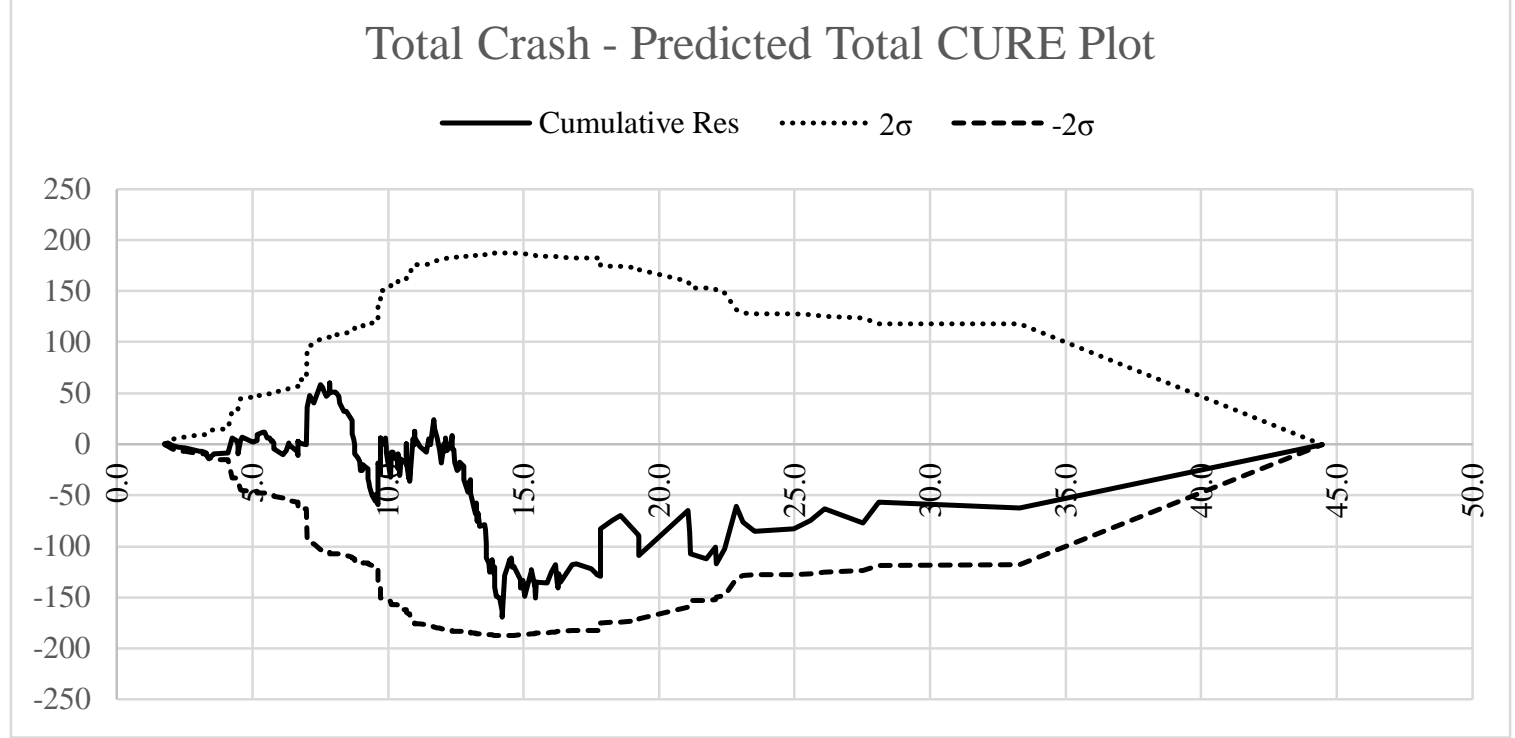

Figure 5 Total Crash - Predicted Total CURE Plot for Michigan Sites 


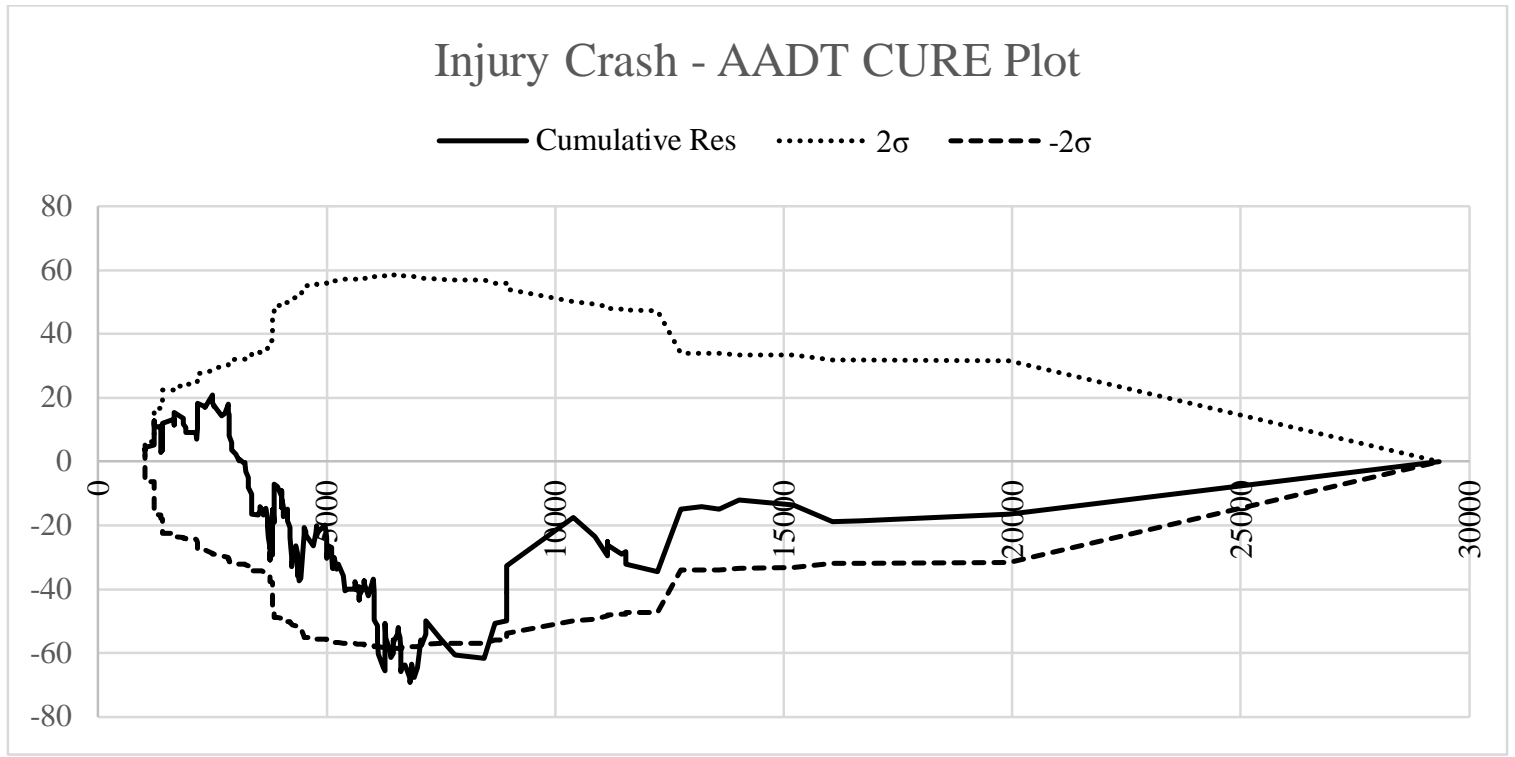

Figure 6 Injury Crash - AADT CURE Plot for Michigan Sites

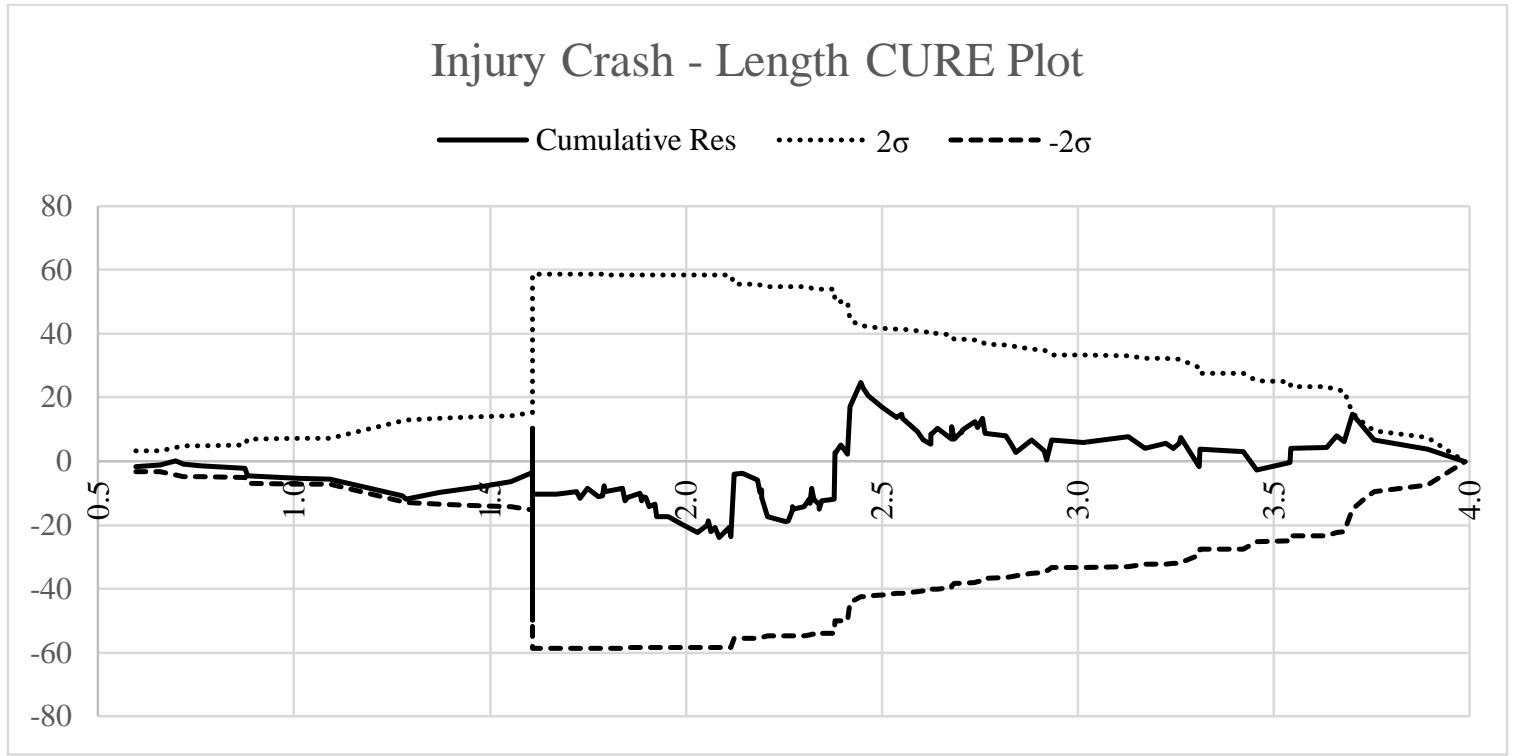

Figure 7 Injury Crash - Length CURE Plot for Michigan Sites 


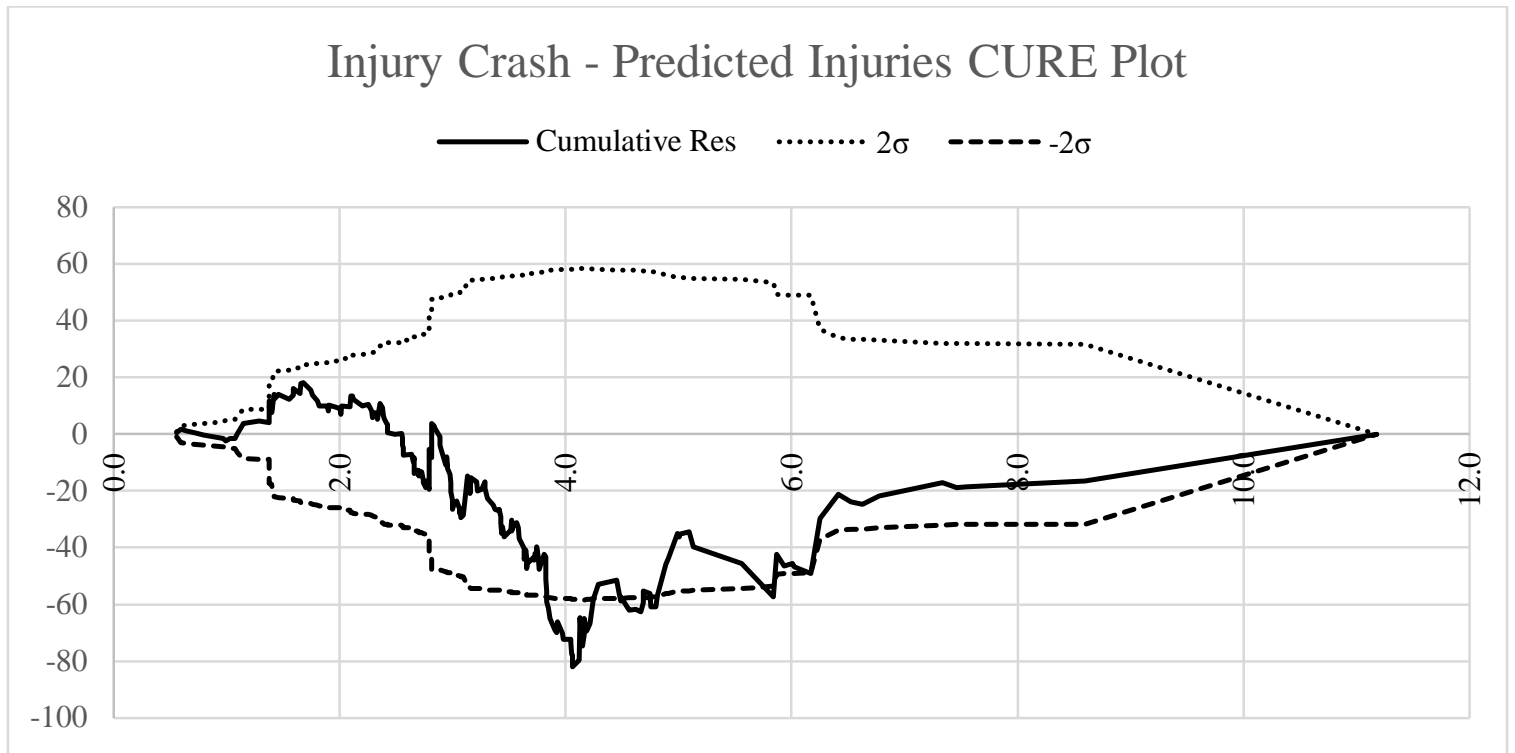

Figure 8 Injury Crash - Predicted Injuries CURE Plot for Michigan Sites

\subsection{Ontario Model}

The parameters were first determined by Generalized Linear Modelling, assuming a Negative Binomial error distribution as before. In so doing, the estimated over dispersion parameter was found to be close to zero and highly insignificant, suggesting that a Poisson error distribution was more appropriate than the NB. The parameter estimates for the model under a Poisson assumption are provided below in Table 11. The coefficient estimates and the dispersion parameter for models distinguished by different crash types are statistically significant at the 5\% level. The CURE plots for the Ontario are shown below. For Total crashes, the cumulative residuals lie between the $95 \%$ confidence boundaries and that they oscillate consistently, showing little or no bias. The MAD and MPB are presented in Table 12 and show little bias in the data as well. The MSE and MPSE are close in value, which is desirable.

$$
\frac{\text { Crashes }}{\text { Year } * k m}=e^{\alpha} A A D T^{\beta_{1}} e^{\beta_{2}(\text { Length } * P L)}
$$


Table 11 Parameter Estimates for Ontario Passing Lane Model

\begin{tabular}{ccccc}
\hline Crash Type & \multicolumn{2}{c}{ Total } & \multicolumn{2}{c}{ Fatal plus Injury } \\
\hline Coefficient & Estimate & $\operatorname{Pr}>$ ChiSq & Estimate & Pr $>$ ChiSq \\
\hline A & -7.5429 & $<0.0001$ & -10.1162 & $<0.0001$ \\
$\beta 1$ & 0.8446 & $<0.0001$ & 0.9904 & 0.1448 \\
$\beta 2$ & -0.1214 & 0.03576 & -0.2170 & 0.0059
\end{tabular}

Table 12 Ontario Passing Lane Model GOF Measures

\begin{tabular}{ccc}
\hline Performance Measure & Total & Injury \\
\hline$M P B=\frac{\sum_{i=1}^{n}\left(\hat{Y}_{i}-Y_{i}\right)}{n}$ & 0.002 & 0.069 \\
$M A D=\frac{\sum_{i=1}^{n}\left|\hat{Y}_{i}-Y_{i}\right|}{n}$ & 1.856 & 1.009 \\
$M S E=\frac{\sum_{i=1}^{n}\left(\hat{Y}_{i}-Y_{i}\right)^{2}}{n-p}$ & 5.662 & 1.580 \\
$M P S E=\frac{\sum_{i=1}^{n}\left(\hat{Y}_{i}-Y_{i}\right)^{2}}{n}$ & 5.560 & 1.552
\end{tabular}

The Equation (5-3) was used to infer Crash Modification Functions related to the length of the passing lane by dividing the model prediction with a passing lane by that without a passing lane. The inferred CMF is as follows:

$$
C M F=e^{\left(\beta_{2} \times \text { Length }\right)}
$$

The inferred CMFs for total and injury plus fatal crashes are plotted in Figure 9 as a function of length. Also plotted are two constant-value CMFs developed recently by Persaud et al. (2013) based on Michigan data, and one recommended in the HSM based a 1985 study by Harwood and St John (1985). The Ontario-based CMFs are applicable when the before condition is no passing lane present. If a passing lane was being lengthened then the CMF would be equal to the prediction from the equation above with the longer length divided by the prediction with the smaller length. 


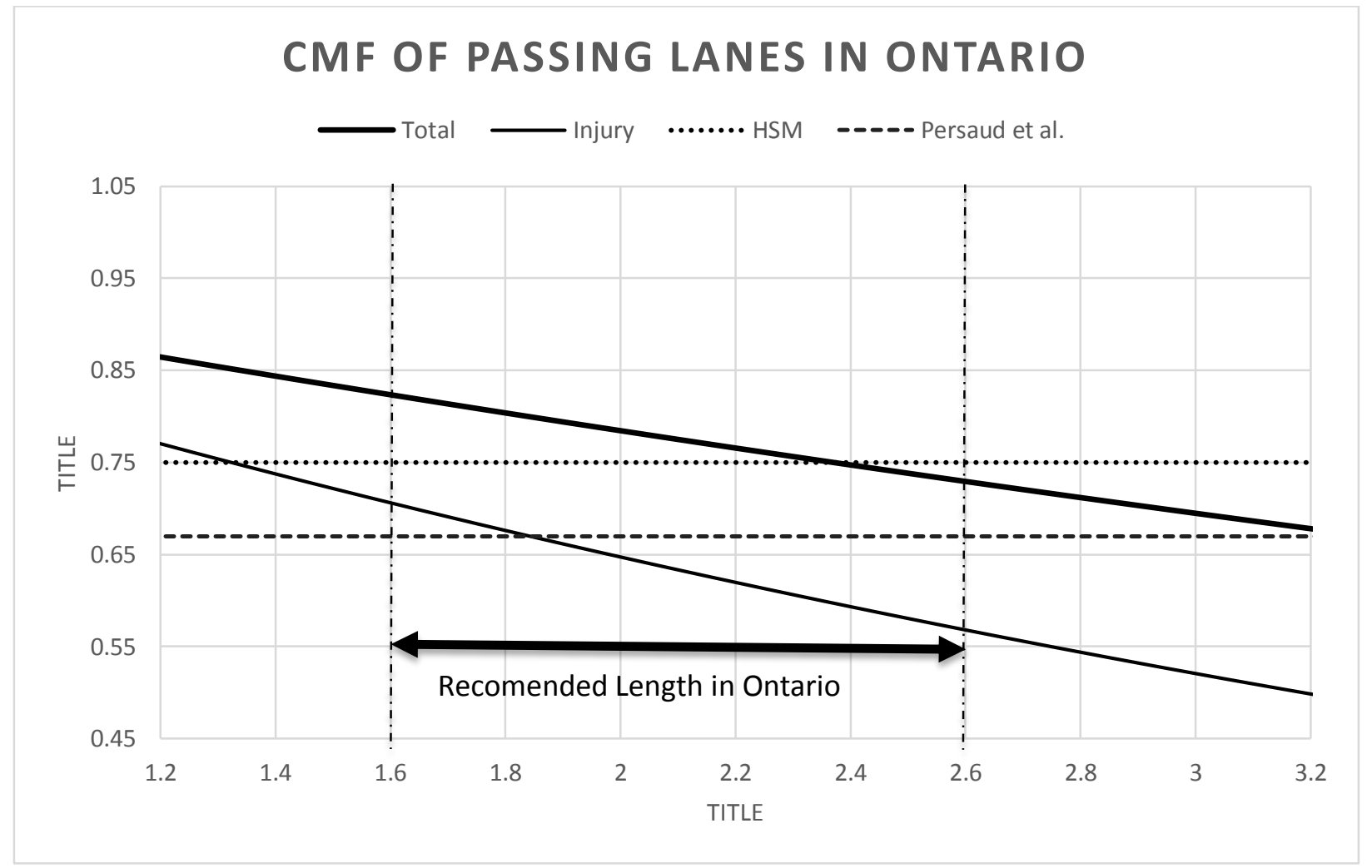

Figure 9 Graph of CMF for Ontario Passing Lanes

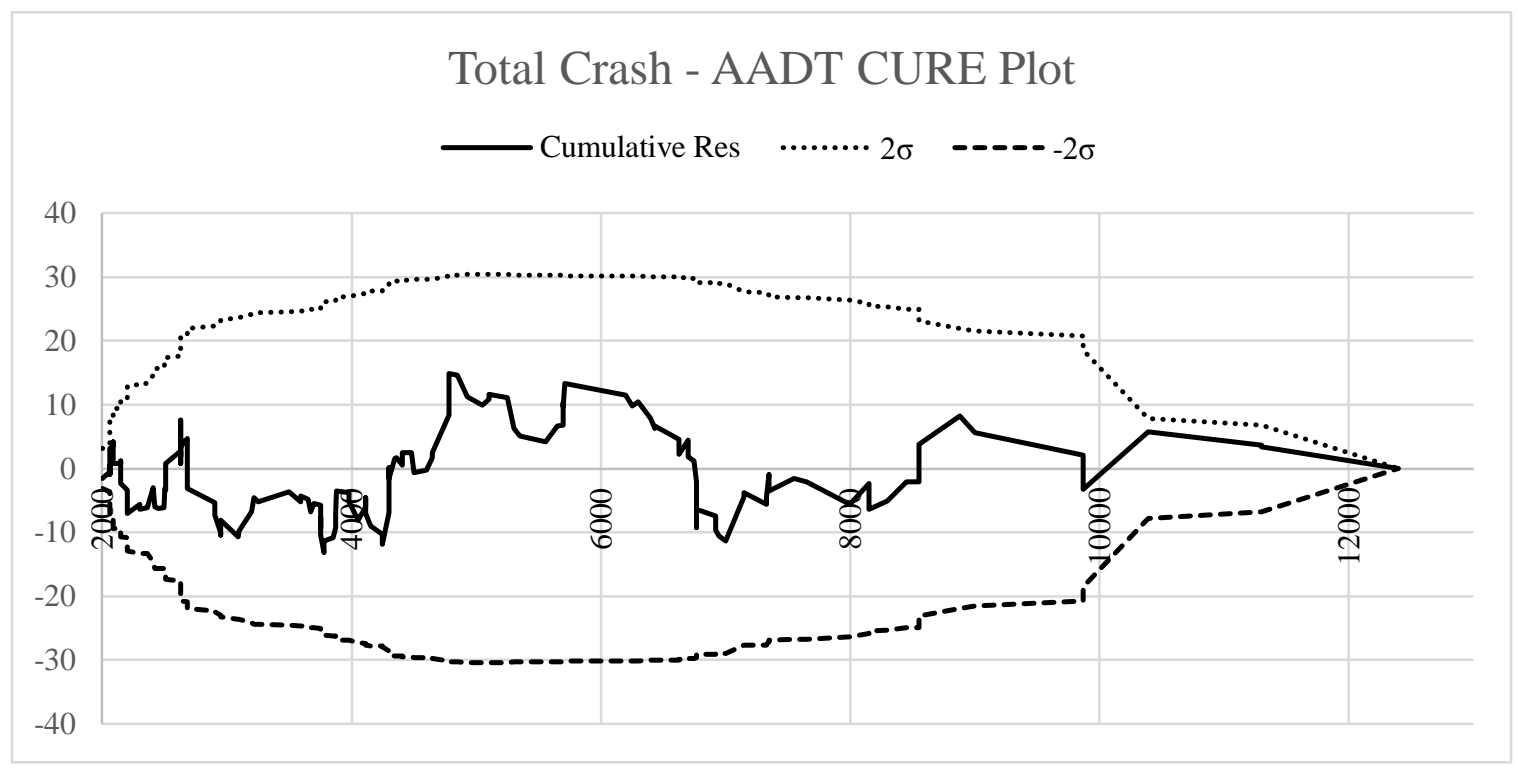

Figure 10 Total Crash - AADT CURE Plot for Ontario Sites 


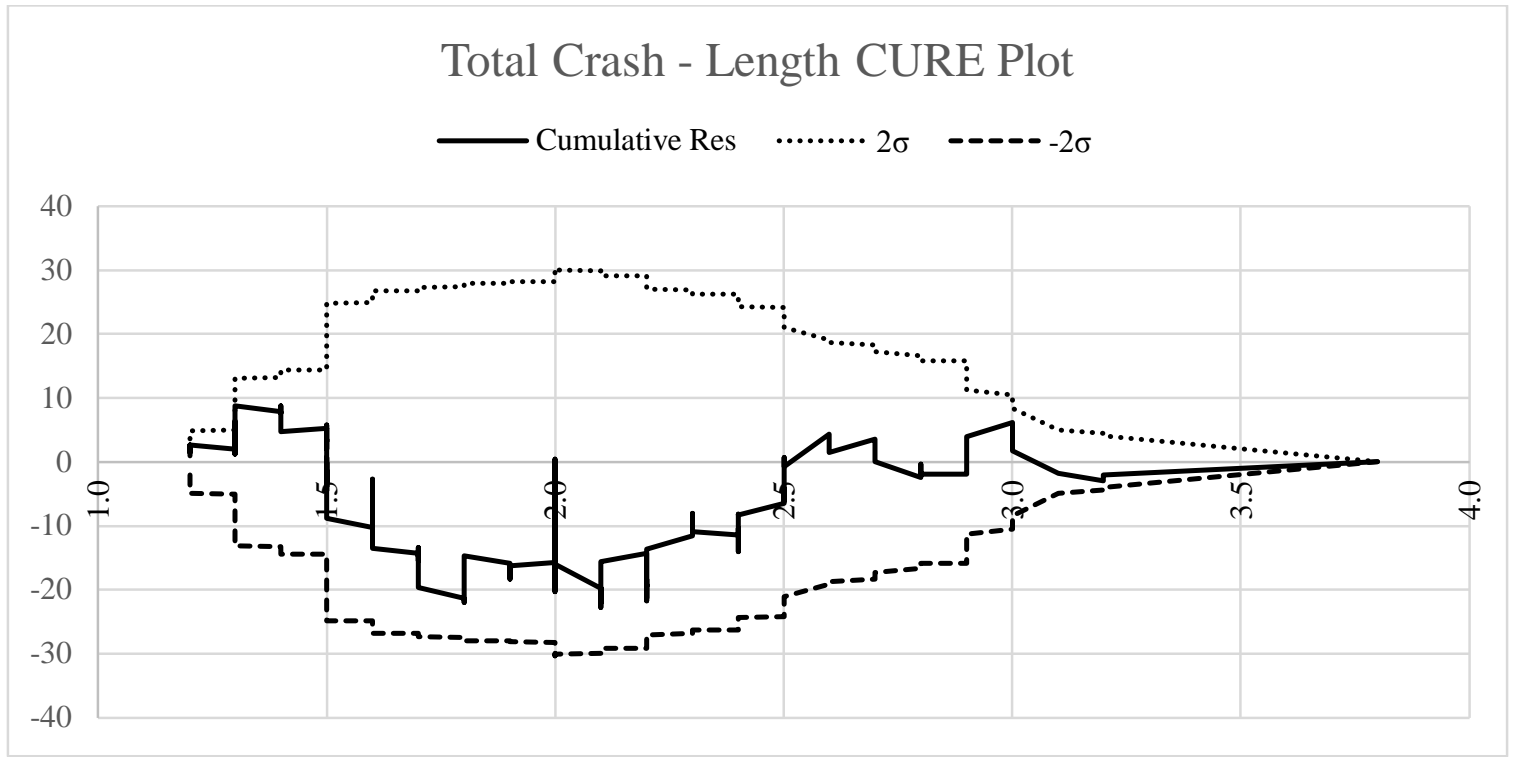

Figure 11 Total Crash - Length CURE Plot for Ontario Sites

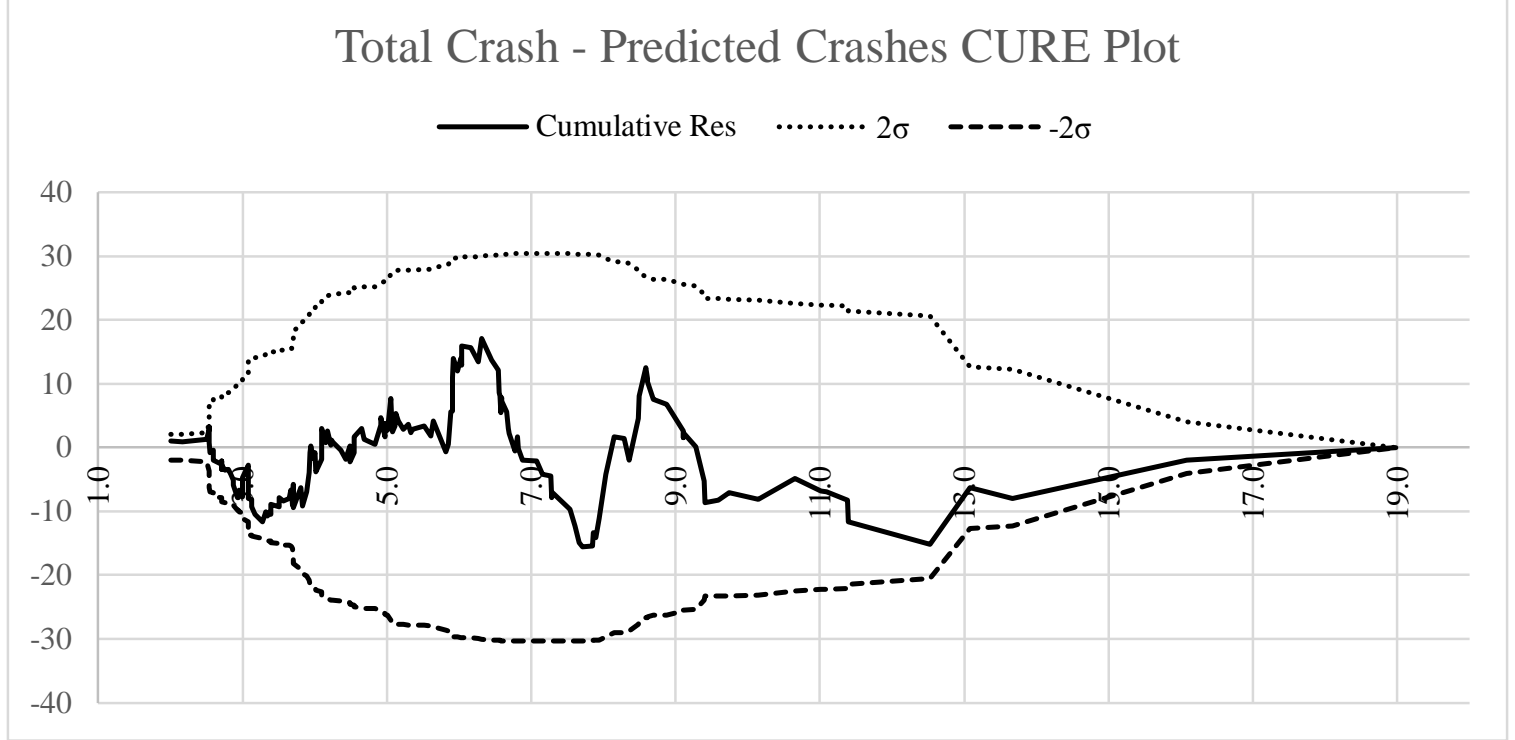

Figure 12 Total Crash - Predicted Injury Crashes CURE Plot for Ontario Sites 


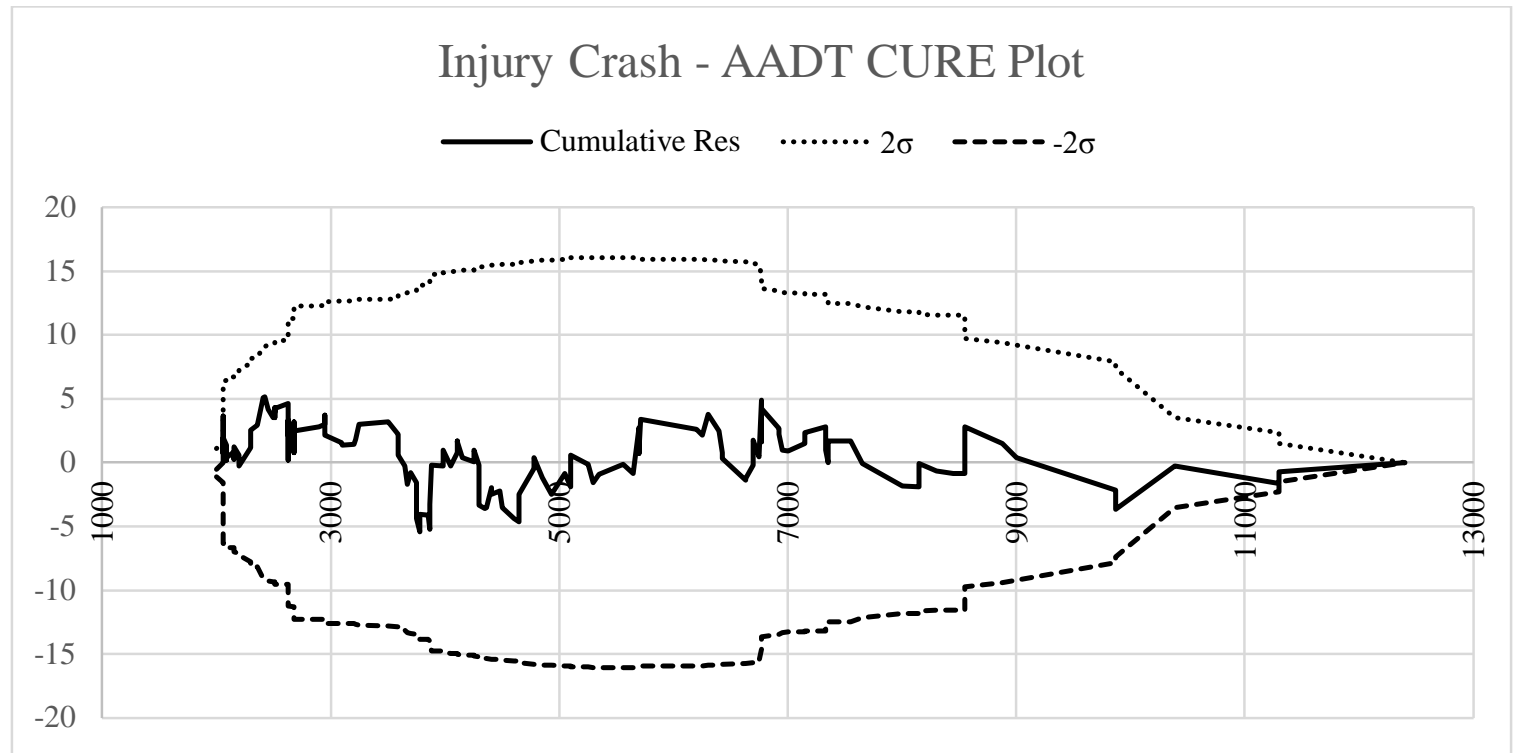

Figure 13 Injury Crash - AADT CURE Plot for Ontario Sites

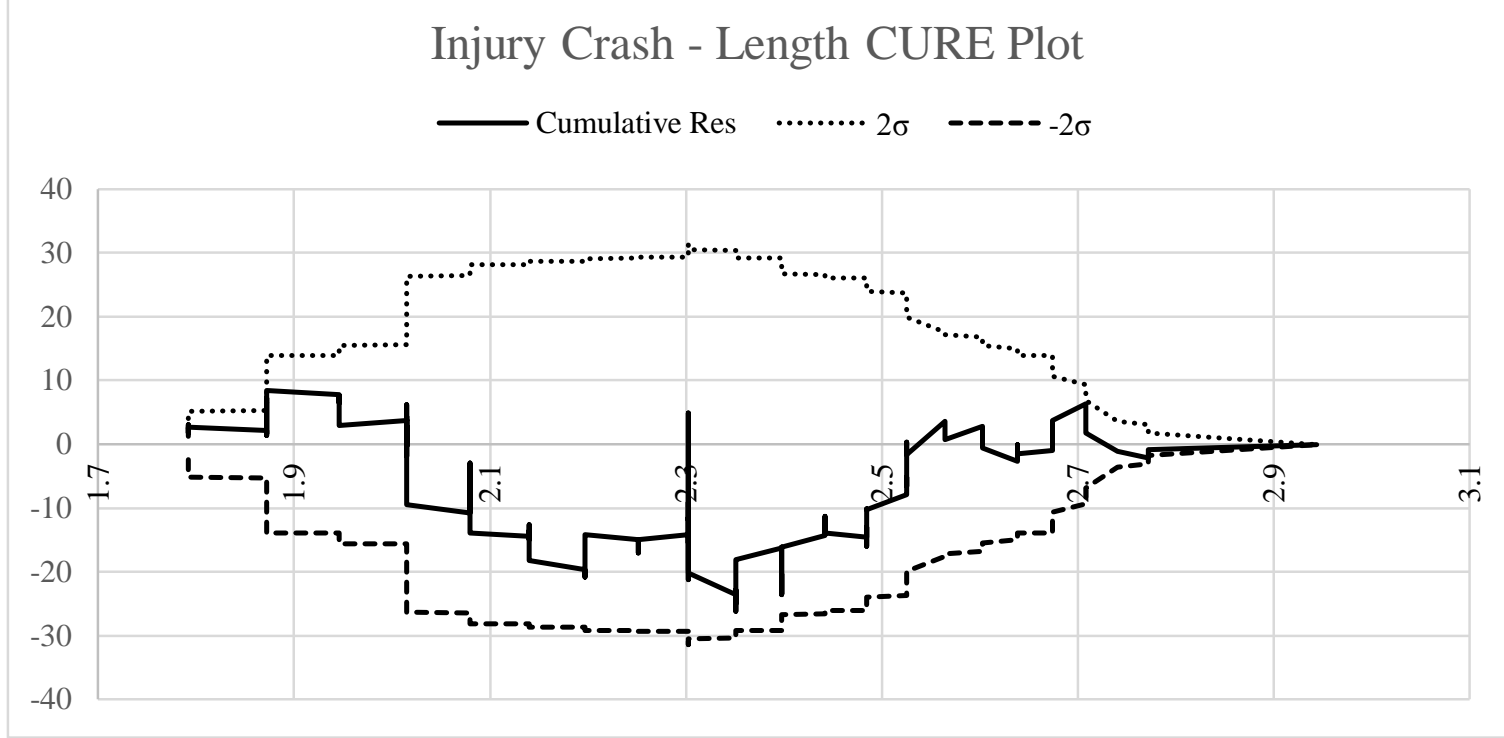

Figure 14 Injury Crash - Length CURE Plot for Ontario Sites 


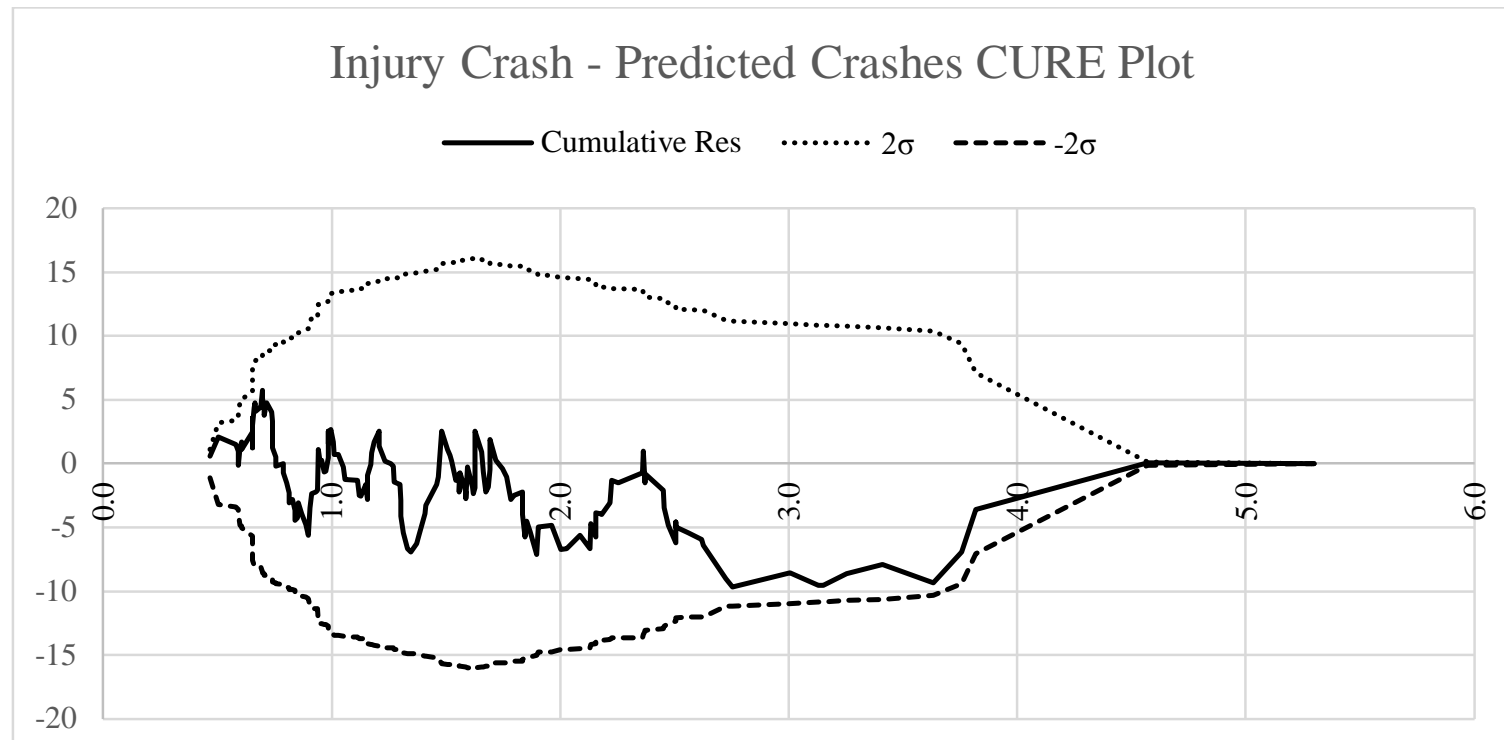

Figure 15 Injury Crash - Predicted Injury Crashes CURE Plot for Ontario Sites

\subsection{Calibration of Michigan Models to Ontario Data to Assess Transferability of Results}

In order to assess the transferability of the safety effect of passing lanes in Michigan to Ontario the procedure presented in the Highway Safety Manual was implemented. The model developed using the Michigan data was applied to the Ontario sites to determine predicted crashes. This was done in order to test the model beyond the data that was used to develop it, the very notion of transferability (Hauer, 2015). In order to account for differences between the jurisdictions other than the treatment effect a calibration factor was applied. This calibration factor was determined by the proportion of the sum of observed crashes and the sum of predicted crashes (AASHTO, 2010). A calibration factor greater than 1 would imply the model over predicts crashes on average. The calibration factor was determined to be 0.9945 for total crashes and 0.8702 for injury crashes. The value for $\beta_{3}$ was found by using the following identity:

$$
\beta_{3}=\ln (\text { calibration factor })
$$


The model predicted almost exactly as many total crashes as was observed but over predicted the injury crashes. The calibration factor was factored into the intercept term and this resulted in a calibrated model for Ontario as follows:

$$
\frac{\text { Crashes }}{\text { Year } * k m}=e^{\left(\alpha+\beta_{3}\right)} A A D T^{\beta_{1}} e^{\beta_{2}(\text { Length } * P L)}
$$

Table 13 Parameter Estimates for Calibrated Michigan Model to Ontario Data

\begin{tabular}{ccccc}
\hline Crash Type & \multicolumn{2}{c}{ Total } & \multicolumn{2}{c}{ Injury } \\
\hline Coefficient & Estimate & $\operatorname{Pr}>$ ChiSq & Estimate & Pr $>$ ChiSq \\
\hline$\alpha$ & -6.691 & $<.0001$ & -7.3546 & $<.0001$ \\
$\beta_{1}$ & 0.7493 & $<.0001$ & 0.6796 & $<.0001$ \\
$\beta_{2}$ & -0.1955 & 0.06533 & & \\
$\beta_{3}$ & -0.00552 & - & -0.1390 & - \\
$\mathrm{k}$ & & 1.4538 & & 1.1318
\end{tabular}

The goodness of fit measures presented in Table 14 reveal that the calibrated model is well suited for the data in Ontario. The MPB of 0 indicates that overall the model does not over or under predict crashes for both total and injury collisions. The CURE plots shown in Figure 16 to Figure 21 indicate that the fit is reasonable enough to pursue improving the model for Ontario application by combining the Michigan and Ontario data with the use of a classification variable to compute new model estimates and implied CMFs; this effort is presented in the next section. 
Table 14 Calibrated Michigan Model Applied to Ontario Data GOF Measures

\begin{tabular}{ccc}
\hline Performance Measure & Total & Injury \\
\hline$M P B=\frac{\sum_{i=1}^{n}\left(\hat{Y}_{i}-Y_{i}\right)}{n}$ & 0.000 & 0.000 \\
$M A D=\frac{\sum_{i=1}^{n}\left|\hat{Y}_{i}-Y_{i}\right|}{n}$ & 1.868 & 1.002 \\
$M S E=\frac{\sum_{i=1}^{n}\left(\hat{Y}_{i}-Y_{i}\right)^{2}}{n-p}$ & 5.914 & 1.639 \\
$M P S E=\frac{\sum_{i=1}^{n}\left(\hat{Y}_{i}-Y_{i}\right)^{2}}{n}$ & 5.807 & 1.610
\end{tabular}

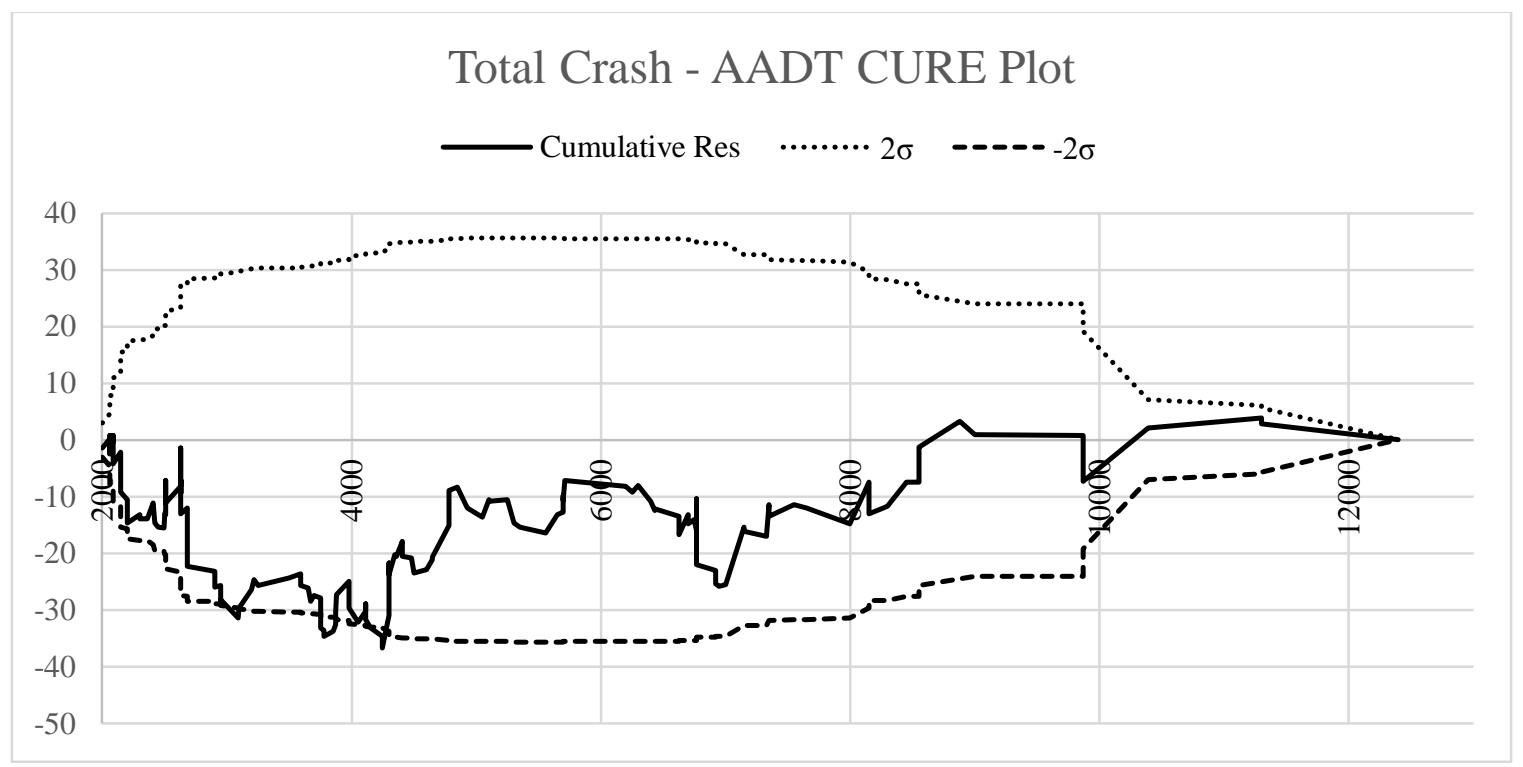

Figure 16 Total Crash - AADT CURE Plot for Calibrated Michigan Model to Ontario 


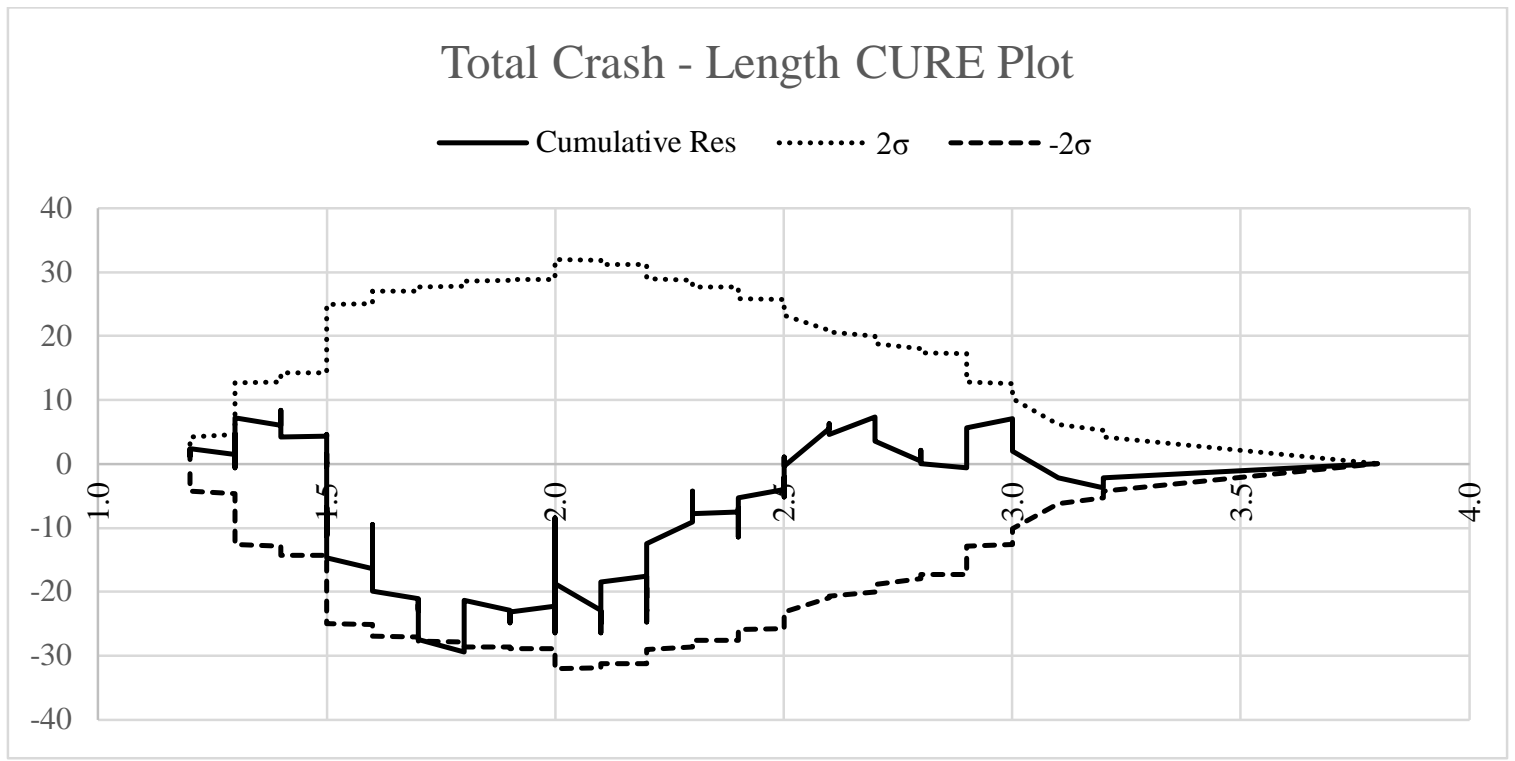

Figure 17 Total Crash - Length CURE Plot for Calibrated Michigan Model to Ontario

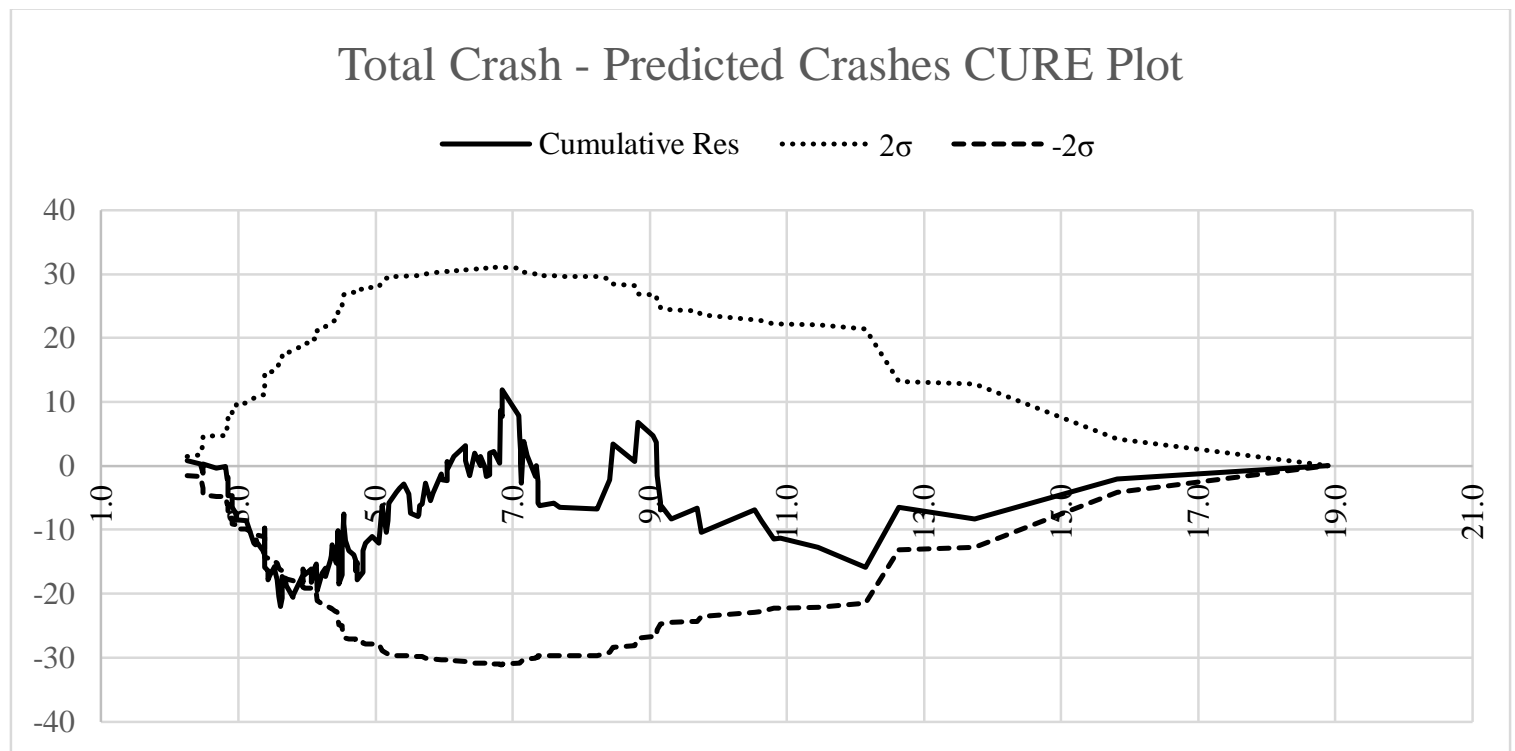

Figure 18 Total Crash - Predicted Total Crashes CURE Plot for Calibrated Michigan Model to Ontario 


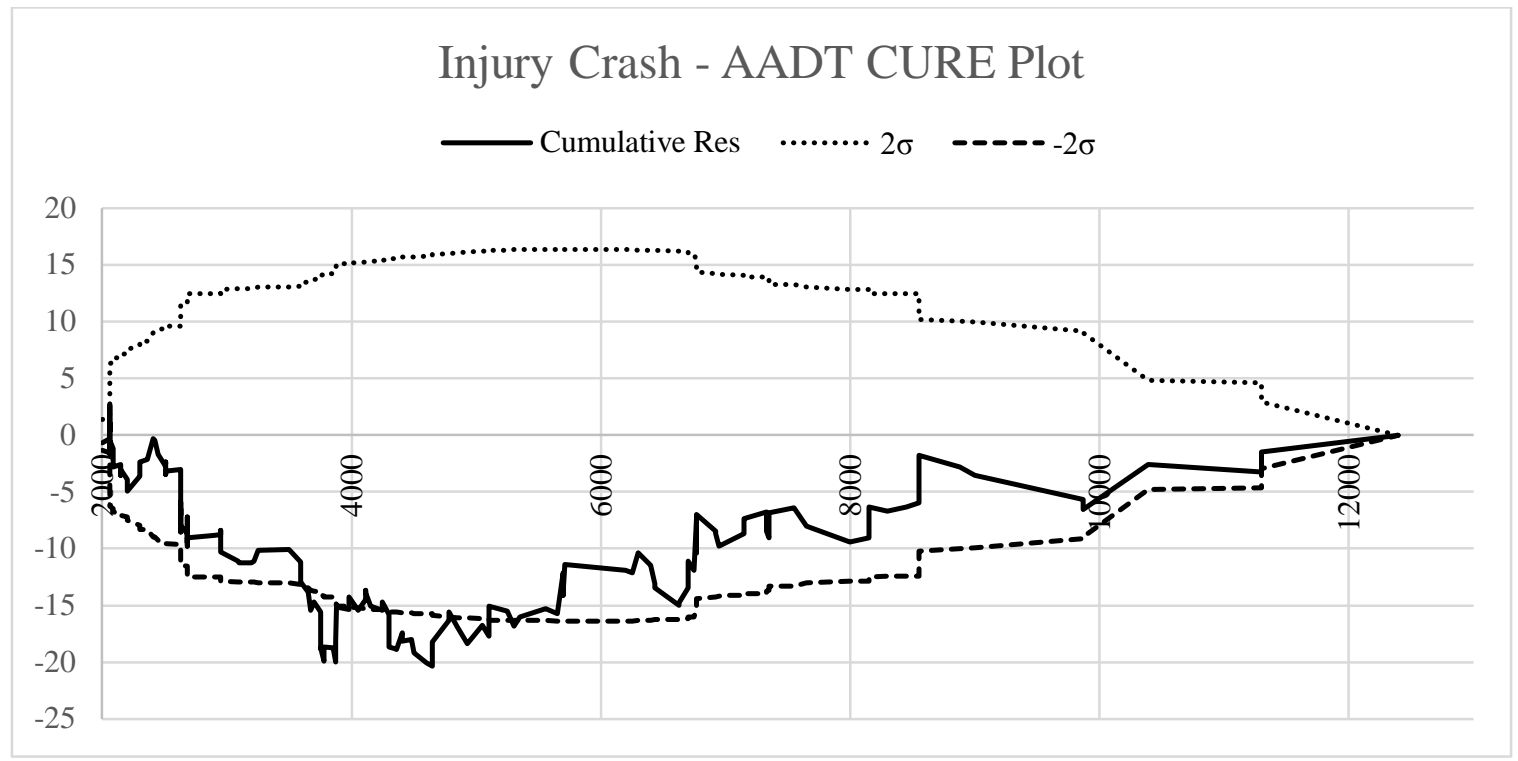

Figure 19 Injury Crash - AADT CURE Plot for Calibrated Michigan Model to Ontario

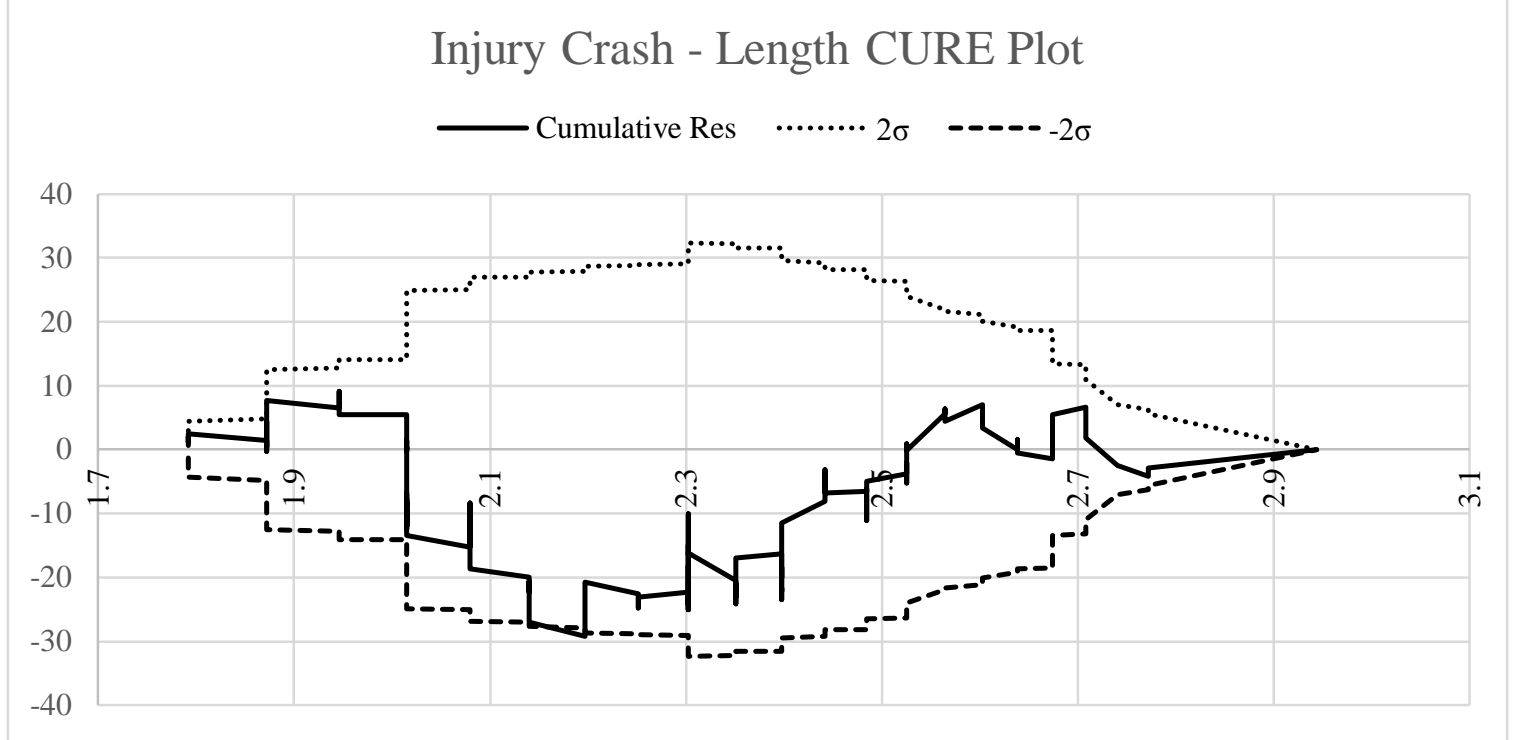

Figure 20 Injury Crash - Length CURE Plot for Calibrated Michigan Model to Ontario 


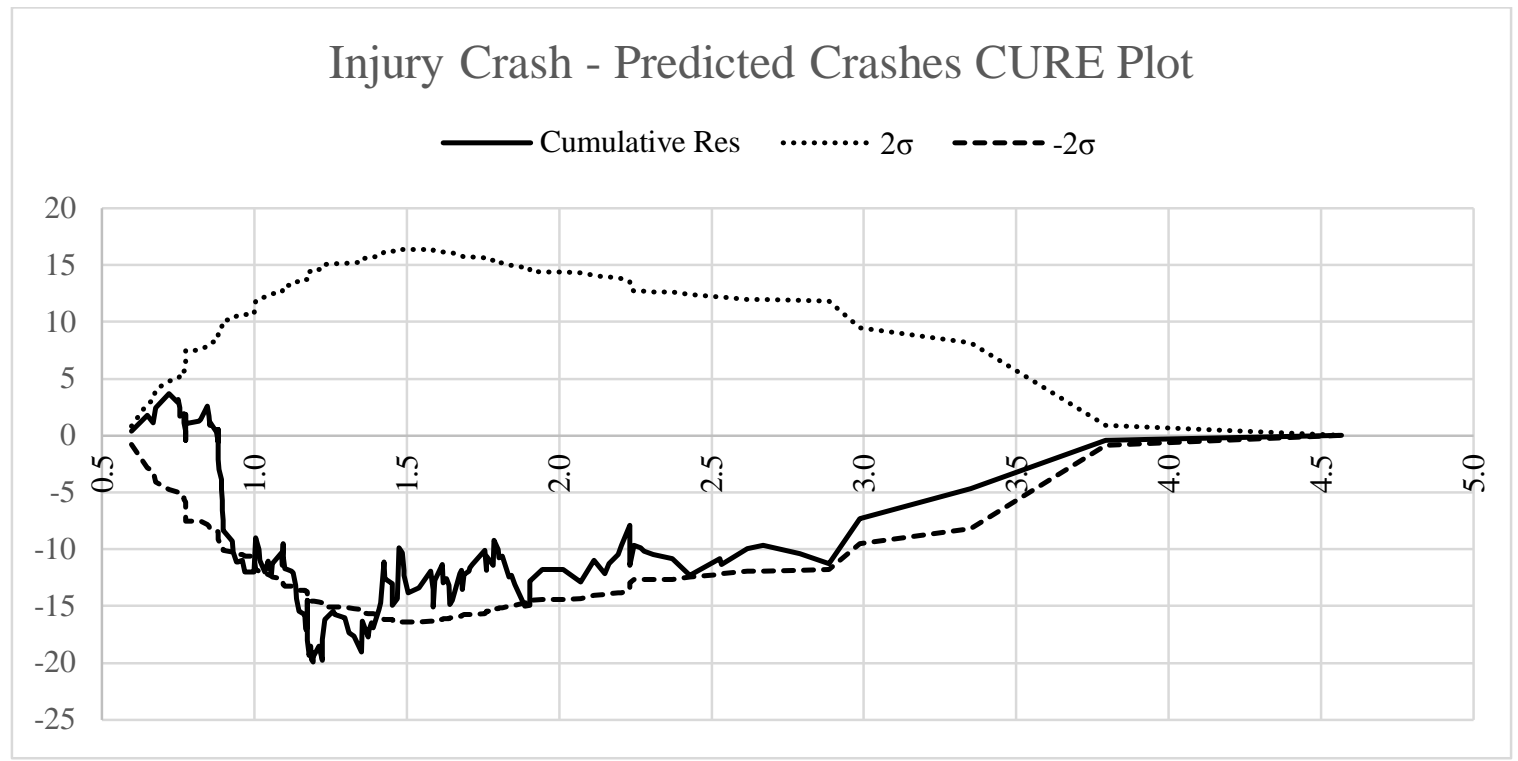

Figure 21 Injury Crash - Predicted Injury Crashes CURE Plot for Calibrated Michigan Model to Ontario

\subsection{Combined Model Using Michigan and Ontario Data}

In order to try to improve the calibrated models for either jurisdiction, the datasets from Michigan and Ontario were merged. To capture the effects limited to each jurisdiction (such as weather, reporting practices, etc.) a classification variable was used in the modeling. The use of the classification variable follows a procedure whereby one jurisdiction would be used as a base case, while the other will have a different intercept term. The coefficients for all the variables except for the intercept are common for both.

The p-values for the parameter estimates were all below 0.05, which is acceptable. The differences between Michigan and Ontario seem to be small as indicated by the small value of the $\beta_{3}$ parameter of 0.0031 for total crashes. The differences in injury crashes may be related to differences in reporting practices between Ontario and Michigan. The CURE plots shown in the cumulative residuals stayed within the $95 \%$ boundaries across the range of covariates. Moreover, the injury CURE plots are reasonable as well although they do cross the 2 standard deviation boundaries at a few points; overall, the majority of points are within these bounds. 


$$
\frac{\text { Crashes }}{\text { Year } * k m}=e^{\left(\alpha+\beta_{3}\right)} A A D T^{\beta_{1}} e^{\beta_{2}(\text { Length } * P L)}
$$

Table 15 Parameter Estimates of Combined Model for Ontario and Michigan

\begin{tabular}{|c|c|c|c|c|c|}
\hline Crash & \multicolumn{3}{|c|}{ Total } & \multicolumn{2}{|c|}{ Injury } \\
\hline Coefficient & & Estimate & $\operatorname{Pr}>C h i S q$ & Estimate & $\mathrm{Pr}>C h i S q$ \\
\hline$\alpha$ & & -7.0024 & $<.0001$ & -8.153 & $<.0001$ \\
\hline$\beta_{1}$ & & 0.783 & $<.0001$ & 0.7539 & $<.0001$ \\
\hline$\beta_{2}$ & & -0.1762 & $<.0001$ & -0.1863 & 0.0001 \\
\hline \multirow{2}{*}{$\beta_{3}$} & ON & 0 & - & 0 & 0.0001 \\
\hline & MI & 0.0031 & 0.9761 & 0.1752 & 0.1708 \\
\hline $\mathrm{k}$ & & \multicolumn{2}{|c|}{0.7572} & \multicolumn{2}{|c|}{0.7995} \\
\hline
\end{tabular}

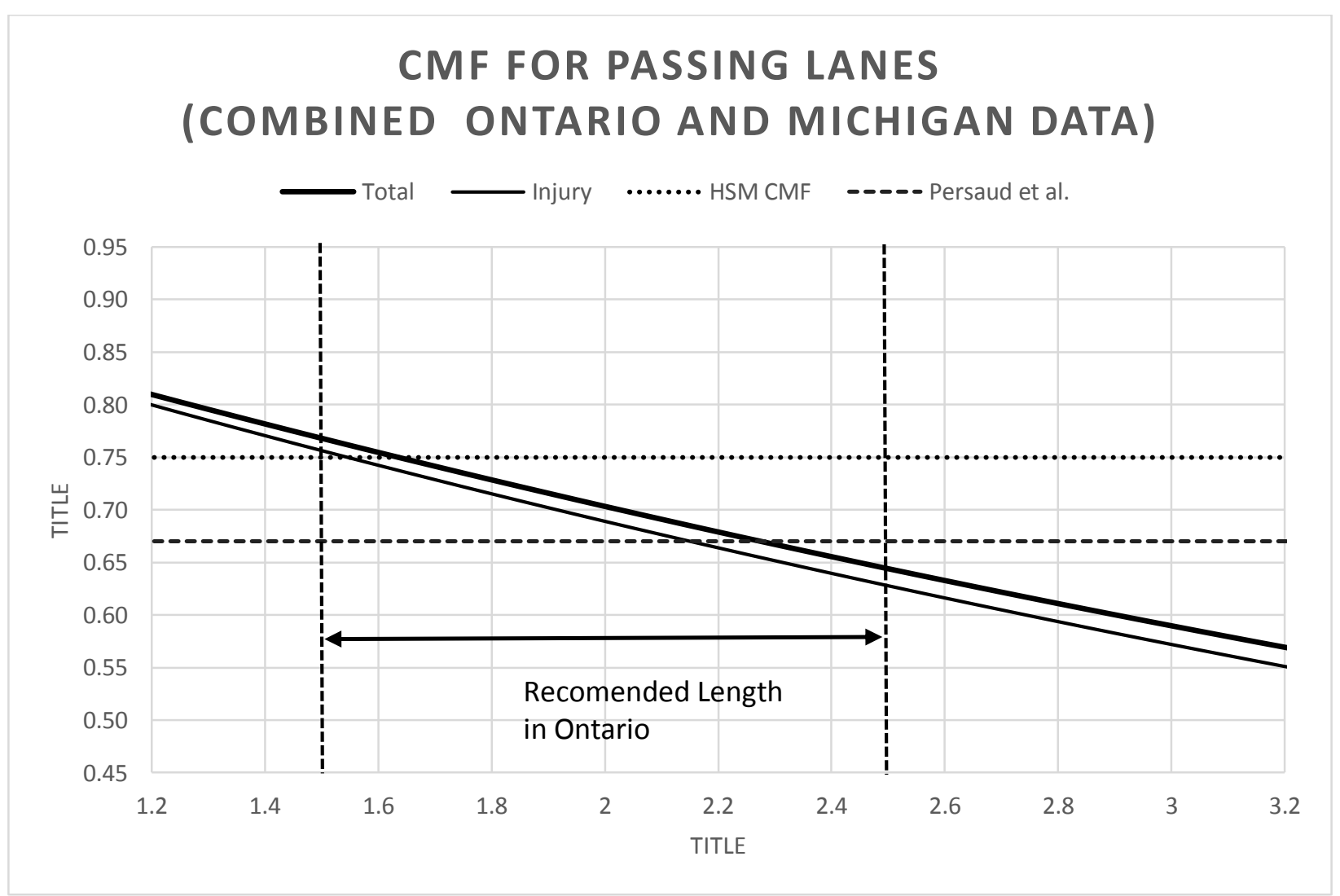

Figure 22 Combined Model for Ontario and Michigan 
Table 16 Combined Passing Lane Model GOF Measures

\begin{tabular}{ccc}
\hline Performance Measure & Total & Injury \\
\hline$M P B=\frac{\sum_{i=1}^{n}\left(\hat{Y}_{i}-Y_{i}\right)}{n}$ & -0.1 & -0.049 \\
$M A D=\frac{\sum_{i=1}^{n}\left|\hat{Y}_{i}-Y_{i}\right|}{n}$ & 5.786 & 1.953 \\
$M S E=\frac{\sum_{i=1}^{n}\left(\hat{Y}_{i}-Y_{i}\right)^{2}}{n-p}$ & 92.549 & 9.373 \\
$M P S E=\frac{\sum_{i=1}^{n}\left(\hat{Y}_{i}-Y_{i}\right)^{2}}{n}$ & 91.837 & 9.301
\end{tabular}

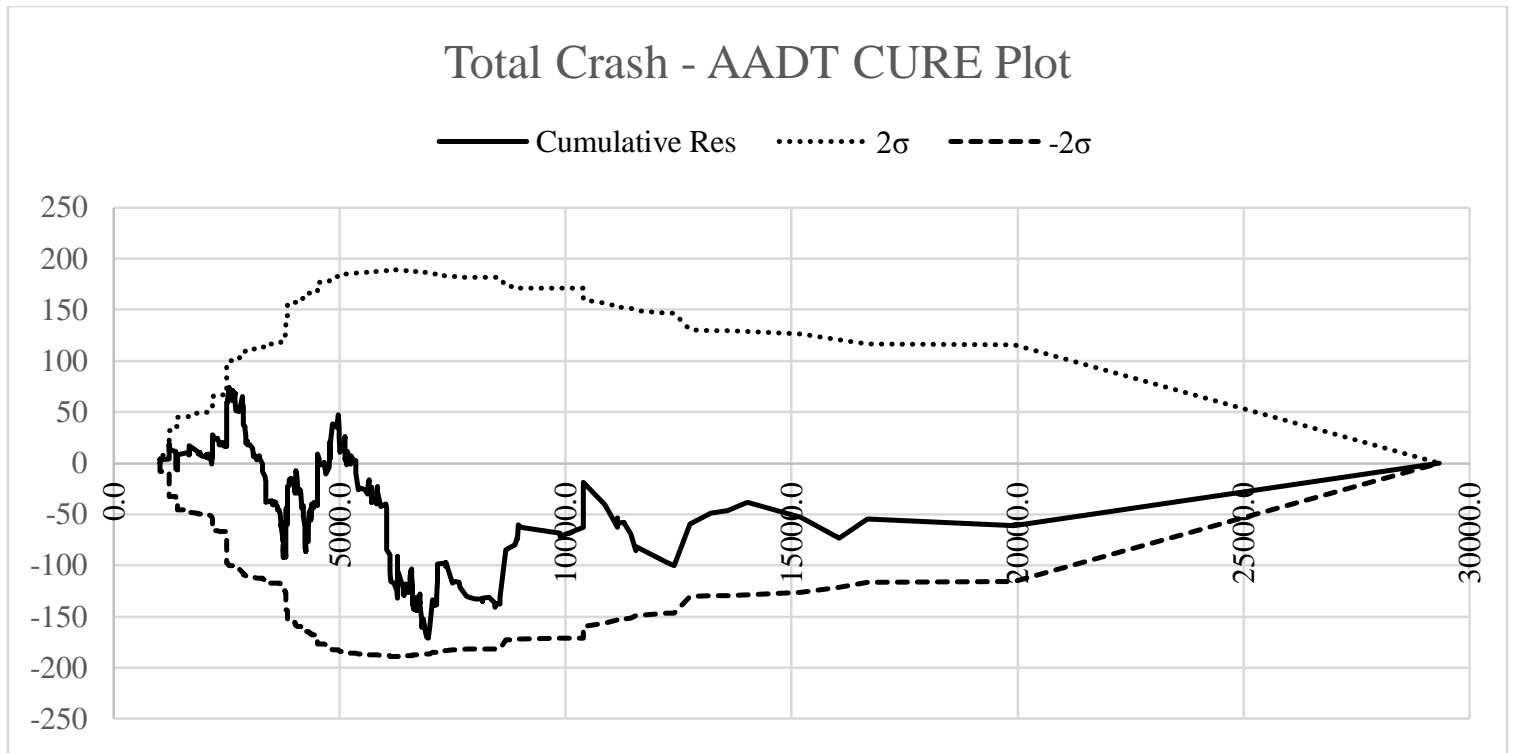

Figure 23 Total Crash - AADT CURE Plot for Combined Model 


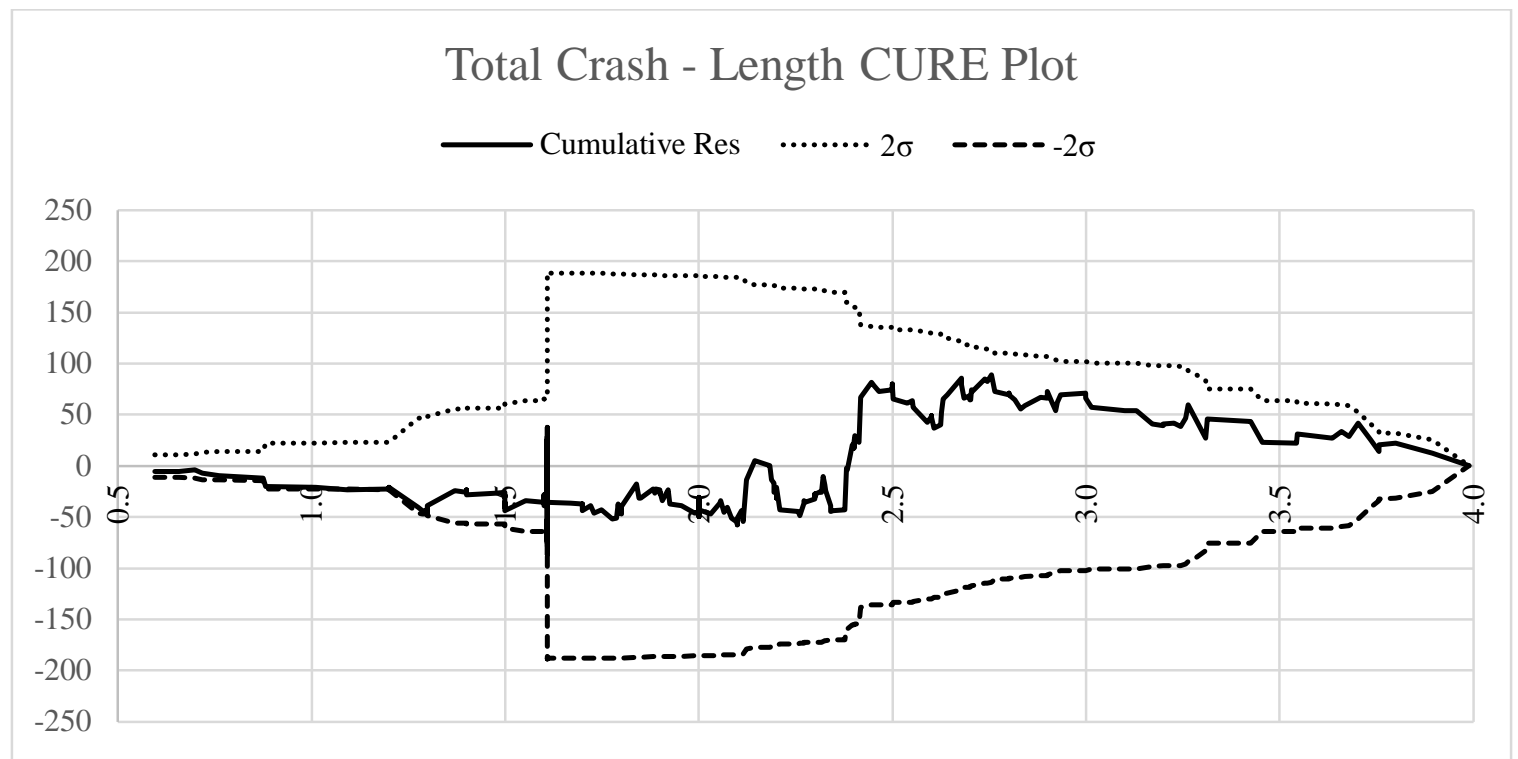

Figure 24 Total Crash - Length CURE Plot for Combined Model

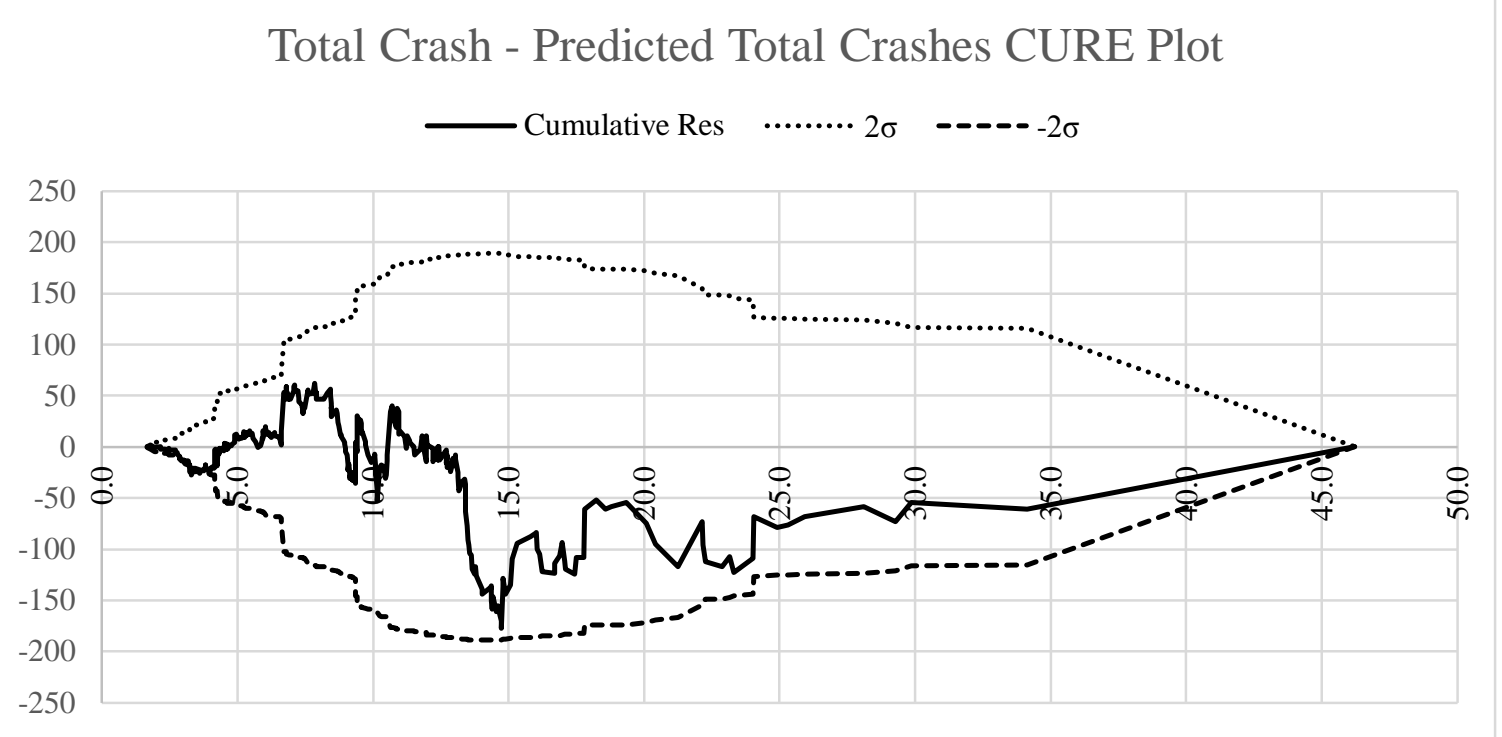

Figure 25 Total Crash - Predicted Total Crashes CURE Plot for Model 


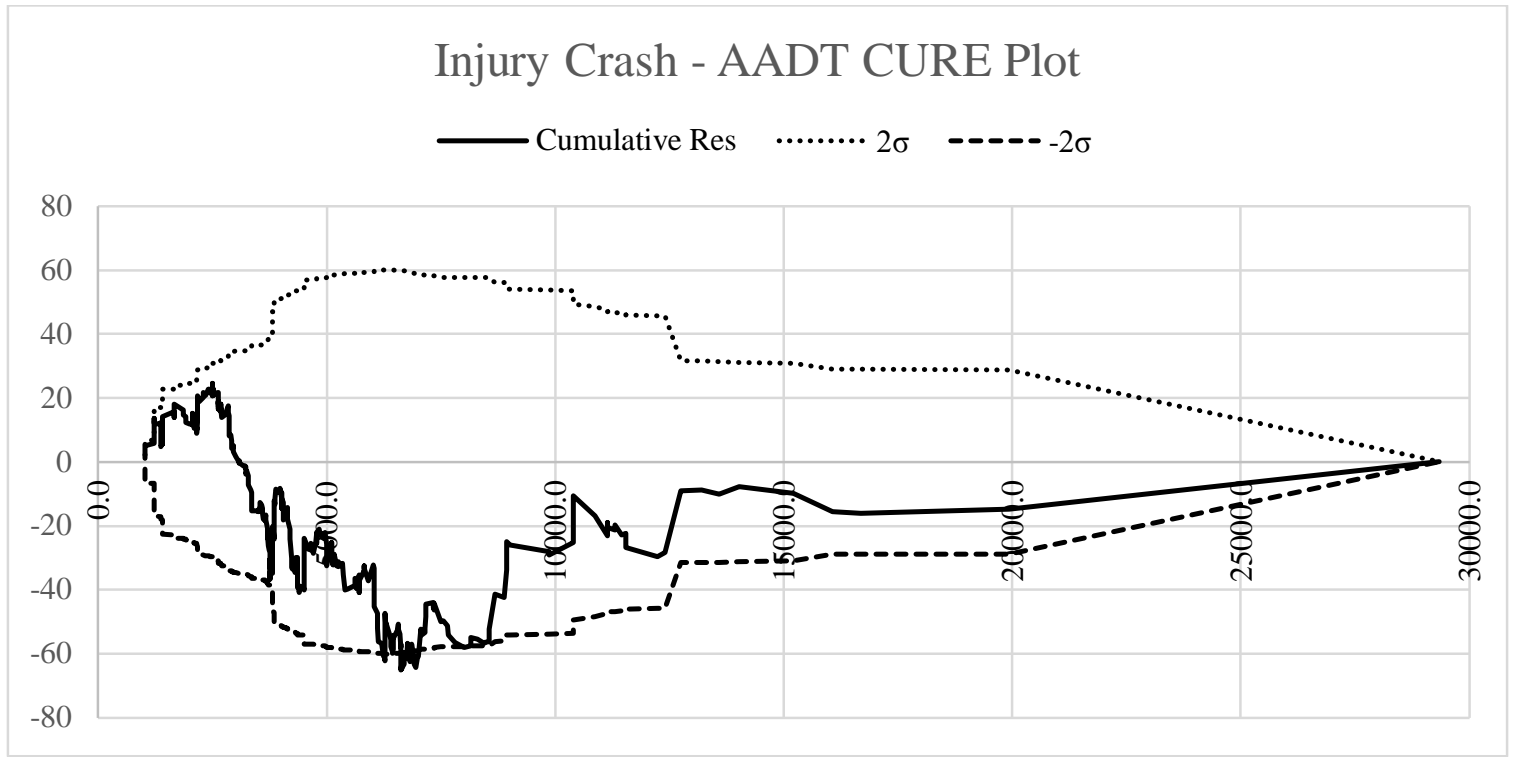

Figure 26 Injury Crash - AADT CURE Plot for Combined Model

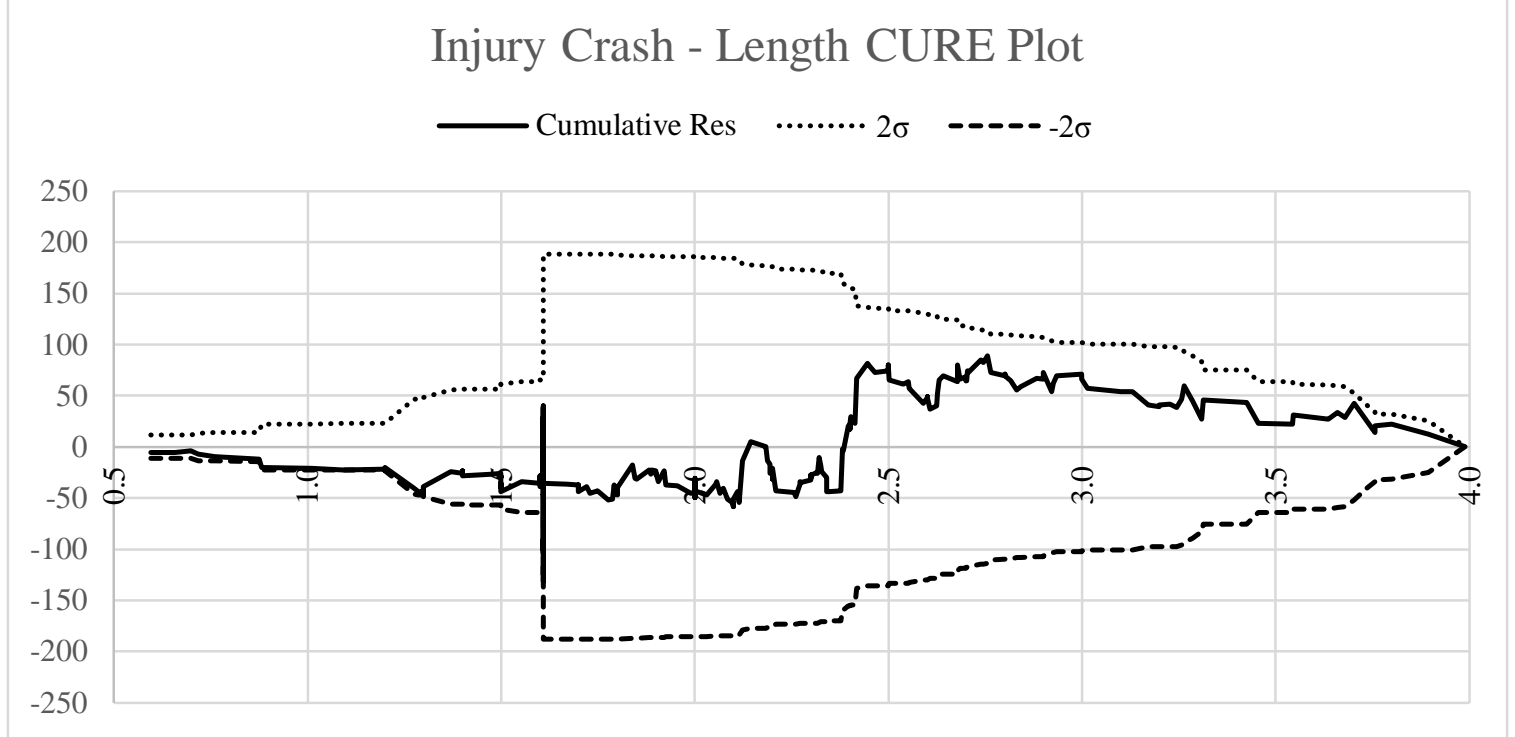

Figure 27 Injury Crash - Length CURE Plot for Combined Model 


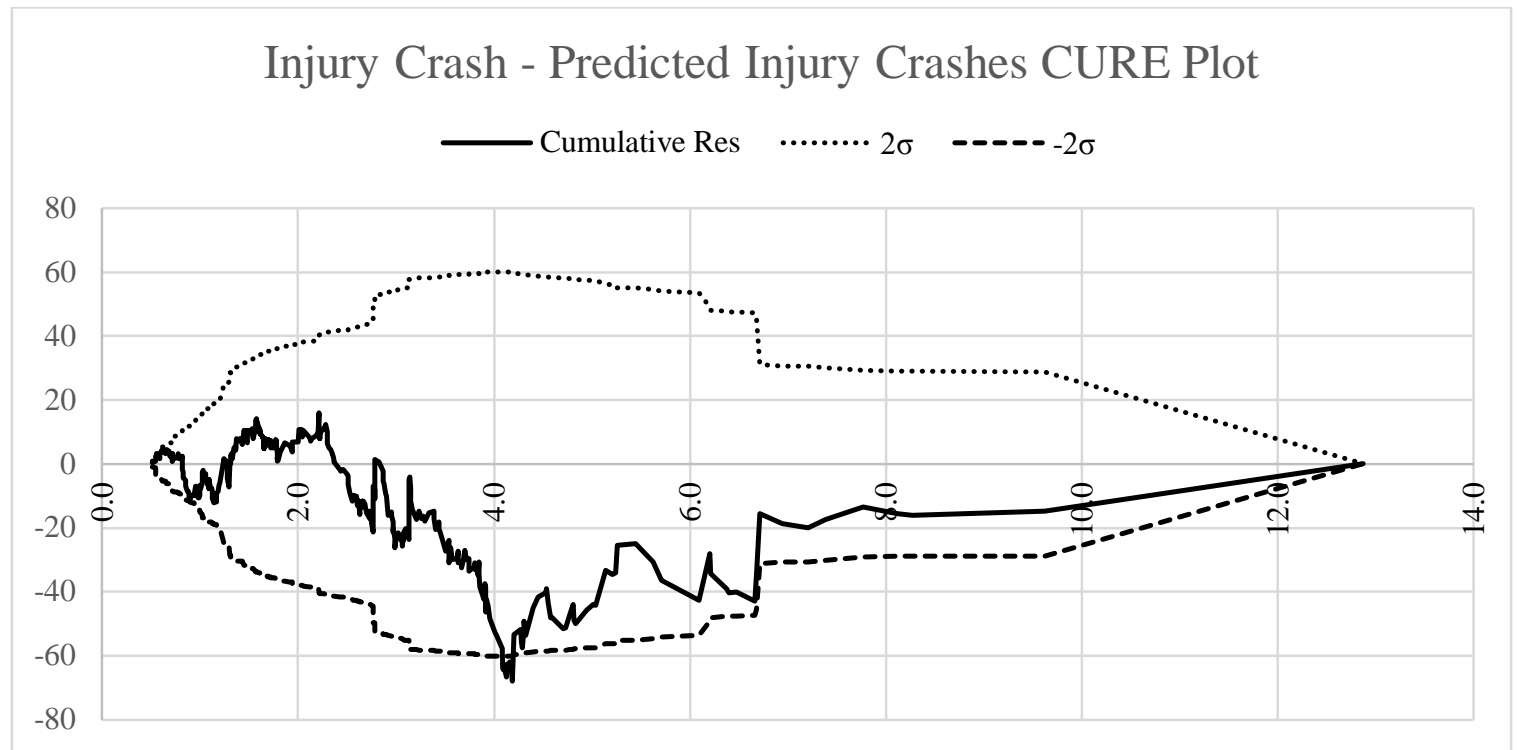

Figure 28 Injury Crash - Predicted Injury Crashes CURE Plot for Combined Model

\subsection{Discussion}

The results for Michigan and Ontario were consistent in terms of indicating a greater safety effect with longer lengths of passing lanes. This is an improvement on the single value CMF in the Highway Safety Manual for installing a passing lane of any length. The individual Michigan model was very well suited for transferring for use in Ontario since the calibration factor was near 1 for total crashes. Ontario did however have a somewhat higher number of injury crashes than predicted by the Michigan model, and there were no conclusive reasons for this to occur; however, reporting practices may be a factor.

Comparing the inferred CMFs developed from the combined model to the one presented in the HSM and from Persaud et al. (2013) there are some noteworthy implications. Between the recommended lengths of passing lanes of 1.5 to $2.5 \mathrm{~km}$ (MDOT, 2012; MTO, 1985), the CMF for introducing a passing lane varies from 0.78 to 0.64. This calculates to an average of 0.71 , which is very comparable to the HSM of 0.75 and Persaud et al. (2016)'s of 0.67. The injury crash CMFs followed a similar pattern to those for total crashes. These results are valid only for the range of data used in these models, i.e. passing 
lane lengths of between $1.7 \mathrm{~km}$ and $3.8 \mathrm{~km}$ with an average length of $\sim 2.4 \mathrm{~km}$ as can be seen from Tables 2.1 and 2.2.

Overall, the models provide better guidance for considering safety implications in determining the design length of a passing lane compared to other sources, notably the Highway Safety Manual. The recommended combined model can be applied to a cost benefit analysis in order to calculate the ideal length of a passing lane and this is demonstrated in Chapter 7Application. The Ontario-based CMFs are applicable when the before condition is no passing lane present. If a passing lane was being lengthened then the CMF would be equal to the prediction from the equation above with the longer length divided by the prediction with the smaller length.

The combined results indicate that when installing a new passing lane, as the length of the passing lane increases, the safety benefits also increase. This is intuitive since it is expected that passing lanes would mitigate crashes resulting from platooning cars. Thus, as the platoon disperses along the passing lane the safety effect would be relatively greater on a larger stretch. Furthermore, longer passing lanes improve the level of service by reducing the percent of time spent following which is a commonly used indicator for the operational performance of 2-lane highways; this can translate into safety benefits by perhaps reducing driver frustration. 


\section{Chapter 6 Dual Rumble Strip Modeling Results.}

This chapter provides the results of the dual centerline and shoulder rumble strip analysis. An Empirical Bayes (EB) study was conducted using 6 Ontario sites and the results compared to those from a previous EB study by Persaud at al. (2016). Data were made available from that study for treatment and reference sites in Missouri, Pennsylvania, and Kentucky. These data were used to develop cross sectional models in order to corroborate the EB studies. The following sections provide the results of the analysis and present a comparison of the safety effects between the different jurisdictions and study types.

\subsection{Empirical Bayes Before-After Study}

A limited Empirical Bayes (EB) before-after study was conducted for $69.5 \mathrm{~km}$ of shoulder rumble strip application on two-lane roads in Ontario. Sites with dual rumble strip application were not available for this, so the results are likely to be conservative. Due to the limited sample size, the evaluation was based on only two crash types, total crashes and fatal plus injury crashes. The objective was to validate the US-based dual rumble application CMFs recently estimated by Persaud at al. (2016) for application in Ontario.

For the EB study, SPFs were developed using 22 untreated reference segments that were chosen to be similar to the rumble strip segments. The form of the SPFs is shown in Equation (6-1), while the parameter estimates are shown in Table 17.

$$
\frac{\text { Crashes }}{\text { Year } * k m}=e^{(\alpha)} A A D T^{\beta_{1}} \text { Length }^{\beta_{2}}
$$

Table 17 Parameter Estimates for SPF used in Empirical Bayes Methodology

\begin{tabular}{ccccc}
\hline Crash Type & \multicolumn{2}{c}{ Total } & \multicolumn{2}{c}{ Injury } \\
\hline Coefficient & Estimate & $\operatorname{Pr}>$ ChiSq & Estimate & Pr $>$ ChiSq \\
\hline$\alpha$ & -7.5527 & $<0.0001$ & -9.9185 & $<0.0001$ \\
$\beta_{1}$ & 0.7710 & $<0.0001$ & 0.8976 & $<0.0001$ \\
$\beta_{2}$ & 1.0647 & $<0.0001$ & 1.0518 & 0.0001 \\
$\mathrm{k}$ & & & & 0.0371
\end{tabular}


The results of the EB study, shown in Table 18, indicate statistically significant CMFs of 0.706 and 0.600 for total and fatal plus injury crashes, respectively. This compares to reductions of CMFs of 0.800 and 0.779 found in the Persaud at al. (2016) study for combined data for three US states. For those states, the statistically significant CMFs ranged from 0.653 to 0.842 for total crashes 0.558 to 0.812 for fatal plus injury crashes. Thus, it can be concluded that the Ontario CMFs are consistent with those from the US study, considering the estimates of uncertainty for each CMF. Recall that the Ontario CMFs pertain to treatment sites where a shoulder rumble strip was added on segments that may or may not have included a center-line rumble strip, similar in principle to the case of data for one state (Kentucky) used for the Persaud et al. (2016) study, where centerline rumble strips were added to sites that already had shoulder rumble strips. Thus, the Ontario results by themselves are likely to be conservative if used for dual rumble strip application. Nevertheless, given the small sample size for the limited Ontario EB before-after study it is recommended that, until an evaluation can be done for the recent dual rumble strip application in Ontario, the CMFs from the definitive US study by Persaud et al. 2016 be used.

Table 18 Results of Ontario EB Study

\begin{tabular}{|l|c|c|}
\hline \multicolumn{1}{|c|}{ Item } & Total & Fatal Plus Injury \\
\hline $\begin{array}{l}\text { EB estimate of crashes expected } \\
\text { in the after period without treatment }\end{array}$ & 242.07 & 66.74 \\
\hline $\begin{array}{l}\text { Count of crashes observed } \\
\text { in the after period }\end{array}$ & 171 & 40 \\
\hline $\begin{array}{l}\text { Estimate of CMF } \\
\text { (and standard error) }\end{array}$ & 0.706 & 0.600 \\
\hline
\end{tabular}

\subsection{Cross Sectional Study}

This section presents the CMFs developed from cross sectional models using the after period data at the treatment sites (with rumble strips) and the reference site data (no rumble 
strips), with and indicator variable for the presence of rumble strips. The CMFs are implied from this indicator variable. Models were developed for Kentucky and Pennsylvania separately and for a combined dataset, and these results, i.e., the inferred CMFs, were compared to those of the EB study in the previous section. Missouri did not have a reference site dataset that could be used in the cross sectional analysis. In addition, due to the small sample size Ontario models could not be estimated. The models for Kentucky and Pennsylvania took the following form and the parameter estimates are shown below.

$$
\frac{\text { Crashes }}{\text { Year }}=e^{(\alpha)} A A D T^{\beta_{1}} \text { Length }^{\beta_{2}} e^{\beta_{3}(R S)}
$$

Where

RS is equal to 1 if there are rumble strips present and 0 otherwise.

Table 19 Parameter Estimates for Kentucky Rumble Strip Models

\begin{tabular}{|c|c|c|c|c|c|c|}
\hline Crash & \multicolumn{2}{|c|}{ Total } & \multicolumn{2}{|c|}{ Injury } & \multicolumn{2}{|c|}{ Run-off-road } \\
\hline Coefficient & Estimate & $\operatorname{Pr}>C h i S q$ & Estimate & $\operatorname{Pr}>C h i S q$ & Estimate & $\operatorname{Pr}>C h i S q$ \\
\hline$\alpha$ & -4.9337 & $<.0001$ & -5.2999 & $<.0001$ & -3.9604 & $<.0001$ \\
\hline$\beta_{1}$ & 0.6569 & $<.0001$ & 0.5556 & $<.0001$ & 0.3991 & $<.0001$ \\
\hline$\beta_{2}$ & 0.7956 & $<.0001$ & 0.8434 & $<.0001$ & 0.8595 & $<.0001$ \\
\hline$\beta_{3}$ & -0.4037 & 0.0426 & -0.5583 & 0.0072 & -0.8376 & 0.0006 \\
\hline $\mathrm{k}$ & \multicolumn{2}{|c|}{0.8426} & \multicolumn{2}{|c|}{0.7079} & \multicolumn{2}{|c|}{0.9221} \\
\hline Crash & \multicolumn{2}{|c|}{ Head-on } & \multicolumn{2}{|c|}{ Side Swipe } & & \\
\hline Coefficient & Estimate & $\mathrm{Pr}>\mathrm{ChiSq}$ & Estimate & $P r>C h i S q$ & & \\
\hline$\alpha$ & -8.152 & $<.0001$ & -6.0698 & $<.0001$ & & \\
\hline$\beta_{1}$ & 0.6185 & $<.0001$ & 0.43 & $<.0001$ & & \\
\hline$\beta_{2}$ & 0.8348 & $<.0001$ & 0.7884 & $<.0001$ & & \\
\hline$\beta_{3}$ & -1.035 & 0.0044 & -0.4724 & 0.1181 & & \\
\hline $\mathrm{k}$ & \multicolumn{2}{|c|}{0.7735} & \multicolumn{2}{|c|}{0.8202} & & \\
\hline
\end{tabular}


Table 20 Parameter Estimates for Pennsylvania Rumble Strip Models

\begin{tabular}{ccccccc}
\hline Crash & \multicolumn{2}{c}{ Total } & \multicolumn{2}{c}{ Injury } & \multicolumn{2}{c}{ Run-off-road } \\
\hline Coefficient & Estimate & $\operatorname{Pr}>$ ChiSq & Estimate & $\operatorname{Pr}>$ ChiSq & Estimate & $\operatorname{Pr}>$ ChiSq \\
$\alpha$ & -6.2295 & $<.0001$ & -7.0514 & $<.0001$ & -10.8247 & $<.0001$ \\
$\beta_{1}$ & 0.7071 & $<.0001$ & 0.7304 & $<.0001$ & 0.8808 & $<.0001$ \\
$\beta_{2}$ & 0.5861 & $<.0001$ & 0.6542 & $<.0001$ & 0.6789 & $<.0001$ \\
$\beta_{3}$ & -0.1703 & 0.0018 & -0.0882 & 0.1868 & -0.1524 & 0.4612 \\
$\mathrm{k}$ & \multicolumn{2}{c}{0.431} & \multicolumn{2}{c}{0.4271} & \multicolumn{2}{c}{0.9633} \\
\hline
\end{tabular}

\begin{tabular}{ccccc}
\hline Crash & \multicolumn{2}{c}{ Head-on } & \multicolumn{2}{c}{ Side Swipe } \\
\hline Coefficient & Estimate & $\operatorname{Pr}>$ ChiSq & Estimate & $\operatorname{Pr}>$ ChiSq \\
$\alpha$ & -5.9772 & $<.0001$ & -10.5596 & $<.0001$ \\
$\beta_{1}$ & 0.4795 & $<.0001$ & 0.7911 & $<.0001$ \\
$\beta_{2}$ & 0.6961 & $<.0001$ & 0.6922 & $<.0001$ \\
$\beta_{3}$ & -0.2561 & 0.0276 & -0.2251 & 0.4089 \\
$\mathrm{k}$ & \multicolumn{2}{c}{0.7184} & \multicolumn{2}{c}{0.7434}
\end{tabular}

The combined dataset used was analyzed by assigning a classification variable to each state in order to develop different intercept terms in the model for each location. This would allow for differences in crash counts between jurisdictions that may be related to weather, reporting practices, etc. The model for the combined dataset along with parameter estimates is presented in Table 21 .

$$
\frac{\text { Crashes }}{\text { Year }}=e^{\left(\alpha+\beta_{4}\right)} A A D T^{\beta_{1}} \text { Length }^{\beta_{2}} e^{\beta_{3}(R S)}
$$

Where $\mathrm{RS}=1$ if rumble strips are present and 0 otherwise. 
Table 21 Parameter Estimates for Combined Rumble Strip Models

\begin{tabular}{lcccc}
\hline \multicolumn{1}{c}{ Crash Type } & \multicolumn{2}{c}{ Total } & \multicolumn{2}{c}{ Injury } \\
\hline \multicolumn{1}{c}{ Coefficient } & Estimate & Pr $>$ ChiSq & Estimate & Pr $>$ ChiSq \\
$\mathrm{A}$ & -6.2232 & $<0.0001$ & -7.0144 & $<0.0001$ \\
$\beta_{1}$ & 0.7082 & $<0.0001$ & 0.7275 & $<0.0001$ \\
$\beta_{2}$ & 0.6298 & $<0.0001$ & 0.6927 & $<0.0001$ \\
$\beta_{3}$ & -0.1241 & 0.0131 & -0.0946 & 0.1241 \\
$\beta_{4}$ (Kentucky) & 0.6139 & $<.0001$ & 0.0926 & 0.0031 \\
$\beta_{4}$ (Ontario) & 0.1819 & 0.1807 & -0.6622 & $<0.0001$ \\
$\beta_{4}$ (Pennsylvania) & 0 & - & 0 & - \\
Overdispersion, $\mathrm{k}$ & \multicolumn{2}{c}{0.4437} & & \multicolumn{2}{c}{0.4372}
\end{tabular}

\begin{tabular}{|c|c|c|c|c|}
\hline \multirow{2}{*}{$\begin{array}{c}\text { Crash Type } \\
\text { Coefficient }\end{array}$} & \multicolumn{2}{|c|}{ Run-Off-Road } & \multicolumn{2}{|c|}{ Head-On } \\
\hline & Estimate & $\operatorname{Pr}>C h i S q$ & Estimate & $\operatorname{Pr}>C h i S q$ \\
\hline A & -5.956 & $<0.0001$ & -10.7315 & $<0.0001$ \\
\hline$\beta_{1}$ & 0.4786 & $<0.0001$ & 0.8713 & $<0.0001$ \\
\hline$\beta_{2}$ & 0.7416 & $<0.0001$ & 0.7152 & $<0.0001$ \\
\hline$\beta_{3}$ & -0.2575 & 0.0131 & -0.3016 & 0.0915 \\
\hline$\beta_{4}$ (Kentucky) & 1.0442 & $<.0001$ & 0.2741 & $<.0001$ \\
\hline$\beta_{4}($ Ontario $)$ & -1.1154 & 0.1807 & 0.4435 & 0.0890 \\
\hline$\beta_{4}$ (Pennsylvania) & 0 & - & 0 & - \\
\hline Overdispersion, $\mathrm{k}$ & \multicolumn{2}{|c|}{0.9622} & \multicolumn{2}{|c|}{0.7392} \\
\hline
\end{tabular}

\begin{tabular}{lccc}
\hline \multicolumn{1}{c}{ Crash Type } & \multicolumn{2}{c}{ Sideswipe } & Injury \\
\hline \multicolumn{1}{c}{ Coefficient } & Estimate & Pr $>$ ChiSq & \\
$\mathrm{A}$ & -10.3269 & $<0.0001$ & \\
$\beta_{1}$ & 0.7652 & $<0.0001$ & \\
$\beta_{2}$ & 0.7336 & $<0.0001$ & \\
$\beta_{3}$ & -0.1844 & 0.3083 & \\
$\beta_{4}$ (Kentucky) & 1.2914 & $<0.0001$ & \\
$\beta_{4}$ (Ontario) & 2.0688 & $<0.0001$ & \\
$\beta_{4}$ (Pennsylvania) & 0 & - &
\end{tabular}


A comparison of the CMFs from EB studies and the CMFs implied from the cross sectional study is presented below in Table 22 to Table 26. The comparison shows that generally the results of the EB study are consistent with those of the cross sectional study as the results from one study mostly fall within the realm of uncertainty of the those from the other.

Table 22 Comparison of EB and Cross Sectional CMFs for Total Crashes

\begin{tabular}{ccc}
\hline State & \multicolumn{2}{c}{ CMF (Standard Error) } \\
\cline { 2 - 3 } & EB Study & Cross Sectional Study \\
\hline Ontario & $0.706(0.068)$ & 0.94 \\
Kentucky & $0.84(0.054)$ & 0.67 \\
Pennsylvania & $0.975(0.046)$ & 0.84 \\
Missouri & $0.653(0.029)$ & - \\
Combined & $0.800(0.025)$ & 0.88
\end{tabular}

Table 23 Comparison of EB and Cross Sectional CMFs for Injury Crashes

\begin{tabular}{ccc}
\hline State & \multicolumn{2}{c}{ CMF (Standard Error) } \\
\cline { 2 - 3 } & EB Study & Cross Sectional Study \\
\hline Ontario & $0.60(0.063)$ & 0.73 \\
Kentucky & $0.812(0.088)$ & 0.57 \\
Pennsylvania & $1.019(0.063)$ & 0.92 \\
Missouri & $0.558(0.039)$ & - \\
Combined & $0.771(0.034)$ & 0.91
\end{tabular}


Table 24 Comparison of EB and Cross Sectional CMFs for Run-off-road Crashes

\begin{tabular}{ccc}
\hline State & \multicolumn{2}{c}{ CMF (Standard Error) } \\
\cline { 2 - 3 } & EB Study & Cross Sectional Study \\
\hline Ontario & - & - \\
Kentucky & $0.613(0.073)$ & 0.43 \\
Pennsylvania & $0.92(0.103)$ & 0.86 \\
Missouri & $0.758(0.050)$ & - \\
Combined & $0.742(0.041)$ & 0.77
\end{tabular}

Table 25 Comparison of EB and Cross Sectional CMFs for Head-on Crashes

\begin{tabular}{ccc}
\hline State & \multicolumn{2}{c}{ CMF (Standard Error) } \\
\cline { 2 - 3 } & EB Study & Cross Sectional Study \\
\hline Ontario & - & - \\
Kentucky & $0.480(0.142)$ & 0.36 \\
Pennsylvania & $1.021(0.210)$ & 0.77 \\
Missouri & $0.506(0.105)$ & - \\
Combined & $0.632(0.085)$ & 0.74
\end{tabular}

Table 26 Comparison of EB and Cross Sectional CMFs for Sideswipe Crashes

\begin{tabular}{ccc}
\hline State & \multicolumn{2}{c}{ CMF (Standard Error) } \\
\cline { 2 - 3 } & EB Study & Cross Sectional Study \\
\hline Ontario & - & - \\
Kentucky & $0.891(0.210)$ & 0.62 \\
Pennsylvania & $0.907(0.246)$ & 0.80 \\
Missouri & $0.628(0.113)$ & - \\
Combined & $0.767(0.097)$ & 0.83
\end{tabular}




\subsection{Discussion}

There was consistency between results of the EB study and those of the cross sectional study based on US-data, with CMF values from one study falling within the realm of uncertainty of the values from the other study. This is a key conclusion since it suggests that the cross-sectional approach can be applied where there are insufficient sites to conduct the preferred EB before-after study.

Of the EB studies, Ontario showed the largest safety impact, despite the fact that the estimates are for shoulder rumble strip application only and are likely conservative for dual application. This may arise from the fact that rumble strips in Ontario are relatively new treatments and may produce results that are more pronounced. In addition, the Ontario study was limited by the sample size and a larger sample can lead to results that are more accurate. Overall, since the cross sectional study corroborated both the US and the limited Ontario EB studies, it can be concluded that the combined results from the latter study could be confidently applied in Ontario. 


\section{Chapter 7 Application.}

This chapter illustrates how to apply the variable CMFunction developed for passing lanes for practical purposes. An economic analysis is presented showing the differences in cost-benefit ratio for different combinations of length of passing lane and AADT. The following "ballpark" assumptions were used for the cost-benefit analysis:

Table 27 Economic Analysis Assumptions Table

\begin{tabular}{cc}
\hline Variable & Assumed Value \\
\hline Service Life & 20 Years \\
Discount Rate & $3 \%$ \\
Capital Recovery Factor & 0.067 \\
Cost per Crash & $\$ 150,000$ \\
Cost of Passing Lane per km & $\$ 500,000$ \\
Annual Cost (CRF x Construction Cost)/km & $\$ 33,500$
\end{tabular}

The purpose of the analysis is to calculate the benefit cost ratio for combinations of AADT and passing lane length to see which combination provides the highest value for dollars spent. This was done by the following steps:

Step 1: Calculate the SPF predictions for the length and AADT combinations of interest:

\begin{tabular}{c|ccccc}
\hline \multicolumn{5}{c}{ Reference SPF prediction for AADT } \\
\hline Length $(\mathrm{km})$ & 4000 & 6000 & 8000 & 10000 & 12000 \\
\hline 1.6 & 1.82 & 2.47 & 3.06 & 3.61 & 4.14 \\
1.8 & 2.05 & 2.77 & 3.44 & 4.06 & 4.66 \\
2.0 & 2.28 & 3.08 & 3.82 & 4.51 & 5.17 \\
2.2 & 2.51 & 3.39 & 4.20 & 4.97 & 5.69 \\
2.4 & 2.73 & 3.70 & 4.59 & 5.42 & 6.21 \\
2.6 & 2.96 & 4.01 & 4.97 & 5.87 & 6.72 \\
2.8 & 3.19 & 4.32 & 5.35 & 6.32 & 7.24 \\
3.0 & 3.42 & 4.62 & 5.73 & 6.77 & 7.76 \\
3.2 & 3.64 & 4.93 & 6.11 & 7.22 & 8.28
\end{tabular}


Step 2: Calculate the expected number of saved crashes from the CMFunction by taking (1$\mathrm{CMF}) *($ Predicted Crashes) as follows:

\begin{tabular}{c|c|ccccc}
\hline \multicolumn{5}{c}{} & \multicolumn{5}{c}{ Annual Crash reduction for AADT } \\
\hline Length $(\mathrm{km})$ & CMF & 4000 & 6000 & 8000 & 10000 & 12000 \\
\hline 1.6 & 0.75 & 0.45 & 0.61 & 0.75 & 0.89 & 1.02 \\
1.8 & 0.73 & 0.56 & 0.75 & 0.93 & 1.10 & 1.27 \\
2.0 & 0.70 & 0.68 & 0.92 & 1.13 & 1.34 & 1.54 \\
2.2 & 0.68 & 0.80 & 1.09 & 1.35 & 1.60 & 1.83 \\
2.4 & 0.66 & 0.94 & 1.28 & 1.58 & 1.87 & 2.14 \\
2.6 & 0.63 & 1.09 & 1.47 & 1.83 & 2.16 & 2.47 \\
2.8 & 0.61 & 1.24 & 1.68 & 2.08 & 2.46 & 2.82 \\
3.0 & 0.59 & 1.40 & 1.90 & 2.35 & 2.78 & 3.19 \\
3.2 & 0.57 & 1.57 & 2.13 & 2.64 & 3.11 & 3.57
\end{tabular}

Step 3: Multiply each value in Step 2 by the cost of each accident to obtain the following table:

\begin{tabular}{c|ccccc}
\hline \multicolumn{5}{c}{ Cost of Annual Crashes reduced for AADT } \\
\hline Length $(\mathrm{km})$ & 4000 & 6000 & 8000 & 10000 & 12000 \\
\hline 1.60 & $\$ 67,136$ & $\$ 90,875$ & $\$ 112,651$ & $\$ 133,076$ & $\$ 152,484$ \\
1.80 & $\$ 83,559$ & $\$ 113,104$ & $\$ 140,207$ & $\$ 165,628$ & $\$ 189,783$ \\
2.00 & $\$ 101,456$ & $\$ 137,331$ & $\$ 170,239$ & $\$ 201,104$ & $\$ 230,434$ \\
2.20 & $\$ 120,749$ & $\$ 163,445$ & $\$ 202,611$ & $\$ 239,346$ & $\$ 274,252$ \\
2.40 & $\$ 141,359$ & $\$ 191,342$ & $\$ 237,194$ & $\$ 280,199$ & $\$ 321,063$ \\
2.60 & $\$ 163,213$ & $\$ 220,924$ & $\$ 273,864$ & $\$ 323,518$ & $\$ 370,700$ \\
2.80 & $\$ 186,242$ & $\$ 252,095$ & $\$ 312,505$ & $\$ 369,164$ & $\$ 423,004$ \\
3.00 & $\$ 210,378$ & $\$ 284,766$ & $\$ 353,004$ & $\$ 417,006$ & $\$ 477,823$ \\
3.20 & $\$ 235,559$ & $\$ 318,850$ & $\$ 395,256$ & $\$ 466,918$ & $\$ 535,014$
\end{tabular}


Step 4: Calculate the benefit cost ratios.

\begin{tabular}{c|ccccc}
\hline \multicolumn{5}{c}{ Benefit Cost Ratio for AADT } \\
\hline $\begin{array}{c}\text { Length } \\
(\mathrm{km})\end{array}$ & 4000 & 6000 & 8000 & 10000 & 12000 \\
\hline 1.60 & 1.0 & 1.4 & 1.8 & 2.1 & 2.4 \\
1.80 & 1.2 & 1.6 & 1.9 & 2.3 & 2.6 \\
2.00 & 1.3 & 1.7 & 2.1 & 2.5 & 2.9 \\
2.20 & 1.4 & 1.8 & 2.3 & 2.7 & 3.1 \\
2.40 & 1.5 & 2.0 & 2.5 & 2.9 & 3.3 \\
2.60 & 1.6 & 2.1 & 2.6 & 3.1 & 3.5 \\
2.80 & 1.7 & 2.2 & 2.8 & 3.3 & 3.8 \\
3.00 & 1.7 & 2.4 & 2.9 & 3.5 & 4.0 \\
3.20 & 1.8 & 2.5 & 3.1 & 3.6 & 4.2
\end{tabular}

\subsection{Discussion}

The above steps demonstrate how this research can be used in practice in order to conduct a cost-benefit analysis to do a tradeoff between passing lane length and cost versus safety benefits. A cost-benefit ratio of 2 or greater is considered satisfactory. The results for the assumed inputs showed that locations with AADT greater than 10,000 had cost-benefit ratios of at least 2.0 for all lengths and this ratio grows up to 4.2 with longer lengths and higher AADT combinations. Furthermore, cost-benefit ratios remained below 2.0 for all lengths for AADTs of 4,000 or less. The recommended length for passing lanes in Michigan and Ontario range between $1.5 \mathrm{~km}$ and $2.5 \mathrm{~km}$ and it can been seen from cost-benefit table that installing short passing lanes on low AADT segments may not produce satisfactory economic appraisal results in terms of safety rewards. 


\section{Chapter 8 Summary and Conclusions}

The purpose of this study was to explore the transferability of crash modification factors for passing lanes and dual rumble strips for application on Ontario highways. Each of these treatments was examined separately in order to determine if their safety effects are transferable between the different jurisdictions.

The passing lane study included data from the Michigan Department of Transportation (MDOT) for 124 passing lane sites and 100 reference sites. This data set was used in a previous study by Persaud et al. (2013) and it was found that the presence of passing lanes in Michigan reduced crashes by 33\%. The locations of passing lanes for Ontario were provided by the Ministry Transportation Ontario (MTO) and with the aid of Google Maps a list of 44 passing lane sites and 122 reference sites were compiled. It was found that the safety effect of passing lanes varies with its length, not just its presence, and that these results transferrable between the jurisdictions. The goodness of fit measures included the Mean Prediction Bias, Mean Absolute Bias, Mean Square Prediction Error, Mean Square Error, and CURE plots. The models were satisfactory against these measures and most of their parameter estimates were significant at the $5 \%$ level.

For dual rumble strips, the objective of this study was to develop CMFs for application in Ontario. To this end an empirical Bayes (EB) Before-After study was conducted based on limited Ontario data and the results compared to those from a more rigorous and definitive US-based EB study. A secondary objective was to see if the results of the EB study could be corroborated, for better transferability, by a cross sectional study using the data from treated and untreated sites. Installation sites and dates for Ontario were provided by MTO and data from previous research by Persaud et al. (2016) for the states of Kentucky, Pennsylvania, and Missouri were also made available. For Ontario, the EB study showed a $29.4 \%$ reduction in total crashes and a $40 \%$ reduction in injury related crashes. Ontario showed the largest safety impact, despite the fact that the estimates are for shoulder rumble strip application only and are likely conservative for dual application. This may arise from the fact that rumble strips in Ontario are relatively new treatments and may produce 
results that are more pronounced. There was consistency between results of the EB study and those of the cross sectional study based on US-data, with CMF values falling from one within the realm of uncertainty of values from the other. This is a key conclusion since it suggests that the cross-sectional approach can be applied where there are insufficient sites to conduct the preferred EB before-after study. Since the cross sectional study corroborated both the US and the limited Ontario EB studies, it can be concluded that the combined results from the latter study could be confidently applied in Ontario.

The limitations that existed in this research included the small sample size of the Ontario passing lane and Rumble strip segments. Ideally, a larger sample size would provide more accurate results. The rumble strip EB study had only six sites since the installation of dual application of edge line and centerline rumble strips were too recent to include in the before-after study. The passing lane sites relied on the use of Google Maps to identify their locations. The quality of the photos varied and some passing lanes could not be identified as a result of poor imagery.

In future work, this study can be improved by considering the effects of passing lanes beyond the passing lane site. Persaud et al. (2013) showed similar benefits $1.6 \mathrm{~km}$ up and down stream of passing lanes and this effect was not considered in this paper. Furthermore, passing lane configurations can have a safety component associated with them. This study focused primarily on isolated passing lanes and intermittent passing lanes that were at least $1.6 \mathrm{~km}$ apart. This was done to minimize any interaction between consecutive passing lanes. Other configurations of passing lanes include overlapping passing lanes in each direction, intermittent passing lanes joined tail to tail, intermittent passing lanes joined head to head, and short 4-lane segments. Quantifying this interaction between passing lane configurations would lead to better design choices in practice.

Engineers can use this research during the design stage or in evaluating potential treatments at an existing problematic site. Understanding the safety effects of design choices is imperative for building roads to a desired safety level and this research has contributed to that understanding. 


\section{$\underline{\text { References }}$}

AASHTO. AASHTO Website. (2016, April 1) Retrieved from http://www.safetyanalyst.org/

AASHTO. (2010). Highway Safety Manual (1st ed.). Washington, D.C.: American Association of State Highway and Transportation Officials.

Bagdade, J., Ceifetz, A., Myers, M., Redinger, C., Persaud, B., \& Lyon, C. (2012). Evaluating Performance And Making Best Use of Passing Relief Lanes. (RC-1565).

Begum, S.M. Morjina Ara. (2008). Investigation of model calibration issues in the safety performance assessment of Ontario highways. Theses and dissertations., (168).

Elvik, R. (2013). International transferability of accident modification functions for horizontal curves. Accident Analysis \& Prevention, 59, 487-496.

Fitzpatrick, K. (2000). Accident mitigation guide for congested rural two-lane highways. NCHRP report: Vol. 440. Washington, D.C.: National Academy Press.

Gates, T., Savolainen, P., Datta, T., Todd, R., Russo, B., \& Morena, J. (2012). Use of Both Centerline and Shoulder Rumble Strips on High-Speed Two-Lane Rural Roadways. Transportation Research Record: Journal of the Transportation Research Board, 2301, 36-45. doi:10.3141/2301-05

Gattis, J., Alguire, M., Townsend, K., \& Rao, S. (1997). Rural Two-Lane Passing Headways and Platooning. Transportation Research Record: Journal of the Transportation Research Board, 1579, 27-34. doi:10.3141/1579-04

Gross, F., Persaud, B., \& Lyon, C. (2010). A guide to developing quality crash modification factors.

Harwood, D. W. (1995). Relationships between operational and safety considerations in geometric design improvements. Transportation research record, (1512), 1-6.

Harwood, D. W., Council, F. M., Hauer, E., Hughes, W. E., \& Vogt, A. (2000). Prediction of the expected safety performance of rural two-lane highways. (No. FHWA-RD-99-207).

Harwood, D. W., \& St John, A. D. (1985). Passing lanes and other operational improvements on two-lane highways. Phase I technical report. 
Hauer, E. (1997). Observational Before--after Studies in Road Safety: Estimating the Effect of Highway and Traffic Engineering Measures on Road Safety: Pergamon.

Hauer, E. (1999). Safety Review of Highway 407: Confronting Two Myths. Transportation Research Record: Journal of the Transportation Research Board, 1693, 9-12. doi:10.3141/1693-02

Hauer, E. (2015). The art of regression modeling in road safety. Cham: Springer.

Kay, J., Savolainen, P. T., Gates, T. J., Datta, T. K., Finkelman, J., \& Hamadeh, B. (2015). Safety Impacts of a Statewide Centerline Rumble Strip Installation Program. Transportation Research Record: Journal of the Transportation Research Board, 2515, 34-40. doi:10.3141/2515-05

MDOT. (2012). Michigan Department of Transportation Road Design Manual. Retrieved from http://mdotcf.state.mi.us/public/design/englishroadmanual/

Ministry Transportation Ontario. (2012). Ontario Road Safety Annual Report 2012.

MTO. (2015). iCorridor. (2016, April 1) Retrieved from http://www.mto.gov.on.ca/iCorridor/

MTO. (1985). Geometric design standards for Ontario highways. Downsview, On: Ontario Ministry of Transportation, Surveys \& Designs Office.

MTO. (2009). MS Access Query User Guide: Version 1.9: Ministry of Transportation Traffic Office and Systems Development Office.

Mutabazi, M., Russell, E., \& Stokes, R. (1998). Drivers' Attitudes, Understanding, and Acceptance of Passing Lanes in Kansas. Transportation Research Record: Journal of the Transportation Research Board, 1628, 25-33. doi:10.3141/1628-04

Neuman, T. R., Pfefer, R., Slack, K. L., Hardy, K. K., McGee, H., Prothe, L., . . Council, F. (2003). NCHRP Report 500: Guidance for Implementation of the AASHTO Strategic Highway Safety Plan. Volume 4: A Guide for Addressing Head-On Collisions. Transportation Research Board of the National Academies, Washington, DC, OECD and ITF. Sharing Road Safety: Developing an International Framework for Crash Modification Functions. doi:10.1787/9789282103760-en 
Persaud, B., Lord, D., \& Palmisano, J. (2002). Calibration and Transferability of Accident Prediction Models for Urban Intersections. Transportation Research Record: Journal of the Transportation Research Board, 1784, 57-64. doi:10.3141/1784-08

Persaud, B., Lyon, C., \& Srinivasan, R. On the Transferability of Crash Modification Factors for Highway Geometric Design Elements.

Persaud, B., Lyon, C., Bagdade, J., \& Ceifetz, A. (2013). Evaluation of Safety Performance of Passing Relief Lanes. Transportation Research Record: Journal of the Transportation Research Board, 2348, 58-63. doi:10.3141/2348-07

Persaud, B., Lyon, C., Eccles, K., \& Soika, J. (2016). Safety Effectiveness of Centerline Plus Shoulder Rumble Strips on Two-Lane Rural Roads. Journal of Transportation Engineering, 4016012. doi:10.1061/(ASCE)TE.1943-5436.0000821

Potts, I. B., \& Harwood, D. W. (2004). Benefits and design/location criteria for passing lanes.

Professional Engineers of Ontario. (1997). Highway 407 Safety Review. Retrieved from www.peo.on.ca

SAS®. (2014). SAS/STAT ® 9.1 User's Guide. (2016, March 19) Retrieved from https://support.sas.com/documentation/onlinedoc/91pdf/sasdoc_91/stat_ug_7313.pdf

Sayed, T., deLeur, P., \& Pump, J. (2010). Impact of Rumble Strips on Collision Reduction on Highways in British Columbia, Canada. Transportation Research Record: Journal of the Transportation Research Board, 2148, 9-15. doi:10.3141/2148-02

Shahdah, U., Saccomanno, F., \& Persaud, B. (2012). Integrating Observational and Traffic Simulation Models for Priority Ranking of Unsafe Intersections. Transportation Research Record: Journal of the Transportation Research Board, 2280, 118-126. doi:10.3141/2280-13

Torbic, D., Bauer, K., Hutton, J., \& Campbell, J. (2013). Delta region transportation development program: Rural safety innovation program evaluation: Final Rep., US Dept. of Transportation, Federal Highway Administration, Washington, DC., Google Scholar. 
Torbic, D., Hutton, J., Bokenkroger, C., Bauer, K., Harwood, D., Gilmore, D., . . and Lyon, C. (2009). Guidance for the design and application of shoulder and centerline rumble strips.

Transport Canada. (2013). Canadian Motor Vehicle Collision Statistics: 2013. (2016, March 1) Retrieved from https://www.tc.gc.ca/media/documents/roadsafety/cmvtcs2013_eng.pdf

TRB. (2010). HCM: Highway capacity manual (5th ed.). Washington, D.C.: Transportation Research Board.

U.S. Census Bureau. Statistical Abstract of the United States: 2012 (131st Edition).

Wooldridge, M. D., Messer, C. J., Heard, B. D., Raghupathy, S., Parham, A. H., Brewer, M. A., \& Lee, S. (2001). Design Guidelines for Passing Lanes on Two-Lane Roadways (Super 2).

World Health Organization. (2009). Global status report on road safety: time for action: World Health Organization. 